Universidad deValladolid

\author{
PROGRAMA DE DOCTORADO EN \\ LÓGICA Y FILOSOFÍA DE LA CIENCIA
}

TESIS DOCTORAL:

\title{
FUNDAMENTOS PARA UNA SEMÁNTICA MÍNIMA
}

\author{
Presentada por Leticia Santos Varona \\ para optar al grado de \\ Doctora por la Universidad de Valladolid
}

Dirigida por:

Dr. Juan Luis Barba Escribá

Dr. Agustín Vicente Benito 



\section{Índice}

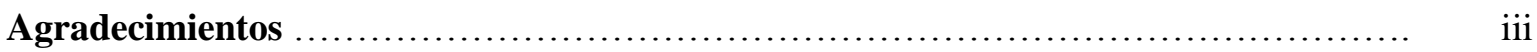

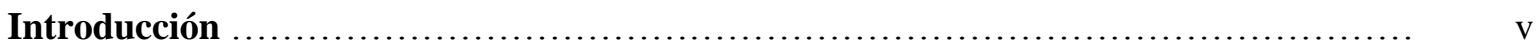

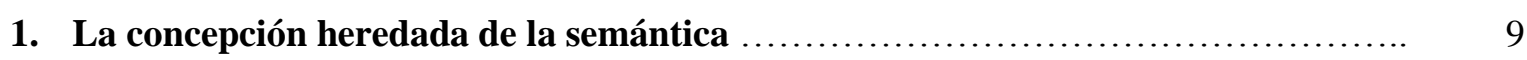

1.1. Lenguaje, pensamiento y realidad: la relación representacional ................. 9

1.2. Las bases del modelo semántico extensional .................................... 12

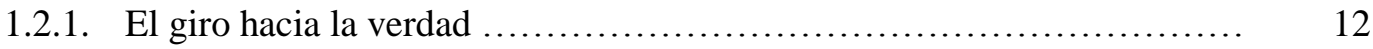

1.2.2. Hacia una semántica lógica ........................................ 16

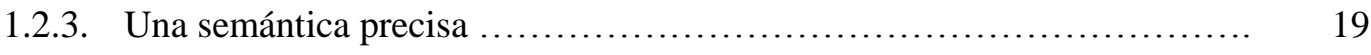

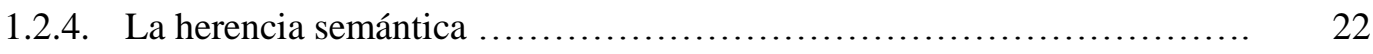

1.3. Los límites de la semántica .................................................. 23

1.4. La crisis de la concepción heredada: el avance de la pragmática ................. 26

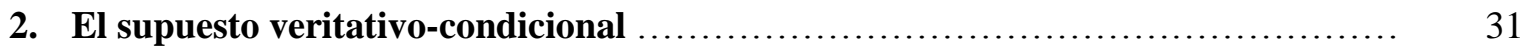

2.1. Ambigüedad $v s$. precisión ........................................... 32

2.2. La teoría de la referencia ............................................. 37

2.2.1. Cuestiones metafísicas y cognitivas ............................. 38

2.2.2. Implicaciones para el tratamiento formal del lenguaje natural ............ 43

2.3. La forma lógica en el lenguaje natural ..................................... 50 
2.4. La verdad en la semántica natural ........................................ 55

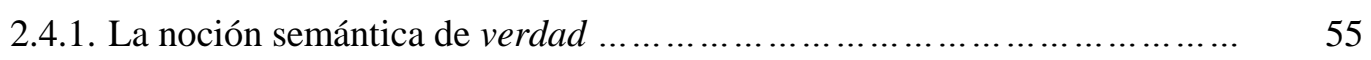

2.4.2. Problemas de la noción semántica de verdad para el lenguaje natural ...... 60

2.5. El dogma extensionalista ............................................... 67

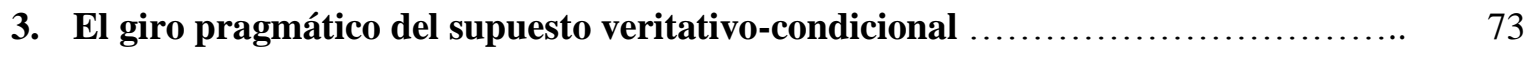

3.1. Sensibilidad al contexto e indéxicos ..................................... 74

3.1.1. El tratamiento de la indexicalidad en el Pragmatismo y el Minimalismo.... $\quad 74$

3.1.2. Problemas en los modelos de explicación de la indexicalidad ............. 77

3.2. Explicatura y enriquecimiento ....................................... 81

3.2.1. El modelo pragmatista .......................................... 82

3.2.2. Objeciones al modelo de explicatura .............................. 86

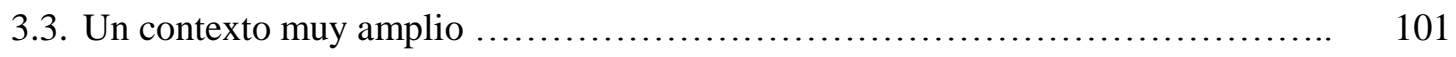

3.4. Algunas evidencias en contra del modelo de inferencia post-léxica .............. 112

4. Del contexto a la competencia. Una semántica natural ......................... 119

4.1. Roles para un contenido semántico mínimo .................................. 120

4.2. Significado y cognición ............................................... 128

4.2.1. Bases para un significado convencional .......................... 128

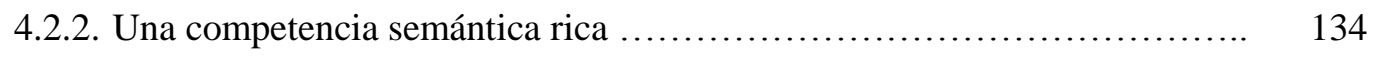

4.3. Un modelo binario de la comprensión lingüística .............................. 149

4.3.1. Una explicación desde la competencia ............................. 140

4.3.2. El significado de la oración y la distinción semántica-pragmática .......... 151

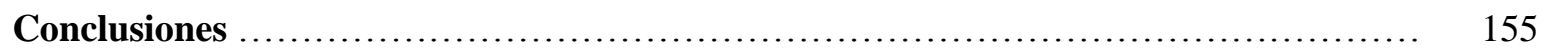

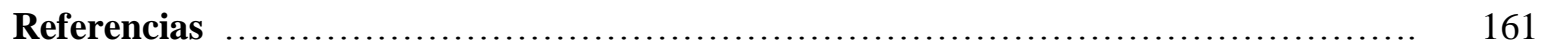




\section{Agradecimientos}

Una tesis implica un gran trabajo, pero también un viaje personal a lo largo de años en el que se experimenta un carrusel emocional que acaba transformándote. Este viaje requiere renuncias a nivel teórico, emocional y social, por lo que exige aprender a identificar lo importante y lo accesorio. De ahí su poder transformador. Es justo agradecer a las personas que me han acompañado en el viaje y han contribuido a su consecución, pero antes debo hacer una confesión. A pesar de presentar la tesis como un trabajo acabado, siento que es ahora cuando apenas empiezo a comprender lo que he estudiado.

Quiero agradecer a los doctores Elena Castroviejo y Antonio Blanco por su evaluación y sus buenas palabras hacia mi trabajo. Sin duda, sus sugerencias han sido valiosas.

A mis directores, Juan y Agustín, nunca tendré palabras suficientes para agradeceros todo lo que me habéis aportado desde mis primeros años de estudiante. Os elegí porque estaba convencida de que seríais justos, objetivos y sensatos y porque sabía que me llevaríais a las reflexiones necesarias. No me equivoqué, vuestras correcciones y sugerencias han sido siempre acertadas y razonables, aportando la calidad al trabajo que sin ellas jamás tendría. Con vosotros he aprendido a escribir y a madurar como investigadora. Ambos sois para mí ejemplo de trabajo, rigor y eficiencia; pero también de calidad humana, contestando a todas mis dudas pacientemente, siempre dispuestos a promover mi reflexión, tratándome con mucha comprensión durante años. 
La tesis lleva característicamente a una vida de trabajo en la que a menudo se renuncia a las relaciones interpersonales. No es fácil estar al lado de un doctorando. Por ello, debo agradecer profundamente a mi familia, especialmente a mis padres Belén y Fernando, la comprensión, el cariño y el respeto que me han dado, propios de un amor incondicional. También a mis amigos su paciencia por todas las veces que han tenido que esperar para compartir un rato conmigo, por estar ahí tantos años a pesar de apenas verme.

David, sé que ha sido difícil aguantar el vaivén emocional y aún así has conseguido hacer mi vida menos dura en este proceso. Me has animado cuando me derrumbaba y apretado cuando me entraba la pereza, dándome el espacio necesario y esperando con paciencia para hacer planes juntos. Gracias por estar cada día de este proceso a mi lado y ser tan generoso conmigo.

No puedo olvidarme de mi pequeña Adriana. La noticia de tu llegada me ha dado el impulso necesario en la recta final de este viaje. Sentirte dentro me llenaba de fuerza cuando me sentaba a escribir, convirtiéndote en mi mayor motivación. 


\section{Introducción}

El significado de las palabras y oraciones de nuestro lenguaje ha sido objeto de estudio desde los orígenes mismos de la reflexión filosófica. Los primeros grandes filósofos necesitaron hacerse cargo de su estudio como parte integrante de la explicación de la realidad. Buen ejemplo de ello son Platón y Aristóteles quienes atisbaron ya los problemas cruciales de la definición del concepto: la cuestión de la capacidad representacional del lenguaje, el problema de la referencia (muy agudo especialmente en relación a los términos generales) y, en general, las relaciones con lo real y lo pensado. Cuestiones que han continuado bajo estudio y sin respuesta satisfactoria hasta hoy.

El motivo de la pervivencia de tales cuestiones y la ausencia de una teoría satisfactoria se debe fundamentalmente a la complejidad de las relaciones que el lenguaje mantiene con otros planos a su vez igualmente complejos, como son el sujeto -usuario y creador del lenguaje- y el mundo -los objetos a los que alude el lenguaje. Dar una solución al problema de la caracterización del lenguaje y del significado exige teorías precisas sobre estos planos que contribuyan a la explicación de las relaciones involucradas. Quizá por ello no podamos contar nunca con la certeza de estar en disposición de una teoría del significado lingüístico definitiva; al menos, no parece presumible desde el estado actual de los desarrollos en ontología, epistemología y, sobretodo, en las llamadas ciencias cognitivas. Podemos sin embargo acercarnos un poco más hacia la verdad si, desde un punto de vista popperiano, continuando con su estudio logramos falsar las teorías que van 
surgiendo y si, mirando con la atención suficiente, podemos extraer algunas constantes comunes en dichas teorías que sirvan de guía para un nuevo análisis.

Una constante que se repite en muchas de las teorías es la admisión de la capacidad representacional del lenguaje como premisa básica en la comprensión del lenguaje. Atendiendo a esto, la semántica en la concepción heredada desde Frege implicó un cambio en la dirección representacional bajo la influencia matemática. Se estableció la representación como una relación entre el lenguaje y el mundo, donde las nociones de referencia y verdad han ocupado un lugar predominante hasta nuestros días conformando lo que llamamos las semánticas veritativocondicionales. Sin embargo, los problemas surgidos en relación a estas nociones para el lenguaje natural han llevado a un debate contemporáneo en el que se han tambaleado las tesis clásicas. Esto ha dado lugar a una explicación del significado mayoritariamente pragmática y a un modelo de la comprensión lingüística tripartito. El significado es visto como un asunto radicalmente dependiente del contexto, postulando el nivel de la forma lógica como un nivel lingüístico no informativo y sin rol en la comunicación, así como dos formas de significado del hablante afectadas por procesos pragmáticos, i.e., la explicatura y las implicaturas. Lo que apenas da lugar a una distinción entre sintaxis y pragmática.

El objetivo de este trabajo consiste en definitiva en una defensa de un nivel semántico de significado, libre de intrusión pragmática, convencional y ligado al léxico que se encuadra en un modelo binario de la comprensión lingüística. Para ello, se lleva a cabo una revisión de las tesis y problemas provenientes de la concepción heredada que están en la base del debate contemporáneo en el primer capítulo. Este primer capítulo muestra además que el problema fundamental del debate contemporáneo se encuentra en la tensión producida por el supuesto veritativo-condicional y el hecho de la dependencia al contexto del lenguaje. Sin embargo, se argumenta que esta tensión puede resolverse desde una perspectiva alternativa a la solución dada por las teorías pragmatistas, de forma que puede rechazarse el supuesto veritativo-condicional y mantener cierta independencia del contexto en el significado. Así, los capítulos segundo y tercero están encaminados a revisar el 
supuesto veritativo-condicional y la dependencia del contexto respectivamente. De los argumentos presentados en estos capítulos se extraerán algunas conclusiones que motivan la defensa de un nivel semántico de significado en el último capítulo. En este sentido, la respuesta a las objeciones pragmatistas dota de mayor importancia a la competencia sintacto-semántica de los hablantes y lleva a rescatar la importancia de la semántica léxica tras la falta de atención de la misma en la concepción heredada. Estos factores hacen que podamos hablar de un nivel de significado independiente del contexto en conexión con la cognición.

La revisión llevada a cabo implica ahondar en los presupuestos de la semántica dominante trayendo como consecuencia un cambio en los fundamentos: las nociones extensionales de referencia y verdad no parecen ser una buena guía para la caracterización del significado por lo que el significado deja de ser idéntico al contenido veritativo-condicional, devolviendo así la dirección representacional a la relación entre el lenguaje y el pensamiento, en términos del sistema conceptual que está en la base del léxico. Las ventajas de esta visión son considerables puesto que constituye una visión naturalizada que explica los factores relativos a la facultad del lenguaje y la competencia de los hablantes, así como encaja con las nociones intuitivas y ordinarias de los hablantes. El modelo defendido contribuye a rescatar un rol para la semántica delimitando con ello las competencias semántica y pragmática. No obstante, el trabajo se enmarca dentro del Minimalismo semántico puesto que defiende la existencia de un nivel de significado independiente del contexto con un rol legítimo en los procesos de comprensión, si bien mínimo en cuanto al completo fenómeno de la comunicación. 



\section{Capítulo 1}

\section{La concepción heredada de la semántica}

Es necesario retomar ciertas cuestiones fundamentales que se retrotraen hasta los inicios de la teoría semántica para tener una visión clara de los presupuestos teóricos en los que se enmarca la discusión. Para ello, se parte de una cuestión fundamental que se erige en el estudio del significado, i.e., la capacidad representacional del lenguaje. Sólo entendiendo cómo la teoría semántica establece el cambio de la relación representacional a la dirección lenguaje-realidad puede comprenderse la importancia de las nociones de referencia y verdad que están en la base de la discusión contemporánea y cuya genealogía lleva, en el apartado segundo, a las primeras semánticas veritativo-condicionales. Una vez expuestos los presupuestos teóricos de la semántica veritativo-condicional se plantea el contexto de la discusión actual en los dos últimos apartados. Estos mostrarán las nociones teóricas que están en juego y la tensión existente entre algunos presupuestos de la concepción heredada, que han llevado en último término a la explicación del significado siguiendo un modelo tripartito.

\subsection{Lenguaje, pensamiento y realidad: la relación representacional}

Una explicación del lenguaje y el significado exige explicar las relaciones que el lenguaje mantiene con el sujeto y la realidad. Es generalmente aceptado por las teorías que el lenguaje tiene 
capacidad representacional. El lenguaje efectivamente es una forma de comunicación mediante un sistema de signos, entendiendo como signo aquello que refiere a algo distinto de sí mismo a lo que llamamos referente. Sin embargo, para poder comunicarnos debemos previamente representarnos la realidad de forma simbólica para después expresarla a través de un signo, predominantemente lingüístico. Como ya explicó Ockham (1324-1328), los signos tienen la capacidad de la supposittio -ocupan el lugar de las cosas-, de ahí que hablemos de significados pues, permítaseme por ahora la simplicidad, los signos significan cosas. Por ello se vuelve necesario asumir la capacidad representacional como posibilitadora de las dos funciones principales del lenguaje, expresión y comunicación.

Como resultado de la explicación de esta capacidad surge la cuestión de la prioridad representacional. Siguiendo el llamado triángulo semiótico de Ogden y Richards (1923, p. 11) que esquematiza las relaciones entre el lenguaje, el pensamiento y la realidad, se establecen tres relaciones fundamentales: 1) la relación entre el pensamiento y el lenguaje, 2) entre el pensamiento y la realidad y 3) entre el lenguaje y la realidad. El hecho del establecimiento de una u otra como relación prioritaria contribuye a distinguir las diferentes concepciones del lenguaje ${ }^{1}$.

Las concepciones cartesiana y romántica establecen la prioridad representacional en la dirección pensamiento-realidad. Para ambas, el pensamiento construye representaciones y éstas constituyen el código a través del que expresamos y comunicamos nuestras experiencias. Desde esta perspectiva, se combinan dos tesis fundamentales. Por un lado, la concepción de las ideas como representaciones pues, como dijo Descartes (1641, p. 88), las ideas no son sino "las cosas en tanto que en el entendimiento". Por otro, la concepción del significado ligada al pensamiento pues "las palabras, en su significación primaria o inmediata nada significan, salvo las ideas que están en

\footnotetext{
${ }^{1}$ Otro de factor que contribuye a la diferencia entre las concepciones es el establecimiento de una de las dos funciones del lenguaje como función principal. Atendiendo a ambos factores, se sigue aquí la clasificación de Acero (1998) en cuatro concepciones del lenguaje: cartesiana, analítica, romántica y pragmática. Las concepciones cartesiana, analítica y romántica parten del supuesto de la capacidad representacional y de la atención a la función expresiva del lenguaje. Por su parte, la concepción pragmática se centra en la función comunicativa y en la explicación del lenguaje entendido como conducta. No obstante, esto a priori no parece incompatible con la tesis representacional mantenida por otras concepciones.
} 
la mente de quien las usa" (Locke, 1956, p. 394). Por lo tanto, pensar es, en definitiva, operar con estas representaciones. La diferencia entre ambas concepciones está en el tipo de código que la mente usa. Mientras la concepción romántica mantiene que el código del pensamiento representacional es el lenguaje natural mismo, en la concepción cartesiana se encuentran dos códigos diferentes de manera que la mente tiene su propio código que se traduce al lenguaje natural $^{2}$. De esta forma, la concepción cartesiana defiende un lenguaje privado para la representación y un lenguaje público para la comunicación que obliga a introducir dos procesos semánticos básicos para la traducción de uno a otro, codificación y descodificación. Mientras que a través de la codificación se da significado a una expresión del lenguaje con una representación (o idea) como hablantes, con la descodificación se efectúa el proceso inverso, necesario para la interpretación de los inputs lingüísticos como intérpretes. Desde esta perspectiva, no son, como ingenuamente se enunció en líneas precedentes, los signos quienes significan cosas sino que son los hablantes quienes significan a través de sus representaciones mentales.

Ahora bien, cualquier teoría que mantenga como básica la relación representacional pensamiento-realidad implica dos problemas. Las representaciones conllevan la dificultad tanto de su caracterización como de garantizar la comunicación debido a su carácter privado, sólo accesible al sujeto de la representación ${ }^{3}$. Resulta difícil desde esta perspectiva establecer la garantía de que lo descodificado por el oyente coincida con aquello que el hablante ha codificado. En otras palabras, parece difícil contar con la seguridad de que los significados de hablante y oyente de una expresión dada sean los mismos.

\footnotetext{
${ }^{2}$ El desarrollo posterior de las tesis que están en la base de la concepción cartesiana dio lugar a dos importantes líneas de investigación sobre el lenguaje en la filosofía y lingüística contemporáneas: la Teoría Representacional junto a la Teoría Computacional de la Mente y la lingüística generativa, principalmente a través de los estudios de J. Fodor y N. Chomsky respectivamente. Ambas reflexionan sobre el tipo de código desde perspectivas diferentes, cognitiva o gramatical. Se ha considerado que su exposición aquí entorpece el objetivo del capítulo, i.e., esbozar un cuadro general que facilite la comprensión del cambio producido por la semántica veritativo-condicional. En lo que sigue se utilizará la expresión código del pensamiento en un sentido general, ajeno a la discusión sobre la caracterización del código.

${ }^{3}$ La naturaleza de las ideas -entidades mentales- ha sido un amplio tema de discusión a lo largo de la historia. La noción de idea plantea el problema de la explicación de su propia naturaleza. Si las ideas son contenidos representacionales de los estados mentales no está claro qué forma tienen quedando abiertas algunas cuestiones: ¿Son imágenes o tienen forma linguística? ¿Son entidades estructuradas? ¿Son entidades físicas?
} 
La filosofía de finales del siglo XIX y principios del XX, en su intento de eliminar cualquier sospecha de subjetivismo, se convirtió en una filosofía centrada en la búsqueda de fundamentos últimos que garantizasen la objetividad. Proporcionar una explicación objetiva del significado lingüístico llevó a la filosofía analítica a desterrar el término idea usado por las concepciones anteriores debido a "la inseguridad de la conexión entre representaciones y palabras" (Frege, 1892, p. 89) y a buscar un fundamento objetivo del significado, independiente de cada individuo. Volviendo la mirada al triángulo semiótico, eliminar las ideas del esquema representacional trajo como consecuencia el cambio de la prioridad representacional, estableciendo como fundamental la relación lenguaje-realidad.

\subsection{Las bases del modelo semántico extensional}

El cambio en la dirección explicativa de la relación representacional en la semántica clásica centró el objetivo en explicar cómo las expresiones lingüísticas refieren a lo real. La concepción del significado de las filosofías analítica y postanalítica se centra en dos nociones semánticas fundamentales, referencia y verdad. El uso de éstas produce, como se verá a continuación, una teoría semántica veritativa y extensional para cuya explicación es necesario remontarse a tres momentos especialmente relevantes: el origen del vínculo verdad-significado en la teoría fregeana y el establecimiento de la verdad y la referencia como criterios de significado en los desarrollos de la filosofía postanalítica y la semántica formal.

\subsubsection{El giro hacia la verdad}

La respuesta a la cuestión del vínculo entre el lenguaje y la realidad parte de la identificación del tipo de estructura lingüística que es capaz de representar la realidad. En términos generales, la estructura compuesta de los rasgos sintácticos semánticamente relevantes o, en otras palabras, la 
parte sintáctica que representa la realidad se ha denominado forma lógica. En este sentido, el desdoblamiento reduccionista aristotélico de los géneros del ser trajo como consecuencia una ontología en la que sólo tienen cabida sustancias y atributos. Se forja así, como expresa Quine (1974) la herencia cultural de la ley de los atributos según la cual una proposición es la atribución de una cualidad a un objeto ${ }^{4}$. Desde este punto de vista, la forma lógica tradicional se considera idéntica a la forma gramatical sujeto-predicado de manera que en César conquistó las Galias $^{5}$ la forma tradicional dice que hay un sujeto, César, al que se atribuye un atributo, conquistar las Galias. Sin embargo, esta forma lógica falla en la consideración de las relaciones y de la expresión de la generalidad. La motivación fregeana era fundamentalmente matemática, de forma que era necesario expresar las relaciones como elemento básico de la matemática, así como cuantificarlas. Esto hace que Frege reformule la noción de forma lógica:

En mi modo de representar un juicio, no tiene lugar una distinción entre sujeto y predicado. [...] en esto sigo por completo el ejemplo del lenguaje de fórmulas matemático [...] En el primer esbozo de un lenguaje de fórmulas me dejé llevar por el ejemplo del lenguaje ordinario, componiendo los juicios con sujeto y predicado. Pero pronto me persuadí de que esto era contrario a mi propósito y de que sólo conducía a prolijidades inútiles" (1972, p. 14)

La explicación de los juicios fregeana constituye una definición extensional de la noción de forma lógica que marca las directrices de la semántica posterior. Para Frege (Frege, 1891 y 1904) los juicios son una función, de forma que la forma lógica del ejemplo anterior es $\{f($ César $)\}$, donde $f$ es la función que corresponde a ser conquistador de las Galias y César su argumento. Ahora bien, Frege entiende la noción de función como un concepto que posee una extensión cuyos elementos son los objetos. Hablar de un concepto es hablar de los elementos que caen bajo su dominio de forma que son los objetos quienes dan contenido al concepto. Así, el esquema función-argumento se convierte en el esquema concepto-extensión y la noción de forma lógica adquiere un sentido

\footnotetext{
${ }^{4}$ El término proposición se usará aquí en un sentido general desde la perspectiva de la semántica clásica como la entidad lingüística portadora del significado o contenido veritativo-condicional por oposición a las características físicas y gramaticales de una oración; lo que de otra forma se ha denominado el contenido semántico de una oración.

${ }^{5}$ Ejemplo tomado de Frege (1891, p.66)
} 
extensional. Esto implica que la relación semántica fundamental, la forma en que el lenguaje representa la realidad, sea la relación de referencia y que Frege se vea obligado a explicar cómo refieren los términos.

En términos generales, las expresiones refieren a objetos, de modo que la referencia de un término es el objeto que designa el término Sin embargo, esta idea inicial le plantea a Frege dos problemas. Por un lado, Frege se ve en la necesidad de apelar al sentido para dar cuenta de la diferencia cognoscitiva de las expresiones que tienen la misma referencia. Esto trae como consecuencia que el significado se desdoble en sentido -el modo de darse la referencia- y referencia. Por otro lado, las expresiones no siempre refieren a objetos. Esto no ocurre cuando lo que se analiza son proposiciones enteras, el elemento principal de análisis para Frege dada su motivación de representar los juicios matemáticos. Consciente de la complicación que supone asignar una referencia a una oración pues, siguiendo su esquema, ésta debería ser un objeto, Frege (1892) se pregunta si está justificado exigir a las proposiciones una referencia y en esta justificación está la clave para comprender el vínculo con la verdad. Según Frege, en la medida en que se adopte un enfoque científico, y sólo bajo esta pretensión, debe uno preocuparse por la verdad (p.92):

Por tanto, tenemos en verdad derecho a no contentarnos con el sentido de una oración y a preguntar también por su referencia. Pero ¿por qué queremos que todo nombre propio tenga no sólo un sentido sino también una referencia? ¿Por qué no nos basta el pensamiento? Porque, y en la medida en que, nos importa su valor de verdad. Éste no es siempre el caso. Al escuchar, por ejemplo, una epopeya, nos cautivan, además de la armonía del lenguaje, el sentido de las oraciones y las representaciones y los sentimientos despertados por ellas. Con la pregunta por la verdad abandonaríamos el goce artístico y adoptaríamos un enfoque científico. Por tanto, nos es indiferente si, por ejemplo, el nombre "Ulises" tiene una referencia, en la medida en que tomemos el poema como una obra de arte.

Al menos algunas oraciones deben ser evaluables, las oraciones declarativas. Una función asociada a argumentos distintos dará como resultado valores diferentes. Dado el ejemplo de la 
función inicial $\{f($ César $)\}$, cabe tener otros argumentos para la misma función como Alejandro Magno o Hernán Cortés, de modo que $\{f($ César $)\}$ tiene valor verdadero mientras que $\{f($ Hernán Cortés)\} tiene valor falso. Esto significa que se debe introducir un nuevo elemento en el juicio. Un juicio consta de una función o concepto, sus argumentos u objetos y su valor de verdad -bajo el presupuesto de bivalencia- (Frege, 1892). De esta forma, Frege da el salto explicativo que perdura hasta hoy en la tradición semántica al afirmar la referencia de una proposición como su valor de verdad:

La forma lingüística de las ecuaciones es una oración asertórica. Tal oración contiene como sentido un pensamiento $-\mathrm{o}$, por lo menos, pretende contenerlo-; y este pensamiento es, en general, verdadero o falso, esto es: tiene, en general, un valor de verdad que debe considerarse como la referencia de la oración. (Frege 1891, p. 65-66)

Con esta tesis, concluye "se ha producido ya el paso del nivel de los pensamientos al nivel de las referencias (de lo objetivo)" (1892, p. 93) ${ }^{6}$. Lo significativo en los juicios no es su descomposición en conceptos sino su valor de verdad, en el sentido en que éste es su referencia y, por tanto, un juicio con sentido tiene siempre un determinado valor de verdad. En palabras de Frege (1891, p. 67), “Una oración asertórica no contiene ningún lugar vacío y por ello hay que considerar que su referencia es un objeto. Pero esa referencia es un valor de verdad".

La forma en que ha de determinarse el valor de verdad de una oración viene dada por el sentido de la misma. El pensamiento, desde el punto de vista fregeano, es la condición necesaria y suficiente para que la oración que lo expresa sea verdadera al dar las condiciones que ha tener la referencia de la oración. Por lo que el sentido de una oración es su condición de verdad. Las condiciones de verdad de las oraciones se convierten en un criterio semántico con el que identificar el valor semántico (su referencia o valor de verdad) de las oraciones ${ }^{7}$.

\footnotetext{
${ }^{6}$ Puesto que esta tesis tiene que encajar en la estructura concepto-objeto, Frege reifica la noción de verdad tomando los valores de verdad como objetos, a priori e independientes cognoscitiva y ontológicamente.

${ }^{7}$ Las oraciones son entidades complejas por lo que determinar las condiciones de verdad, así como el valor de verdad, exige una explicación de cómo las partes contribuyen al todo. La respuesta a esta cuestión se resuelve apelando al principio de composicionalidad para la composición de la referencia de la oración y al principio del contexto para la
} 
En consecuencia a lo anterior, Frege origina los presupuestos básicos de la semántica posterior. En primer lugar, determina que la estructura semántica relevante es la forma lógica de las

oraciones. Éste se convierte en el nivel mínimo de análisis semántico dejando a un lado la semántica léxica. Además, su motivación matemática implica una noción de forma lógica extensional construida sobre las nociones de función y objeto. Así, la referencia de las expresiones (objetos para los términos singulares y conjuntos de objetos para los generales) se convierte en la piedra angular de la teoría semántica. Determinar el significado depende de identificar referencias a través de su modo de presentarse (sentido). El cambio en la concepción de la forma lógica, así como el establecimiento de la oración como nivel mínimo semántico, produce en última instancia el vínculo entre la semántica y la verdad. La referencia de una oración para Frege es su valor de verdad y su sentido es su condición de verdad.

\subsubsection{Hacia una semántica lógica}

Davidson no sólo avanza en el mismo camino emprendido por Frege de dotar a la teoría semántica de un carácter extensional sino que da un paso más. La solución de Davidson pasa por eliminar por un lado, cualquier tipo de entidad intensional al modo empirista quineano y, por otro, la referencia como base del significado. Esto lleva a Davidson a construir la teoría semántica entorno a la noción de verdad. Según Davidson (1977b), éste es el coste de elaborar una teoría empírica del significado lingüístico.

La cuestión de las intensiones nace con los problemas surgidos en el seno de la filosofía analítica en torno a la incapacidad de las referencias de contribuir al valor semántico de las

composición de las condiciones de verdad de las oraciones (Frege, 1892). El principio de composicionalidad es un principio extensional ligado a la noción de referencia propia de la semántica clásica que descansa sobre el principio leibniziano de sustitución salva veritate, i.e., si en una oración sustituimos dos términos con la misma referencia su valor de verdad no varía. Por lo tanto, lo que contribuye a determinar si una oración es verdadera son las referencias de los términos constituyentes de la oración de forma que el valor de verdad de una oración depende de las referencias de sus expresiones componentes más su articulación lógica. En lo que respecta a las condiciones de verdad de las oraciones, el sentido de una oración depende de los sentidos de sus expresiones componentes. En definitiva, esto expresa la idea general de que el significado de una expresión compleja depende del significado de sus expresiones componentes más la forma de combinación de éstas. Ésta última formulación se ha convertido en la literatura posterior en la acepción generalmente asumida sobre la composicionalidad. 
oraciones en las que aparecen (Frege, 1892; Russell, 1905). Este problema es especialmente notable en i) casos de expresiones correferenciales con una diferencia epistémica entre ellas y ii) casos de referencia vacía o múltiple. Como ejemplo de los primeros, se encuentra el caso de las expresiones en las que está involucrada la relación de identidad. Si se reduce el significado a la referencia extensional, enunciados como $a=a$ y $a=b$ tendrían el mismo significado, sin embargo esto no captaría la diferencia epistémica entre ellas que hace que la primera sea un enunciado analítico mientras la segunda añade información a la relación de identidad analítica. Para el segundo tipo de casos, puede ser que no haya disponible una referencia que funcione como el correlato extensional de una expresión (oraciones que involucran contradicciones semánticas como El rey de Francia es calvo u oraciones que refieren a entidades ficticias como Superman es más fuerte que Spiderman), o bien las expresiones son polisémicas de forma que denotan varias referencias distintas (hoja puede denotar una parte de una planta, la parte móvil de una puerta, una lámina de papel o la parte cortante de un cuchillo).

Estos problemas han llevado, ya sea en la línea fregeana o russelliana, a asumir algún tipo de entidad intensional como complemento a la teoría de la referencia. Sin embargo, estas entidades intensionales suponen una amenaza respecto de los fundamentos básicos de la semántica establecidos bajo la pretensión de objetividad. La aprehensión de la intensión es un acto mental individual relegado al ámbito privado pues las intensiones se identifican con elementos abstractos del pensamiento y, por tanto, implican los mismos problemas que la noción de idea. Esto choca con la idea de que los significados deben ser públicos e intersubjetivos para que sea posible la comunicación. De esta forma, la filosofía postanalítica, vinculada al empirismo, ve en las entidades intensionales la causa de la pérdida de la objetividad necesaria para garantizar la comunicación lingüística y emprende así una cruzada contra el intensionalismo encabezada por Quine (1951).

En relación a la cuestión de la referencia como pilar fundamental de la conexión lenguajemundo, ésta se vuelve problemática desde dos perspectivas distintas. Por un lado, la tesis de la 
referencia unida a la tesis según la cual la oración es el nivel mínimo del análisis semántico llevó a Frege a tener que comprometerse con una noción de verdad reificada al postular el valor de verdad de las oraciones como sus referencias. Por otro lado, los desarrollos filosóficos de Hume, Kant, Russell o Quine han objetado la imposibilidad de conocer directamente los objetos. Siguiendo estos, los objetos son postulados, construidos inconscientemente a partir de los datos de observación. En este sentido, el vínculo entre las referencias y las expresiones lingüísticas es indirecto o mediado por la estructura de conocimiento. Es por ello que Quine (1951 y 1986) afirma que no podemos referir lingüísticamente a los objetos de forma directa y que, además, la referencia es inescrutable. No hay garantía de que dos hablantes tengan la misma estimulación cognitiva que garantizaría la concordancia de la referencia extralingüística al ser éste un proceso inconsciente.

En consonancia con las críticas anteriores, Davidson elimina las entidades intensionales y la referencia como base del significado. Para Davidson (1967a) significado no es igual a referencia pues las cuestiones de referencia se establecen por hechos extralingüísticos mientras las cuestiones de significado dependen de la estructura del lenguaje, i.e., de la forma lógica de las oraciones (Davidson, 1977a). Siguiendo esto, el objetivo de la teoría semántica es el análisis composicional de la estructura de las oraciones que permite explicar la recursividad y productividad del lenguaje (Davidson, 1970). La pretensión davidsoniana es la de construir una teoría semántica a partir de la noción de verdad como la única propiedad semántica de las oraciones obteniendo con ello una teoría puramente extensional $(1967 a)^{8}$. Para ello se sirve de la definición semántica de la verdad tarskiana en la que ve la oportunidad de dar un enfoque lógico-deductivo para una teoría recursiva del significado sin la intervención de intensiones ni referencias. Este tipo de teoría, según Davidson (1970) proporciona de un modo mínimo los significados de todas las expresiones en base a un análisis de su estructura, es decir, mediante una teoría del significado entendida como teoría

\footnotetext{
${ }^{8}$ Estrictamente hablando la verdad es para Davidson una propiedad de las emisiones pues la teoría debe atenerse a la verdad relevante y ser, por ello, contextualizada al nivel de la emisión para atender a la sensibilidad al contexto del lenguaje. La verdad es un atributo de las emisiones que depende de la oración emitida, el tiempo y el hablante (Davidson, 1977a).
} 
lógica ${ }^{9}$. Lo que determina el significado de una oración son las condiciones de verdad (intersubjetiva) de dicha oración que pueden ser formalizables siguiendo el modelo extensional tarskiano de las equivalencias $T$, que se analizará en capítulos posteriores.

Los lenguajes naturales son vistos desde esta perspectiva como lenguajes formales complejos.

La lógica se convierte en el recurso idóneo para describir y analizar la estructura del lenguaje natural en una teoría puramente extensional cuyo eje central es la noción de verdad como propiedad semántica pues, en palabras de Davidson (1967a, p. 41): “el concepto semántico de verdad es el fundamento sofisticado y poderoso de una teoría competente del significado" ${ }^{\text {. }}$

\subsubsection{Una semántica precisa}

Quizá la semántica de corte fregeana con mayor impulso en el siglo XX es la Semántica Formal a partir de los desarrollos de R. Montague (Thomason, 1974). Ésta recibe el apelativo formal por el hecho de servirse de las técnicas lógicas de los lenguajes formales para aplicar la semántica veritativo-condicional al lenguaje natural (Cresswell, 2006). Por ello, es también una semántica de carácter lógico-matemático que se construye sobre las nociones de referencia y verdad bajo la inspiración de la Teoría de Conjuntos matemática y el requisito de la composicionalidad. Desde esta perspectiva, significar es referir cosas. La

\footnotetext{
${ }^{9}$ Davidson expulsa del ámbito semántico el análisis del significado de las expresiones particulares (semántica léxica) adoptando una visión holística del significado (1977a y 1977b). El único papel de las palabras es el de contribuir al nivel mínimo de significado -el significado de la oración-, por lo que deben asumirse como elementos primitivos (Davidson, 1973). Ahora bien, parece que hablar de composicionalidad exige hablar de las referencias de las partes de una oración y así lo asumía Tarski al incluir dentro de la teoría semántica los conceptos de designación y satisfacción. Sin embargo, para Davidson (1977a), tales conceptos sólo son conceptos teóricos que, al igual que el concepto de referencia, son subsidiarios de la noción de verdad. De esta forma, para Davidson, la semántica tiene un papel mínimo pues no debe aspirar a la alta pretensión de dar un contenido rico para cada oración sino sólo a encontrar "un mínimo de información acerca de la corrección de la teoría" (1977b, p. 228). Al estudiar la estructura del lenguaje es posible comprender la realidad, en el sentido en que el lenguaje expresa una visión del mundo compartida, por ello este papel mínimo se concreta en la determinación de las condiciones de verdad de las oraciones a diferencia de la determinación de cuáles son las oraciones verdaderas que es tarea de la ciencia.

${ }^{10}$ Sin embargo, como se verá más adelante, la verdad, como propiedad semántica, es incapaz de explicar el significado de las oraciones reforzando con ello el papel de la teoría de la acción comunicativa davidsoniana en detrimento del papel de la semántica. Como el mismo Davidson reconoce (1977b, p. 228): "Las oraciones T no dan el significado pero son suficientes para la comprensión del habla".
} 
semántica es fundamentalmente extensional pues consiste en la asociación de referencias con expresiones del lenguaje (Bach, 1989) ${ }^{11}$.

Si bien es cierto que la Semántica de Mundos Posibles vinculada a la Teoría de Modelos incluye intensiones, estas son estrictamente hablando definibles extensionalmente. En la literatura sobre semántica a menudo se hace referencia a las intensiones como aquello que ayuda a determinar las extensiones de una expresión en cada uno de los mundos (y tiempos) posibles. Sin embargo, esta caracterización puede llevar al error de atribuir a la intensión un carácter que no tiene, uno alejado de la extensionalidad y la teoría de la referencia. En primer lugar, para que una intensión pueda determinar la extensión de una expresión en un mundo (y tiempo) dado se necesita previamente saber la extensión de dicha expresión en todos los mundos (y tiempos). Esto implica un lenguaje definido recursivamente, extensional y especificado completamente. De esta forma, las intensiones, no son más que conjuntos de denotaciones (el conjunto de las denotaciones que una expresión tiene en todos los mundos -y tiempos- posibles). Por tanto, la intensión se define extensionalmente. En segundo lugar, dado que para tener una intensión se debe tener la denotación de la expresión de la que es intensión en cada mundo (y tiempo), se necesita tener también las denotaciones de los nombres y predicados que están involucrados en la expresión ${ }^{12}$. De ahí que, estrictamente hablando, la teoría semántica se construya sólo a partir de denotaciones y funciones que conectan las denotaciones con las expresiones, siendo las intensiones un recurso técnico. En definitiva, el modelo de explicación continúa en la línea de la extensionalidad anterior: es la referencia la que aporta el significado en favor de la objetividad semántica. Una vez más la prioridad representacional está en la dirección lenguaje-realidad (Bach, 1989; Barwise y Perry, 1981; Dowty, Wall y Peters, 1981; Portner, 2005).

\footnotetext{
${ }^{11}$ Se sigue aquí el enfoque dado por Bach (1989) pues este tipo de semántica no es estrictamente formal, en el sentido de estudiar las relaciones existentes entre las expresiones de un lenguaje, sino que fundamentalmente el objetivo consiste en estudiar las relaciones de las expresiones lingüísticas y aquello que no es lenguaje (las cosas de las que hablan) y, por tanto, es más bien una semántica precisa y no tanto formal, de ahí el título con el que se abre el tema.

${ }^{12}$ En este sentido, una de las cuestiones que parece fundamental es saber cuáles son las denotaciones. Sin embargo, ni en la teoría de Montague ni en otras semánticas formales se dice cómo sabemos esta información, simplemente se presupone que la sabemos porque tenemos un lenguaje especificado. Pero sobre esto se volverá en el capítulo segundo.
} 
La idea básica es que un lenguaje consta de dos estructuras diferentes, sintaxis y semántica, que deben estar en relación de correspondencia de forma que a la sintaxis -los símbolos lingüísticos junto a sus modos de combinación- pueda asignársele un contenido -en términos de teoría de modelos, una interpretación. La forma de hacer esto es a través de la Teoría de Modelos de la que se hablará más adelante con motivo de la revisión crítica que se llevará a cabo de la semántica veritativo-condicional. Por el momento, puede decirse, en favor del seguimiento de la exposición, que la semántica formal es el estudio de los modelos adecuados para el tratamiento del lenguaje natural y que, como hizo Frege, admite esencialmente dos tipos de denotaciones en tales modelos para los dos tipos de expresiones que en general encontramos en los lenguajes: los elementos lingüísticos básicos denotan individuos o conjuntos de individuos según sean, siguiendo el orden anterior, términos singulares o predicados, mientras que las oraciones denotan valores de verdad.

Aunque de forma muy general y esquematizada, pueden verse en la semántica formal no solo las tesis fregeanas fundamentales, sino además que ésta va un paso más allá. Como quizá ya se ha podido entrever, parte de la asunción del supuesto según el cual los lenguajes naturales son una extensión del lenguaje formal. Siendo más precisos, parten de lo que Bach (1989) llama las tesis de Chomsky y de Montague. Según la tesis de Chomsky los lenguajes naturales pueden describirse como sistemas formales ${ }^{13}$; a lo que la tesis de Montague añade que los lenguajes naturales pueden ser tratados como lenguajes formales interpretados.

\footnotetext{
${ }^{13}$ En el intento de explicar la productividad lingüística, Chomsky (1957 y 1965) ve en los lenguajes formales la forma de explicar cómo es posible generar tipos de expresiones de forma mecánica y entender una infinidad de oraciones incluso a pesar de ser nuevas para los oyentes. De manera que la Gramática generativa ha estado encaminada a explicar en qué consisten la sintaxis y las reglas de formación de los lenguajes naturales que permitan explicar este hecho mediante una teoría especificada finitamente. En este sentido, el lenguaje natural contendría estructuras y reglas similares a las de los lenguajes formales en las gramáticas representadas internamente en los hablantes. Esto quiere decir que, a pesar de que la lingüística es concebida como una rama de la psicología, en el sentido en que conocer el lenguaje es tener un conocimiento tácito de la gramática interna del lenguaje en la mente de los hablantes, la gramática que es internamente representada se construye matemáticamente como las de los lenguajes formales (Schiffer, 2015).
} 


\subsubsection{La herencia semántica}

Las teorías anteriores han forjado la visión del significado lingüístico como una relación entre las oraciones y sus referentes extensionales. El significado se produce cuando asociamos oraciones con el mundo, por lo que una expresión es significativa cuando se da de forma correcta esta asociación. En otras palabras, si una expresión lingüística representa el mundo de una forma dada entonces es verdadera bajo tales circunstancias, de donde deriva la idea de que la semántica de las oraciones se expresa en términos de condiciones de verdad. Como se vio anteriormente, las condiciones de verdad son la forma técnica de ofrecer una definición recursiva del significado en términos de verdad y referencia como nociones semánticas.

El cuadro general puede explicarse entonces a grandes rasgos de la manera que sigue: una expresión lingüística representa/refiere/significa hechos del mundo, de modo que conocer su significado es conocer los hechos que refiere, es decir, las condiciones que debe tener el mundo bajo las que la oración es verdadera. Se postula de esta forma una relación directa entre la referencia, entendida extensionalmente, y la verdad, lo que produce una teoría referencial, veritativa y extensional del significado lingüístico. Siguiendo el modelo fregeano, ésta deberá estar restringida por el requisito de la composicionalidad. Así, en la literatura actual se acepta que el contenido semántico (contenido veritativo-condicional) de una expresión compleja depende del valor semántico de sus expresiones componentes más la forma de combinación de éstas.

Esta concepción asume con ello cuatro tesis fundamentales: 1) el lenguaje representa por sí mismo la realidad y tal representación se muestra en la forma lógica de las oraciones, entendidas éstas como el nivel primario de significación, 2) la verdad es una propiedad atribuible a las expresiones lingüísticas (concretamente a las oraciones o a las proferencias de las mismas según nos situemos en una u otra teoría), 3) la determinación de las condiciones de verdad de las expresiones es el criterio de su significatividad pues conocer éstas contribuye a saber cómo y qué representan las expresiones y, por tanto, su significado y 4) la determinación de las condiciones de 
verdad de las expresiones lingüísticas está vinculada a la relación de referencia en la medida en que se necesita el conocimiento del mundo para determinarlas. Estas cuatro tesis están suscritas en lo que parecen cuatro teorías combinables dentro de una misma familia de teorías (Portner, 2005): la semántica veritativo-condicional, la semántica formal, la semántica de la Teoría de modelos y la semántica de mundos posibles.

En resumen, cabe destacar dos conclusiones especialmente importantes para el estudio del significado que han marcado los desarrollos desde esta semántica clásica hasta la actualidad: 1) la determinación de las condiciones de verdad es el criterio del significado lingüístico de las oraciones, objetivo e independiente de las ideas o intenciones subjetivas de los hablantes y 2) el lenguaje natural es una extensión del lenguaje formal y como tal las herramientas de la lógica son las herramientas para el estudio del lenguaje natural, capaces de darnos una teoría recursiva del significado.

\subsection{Los límites de la semántica}

Desde la concepción heredada, proveniente de la semántica clásica junto a la teoría griceana, se han establecido ciertos límites entre la semántica y la pragmática. En esta sección se presenta un panorama general de la distinción clásica entre semántica y pragmática, dejando para otros capítulos los detalles relativos al debate que la misma ha suscitado.

En lo que respecta a la semántica, ésta tiene como objeto de estudio el contenido semántico o proposición, en términos veritativo-condicionales. Su tarea es proporcionarnos la información codificada en lo declarado, constituida por las características estables de la oración y restringida por el requisito sintáctico de la composicionalidad. Por su parte, la pragmática, en términos generales, tiene que ver con el uso del lenguaje por parte de los hablantes para realizar objetivos comunicativos (Perry, 2006). En este sentido, trata la información extralingüística que emerge desde el acto real de la proferencia de una oración en un contexto dado. Entre sus objetos de 
estudio se encuentran los actos de habla, las implicaturas, los significados figurados, las expresiones indéxicas y fenómenos como la elipsis o la ambigüedad $^{14}$ (Bianchi, 2004). Se ha concebido que la combinación de la información semántica junto a la información pragmática provee la base para que el oyente comprenda la intención comunicativa del hablante. Desde esta perspectiva, la delimitación de la semántica y la pragmática se corresponde con dos niveles de significado: el significado de la oración y el significado del hablante.

Bajo el dominio de la pragmática se encuentra el significado del hablante. Varios usos del lenguaje se han clasificado tradicionalmente como pragmáticos y no literales. Cuando utilizamos una oración irónicamente o sarcásticamente pretendemos comunicar algo distinto de lo que en realidad decimos con nuestras palabras. Algo similar ocurre en el caso de las implicaturas donde el oyente deriva un significado añadido a las palabras pronunciadas por el hablante, reconociendo la intención de éste de comunicar más de lo que ha dicho. En todos estos casos hay un reconocimiento de que lo comunicado se distingue de lo dicho por la proferencia de una oración. Los hablantes ordinarios piensan que el habla indirecta y las implicaturas explotan los significados convencionales para crear unos nuevos de manera que existe un reconocimiento de que estos significados se derivan de otros más básicos y primarios. Esto trae como consecuencia que el significado del hablante se haya concebido como un significado indirecto e inferido que implica un mayor esfuerzo cognitivo, así como requiere un mayor tiempo para su procesamiento. Además, el hecho de que sea un significado indirecto, inferido y extralingüístico, en el sentido de no estar atado a las palabras proferidas, hace que sea altamente dependiente del contexto y no comprometa al hablante con su contenido.

En contraposición, las características que se atribuyen al significado de la oración pueden clasificarse en tres grupos. El primer grupo engloba las características estrictamente lingüísticas, de tal manera que se concibe como un significado 1) especificado gramaticalmente y codificado en la

\footnotetext{
${ }^{14}$ Esta caracterización de la pragmática ha sido generalmente aceptada, si bien ha habido otras formulaciones debido a la heterogeneidad de su campo de estudio. Así, la describe Bar-Hillel (1971, p. 401) como el campo heterogéneo que intenta explicar los hechos semánticos sin explicación; una especie de papelera de la semántica. Entre estos hechos, se asigna a la pragmática especialmente el estudio de los lenguajes indéxicos (Bar-Hillel, 1954).
} 
forma lógica de las oraciones de acuerdo al criterio de la composicionalidad, 2) ligado al léxico, 3) proposicional $\mathrm{y}$, por último, 4) invariable a los $\operatorname{contextos}^{15}$. El segundo grupo tiene un carácter cognitivo, de forma que se supone que es un significado directo y de rápido acceso cognitivamente. El significado de la oración se ha tomado como un significado literal, convencional e inherente a las palabras en oposición a los sentidos figurados que requieren un modo rico de interpretación o a significados complejos que los hablantes puedan expresar (Israel, 2002). Dada esta concepción común, los hablantes ordinarios asumen que el habla literal es un habla directa donde uno significa lo que está diciendo y el oyente no necesita añadir nada a las palabras del hablante para su comprensión. Además, es el nivel de significado sobre el que establecemos nuestras inferencias para alcanzar las implicaturas y significados secundarios. Desde el punto de vista comunicativo, es un significado que no es cancelable, por lo que compromete completamente al hablante con su contenido. Tradicionalmente, se ha situado éste en el nivel griceano de lo dicho de forma que se ha tomado en un sentido general como el output de la semántica y el input para la pragmática, estando ligado a nociones como lo dicho, el significado literal, la proposición expresada o el significado tipo (Ariel, 2002; Bach, 1999; Dascal, 1987; Lakoff, 1986; Searle, 1978).

De esta caracterización han surgido varios criterios de individuación del significado lingüístico como asunto semántico de acuerdo a las características que se le han asignado. Desde la perspectiva de la semántica veritativo-condicional, se ha adoptado como criterio fundamental que este nivel de significado sea un significado con completo contenido veritativo-condicional; desde el punto de vista de la pragmática griceana, el criterio es fundamentalmente la no cancelabilidad; por último, desde la invariabilidad o independencia del contexto y de las intenciones de los hablantes se hizo popular el criterio de la carta anónima de $\operatorname{Katz}(1977$, p. 14):

The anonymous letter situation is the case where an ideal speaker of a language receives an anonymous letter containing just one sentence of that language, with no clue whatever about the motive,

\footnotetext{
${ }^{15}$ Como se verá en el capítulo tercero, Kaplan (1975) ofreció un análisis adecuado a esta distinción para el tratamiento de la dependencia contextual de los indéxicos que logró salvaguardar un nivel independiente de significado, i.e., el significado lingüístico o carácter.
} 
circumstances of transmission, or any other factor relevant to understanding the sentence on the basis of its context of utterance. [...] We intend to draw a theoretical line between semantic interpretation and pragmatic interpretation by taking the semantic component to properly represent only those aspects of the meaning of a sentence that an ideal speaker-hearer of the language would know in such anonymous letter situation.

Sin embargo, el debate contemporáneo ha mostrado que esta distinción no es tan sólida como parecía. Si se asume que la pragmática está asociada al estudio del contexto y, por tanto, es la que debe explicar las expresiones que son sensibles mientras que la semántica es la que debe estudiar los significados de los símbolos en abstracción de su uso, entonces la tarea semántica se ve comprometida pues parece, como se verá a continuación, que el lenguaje natural es en sí mismo altamente dependiente del contexto.

\subsection{La crisis de la concepción heredada: el avance de la pragmática}

Como se ha explicado en la última sección, pueden distinguirse tres criterios de individuación del significado lingüístico como asunto semántico de acuerdo a las características que se le habían atribuido. De los tres criterios, el de la no cancelabilidad parece que es generalmente aceptado (Dascal, 1987) pues resulta difícil que alguien no esté de acuerdo en que lo que uno dice le compromete. La concepción heredada y las actuales entran en conflicto en relación a las dos características atribuidas al significado lingüístico que están implicadas en los criterios restantes, i.e., el contenido veritativo-condicional y la independencia del contexto.

Cuando uno se propone construir una teoría semántica, desea, como con cualquier otra teoría, poder establecer algunos principios y reglas que expliquen de forma sistemática todos los fenómenos involucrados en relación al hecho a explicar. La concepción clásica funciona bien a este respecto cuando se analiza un nivel idealizado o normativo del lenguaje, como el nivel tipo, pero tan pronto como se pone la atención en el uso ordinario por parte de los hablantes nos enfrentamos 
al hecho de que el lenguaje natural es sensible al contexto de declaración y variable en función de las intenciones comunicativas de los hablantes. Tenemos menos expresiones que realidades queremos representar, así que las usamos de muy diversos modos. De esta forma, como se verá en capítulos posteriores, el lenguaje natural está cargado de expresiones variables en significado.

Este hecho marca dos cuestiones fundamentales presentes en la discusión sobre el significado. Por un lado, ya desde Frege se vio la necesidad de apelar a algún tipo de principio que incluyese en la teoría semántica el contexto como medio de explicación de los cambios de significado. Por otro, el nivel lingüístico que entra en cuestión respecto de los cambios de significado es el nivel de lo dicho. Esto es así debido a que en otros niveles la variación de significados o la sensibilidad al contexto no presenta problema, en el nivel tipo no se dan tales cambios y es generalmente aceptado que el nivel de lo implicado griceano es radicalmente dependiente del contexto y de las intenciones de los hablantes por lo que no puede explicarse de forma sistemática. Así, los criterios están conectados en las críticas contemporáneas a la noción clásica de lo dicho. Ciertamente, en lo que se considera el nivel de lo dicho se encuentran expresiones variables en significado, de ahí que progresivamente se haya llegado a la idea de que la intrusión pragmática es muy abundante en el lenguaje natural.

En los últimos años el debate se ha polarizado fundamentalmente en dos posturas que siguen la herencia de la teoría griceana y de la semántica veritativo-condicional. Por un lado se encuentran aquellas teorías que defienden que el contenido proposicional es producto de procesos semánticos, mientras que por el otro se encuentran aquellas que defienden que en la determinación del contenido proposicional intervienen procesos pragmáticos. Las primeras han recibido el nombre de Minimalismo semántico, Literalismo o Semanticismo, pero, dado que todas ellas se enmarcan dentro de la perspectiva veritativo-condicional, a menudo se referirá a ellas siguiendo la acepción de Bach (2008) de minimalisms about truth-aptitude (en adelante, MTA); mientras que las segundas corresponden al Contextualismo, la Pragmática veritativo-condicional y la Teoría de la 
relevancia, a las que se referirá en lo sucesivo según la acepción general adoptada por Borg (2016) de Modelo Pragmatista o Pragmatismo ${ }^{16}$.

Como se verá en el capítulo tercero, el punto central de la discusión contemporánea en relación al nivel de lo dicho es la objeción pragmatista de la infradeterminación del significado. El pilar explicativo para la noción de lo dicho es que éste es un nivel proposicional, i.e., con completo contenido veritativo-condicional. Sin embargo, desde Frege (1918) se advirtió del hecho de la existencia de oraciones incompletas en este sentido proposicional, oraciones que carecen en su estructura sintáctica (superficial) de algún elemento que sería necesario para determinar las condiciones de verdad de las mismas (p.e., en Llueve parece que sin una provisión de la localización de la proferencia no pueden especificarse sus condiciones de verdad). Según el modelo pragmatista se necesita de la información contextual relevante para especificar las condiciones bajo las que las oraciones son verdaderas o falsas y, por tanto, para poder determinar proposiciones completas, de modo que las características estrictamente lingüísticas son insuficientes para la caracterización del significado oracional, lo que hasta ahora se constituía como el nivel de lo dicho. Esto lleva al Pragmatismo a afirmar que el contenido semántico es radicalmente dependiente del contexto. El MTA por su parte defiende un nivel de significado mínimo invariable al contexto ${ }^{17}$.

Tanto el Pragmatismo como el MTA, han discutido a lo largo de los últimos años cuánta intrusión del contexto hay en el lenguaje, qué niveles estratifican dicha intrusión y cómo se modela la dependencia del lenguaje del contexto. Si bien, como se verá en el tercer capítulo, la diferencia entre ambas posturas es más bien una cuestión de grado o, en otras palabras, el debate es acerca de

\footnotetext{
${ }^{16}$ Sucesivos desarrollos marcados por las objeciones formuladas de uno a otro lado han dado lugar a una ramificación de posturas que van desde los Contextualismos y Minimalismos más radicales hasta otros más moderados. Se pueden encontrar diversas taxonomías (Bianchi, 2004; Camós y Frápoli, 2008; Korta y Perry, 2006; Recanati, 2004 y 2010). Si bien, para facilitar el desarrollo argumental se ha optado por polarizar de esta forma general el debate teniendo en cuenta el principio contextualista. Según éste, una oración adquiere un contenido determinado sólo en el contexto del habla. Esto significa que, dada la persistente sensibilidad al contexto, la oración tipo no tiene un contenido representacional determinado sino sólo propiedades gramaticales abstractas, por lo que no cumple ningún rol en la comunicación. ${ }^{17}$ Se sigue la acepción de Cappelen y Lepore (2005) de contenido semántico mínimo o proposición mínima como el contenido veritativo-evaluable que se genera sobre la base de constituyentes léxico-sintácticos junto a un mínimo aporte contextual, i.e., la función del carácter de las palabras sensibles al contexto. La proposición mínima de una proferencia toma lo que contaría en una comunidad de hablantes como un contenido común o constante a todos los usos de ella, que pudiera ser entendido por cualquiera con independencia del contexto relevante. Por tanto, es previa a un ajuste enriquecido pragmáticamente y puede no corresponder a lo que el hablante pretende comunicar.
} 
qué tipo de contexto interviene. El MTA principalmente admite, siguiendo el modelo kaplaniano, algún tipo de contexto estrecho cuyo alcance es de tipo semántico por la posibilidad de ser explicado de forma sistemática a través de reglas derivadas del conocimiento del léxico estables en la variación de contextos. Las características lingüísticas de las oraciones (léxico y sintaxis) unidas al proceso de saturación proporcionan para el minimalista una proposición mínima sobre la que trabajar para llegar hasta el significado comunicado por el hablante. Es por esto que el Minimalismo es relativo a la función que cumple la semántica en el entendimiento del lenguaje natural y su función comunicativa. Por su parte, el modelo pragmatista, en general, mantiene que este tipo de contexto estrecho no es suficiente. El Pragmatismo amplia el impacto del contexto postulando la necesidad de contextos más amplios que incluyan no sólo los parámetros del ambiente de uso sino también las intenciones de los hablantes y otros factores cognitivos.

Con este nuevo debate la noción clásica de lo dicho se pone en entredicho. Se cuestiona una concepción del significado independiente del contexto y especificada exclusivamente a través de sus características formales, pues a menudo se necesita apelar al contexto para poder determinar el contenido semántico (veritativo-condicional) de las oraciones. De esta forma, la tensión producida entre el criterio veritativo-condicional y el criterio de la independencia se resuelve en las versiones actuales manteniendo la característica veritativo-condicional a la vez que se cuestiona la independencia del contexto.

Estos factores traen como consecuencia que 1) una visión de lo dicho puramente semántica se tambalee en favor de una caracterización pragmática y 2) se anule la distinción semánticapragmática, puesto que no queda nada que se constituya como el campo de estudio de la semántica en favor de una distinción entre sintaxis y pragmática (Carston, 2008; Korta, 2001). De esta forma, se ha intentado mostrar desde múltiples perspectivas que la concepción clásica es insuficiente para la caracterización del significado, así como para el completo entendimiento del funcionamiento del lenguaje. 
Esto ha llevado a las aproximaciones veritativo-condicionales contemporáneas a proponer un modelo tripartito del significado. La tensión producida por el criterio veritativo-condicional y el criterio de la independencia del contexto en relación a lo dicho se ha resuelto introduciendo la noción de explicatura. Desde el Pragmatismo se sugiere que el modelo de la comprensión lingüística se estratifica en tres niveles: forma lógica -único nivel al que no le afecta el contexto-, explicatura -un nivel de lo dicho pragmático- e implicaturas. En lo que sigue se revisarán ambos criterios proponiendo una solución inversa. Es posible descartar el criterio veritativo-condicional, defendiendo una noción semántica de lo dicho, independiente de los contextos, dentro de un modelo binario de la comprensión lingüística. 


\section{Capítulo 2}

\section{El supuesto veritativo-condicional}

El supuesto veritativo-condicional que está en la base de las objeciones pragmatistas descansa en los presupuestos extensionales según los cuales el lenguaje natural es una extensión del lenguaje formal y el significado lo aporta fundamentalmente la referencia. Esto lleva a adoptar la verdad como propiedad semántica para una teoría recursiva del significado. Sin embargo, la comparativa entre el lenguaje natural y el lenguaje formal mostrará que el primero de los presupuestos es injustificado. Además, se argumentará que una teoría veritativo-condicional requiere previamente una caracterización de la noción de forma lógica, una teoría de la referencia y una teoría de la verdad. Sin embargo, estas no pueden adecuarse satisfactoriamente en el tratamiento del lenguaje natural. La revisión de los presupuestos no sólo concluyen con el rechazo de los mismos sino que los motivos para tal rechazo dan la pista para la construcción de un nuevo marco teórico para la teoría semántica que devuelva la dirección representacional a la dirección pensamiento-realidad. Es posible mantener la tesis de que la determinación del contenido veritativo-condicional involucra procesos pragmáticos mientras se niega la tesis de que el nivel de lo dicho, el significado de la oración determinado por las características lingüísticas, sea un asunto pragmático. La solución pasa por rechazar el dogma extensionalista: el contenido semántico no es veritativo-condicional. 


\subsection{Ambigüedad vs. precisión}

El lenguaje natural y el lenguaje formal se componen de elementos similares: un vocabulario de signos -palabras en el lenguaje natural o variables y constantes en el formal-, operadores o símbolos relacionantes para encadenar los signos -operadores lógicos frente a términos funcionales del lenguaje natural- y unas reglas (sintácticas) para el uso correcto de signos y operadores. Además, son sistemas simbólicos con capacidad representacional, por lo que tienen también una dimensión semántica, una forma determinada en la que se relacionan los símbolos con aquello que simbolizan. Si bien, presentan una diferencia crucial. El lenguaje natural es fundamentalmente ambiguo, mientras el lenguaje formal es esencialmente preciso.

El lenguaje formal es un lenguaje artificialmente creado como herramienta de análisis en el que representar ciertos contenidos para estudiar sus características. La utilidad de estos lenguajes se encuentra en su estructura sintáctica. Los lenguajes formales como sistemas lógicos son fundamentalmente sintácticos, de forma que abstraen los contenidos de los enunciados. Esto posibilita representar en un mismo lenguaje distintas realidades con la garantía de que tales sistemas preservan la verdad pues son estructuras donde se garantiza la inferencia válida. Esto se consigue regimentando la sintaxis a través de definiciones recursivas de los elementos y de las relaciones (siempre deductivas) del sistema de modo que haya transparencia sintáctica. De esta forma, los símbolos del lenguaje y la forma en que pueden combinarse están especificados.

La semántica de estos lenguajes explica la relación entre el lenguaje y la realidad sujeta a análisis a partir de nociones incorporadas desde la Teoría de conjuntos matemática y la Teoría de modelos. Dado que el significado de los símbolos no es propiamente lenguaje sino la realidad que representa y en un lenguaje formal no hay hablantes, en la Teoría de modelos se opta por una definición semántica extensional. Se asume que los significados de los símbolos son sus denotaciones pues, como bien dice Seuren (2009, p. 71), "In modern logic and the semantics derived from it, only extensional being [...] can make truth". La tarea semántica entonces consiste 
en interpretar un lenguaje (asignar denotaciones a los símbolos del lenguaje): se deben asignar denotaciones a los elementos básicos y explicar cómo a partir de la combinación de estos se obtienen los significados de las fórmulas complejas.

Para ello son necesarias dos cosas. Primero, es necesario tener denotaciones. Aunque más adelante se revisará esta cuestión, baste por ahora aclarar que en un lenguaje formal se supone que hay un dominio de objetos sobre los que el lenguaje habla. Esto implica que se conocen todos los objetos que hay en el dominio y las propiedades que tienen de manera que el dominio está estructurado en términos de conjuntos matemáticos. Lo que se encuentra en el dominio son exclusivamente objetos y las propiedades están definidas en sentido extensional como conjuntos de individuos, donde la pertenencia a un conjunto es una cuestión definida. Segundo, debe especificarse la relación que los objetos tienen con las expresiones del lenguaje, i.e., debe estar clara la forma en que se conectan los símbolos con el dominio. Esto se consigue a través del concepto matemático de función -una relación unívoca entre dos conjuntos de forma que a cada elemento del primer conjunto le corresponde inequívocamente un elemento del segundo. En la Teoría de modelos se dispone entonces de un dominio y una interpretación; es decir, un conjunto de objetos y una especificación en forma de función de la asignación de valores a los términos y predicados. El resultado es un sistema semánticamente transparente puesto que no sólo la relación entre estos es inequívoca sino que además a cada símbolo le corresponde un elemento del dominio. En definitiva, no hay símbolos sin interpretación y la sintaxis está en correspondencia absoluta con la semántica a través de la garantía de la noción de función matemática y de las definiciones recursivas. (Barba, 2010; Deaño, 1974; Portner, 2005).

Además, la función, como objeto matemático que es, también es una expresión de cálculo (Frege, 1904). Esto es fácilmente visible cuando de lo que se trata es de identificar las denotaciones (significados) de las fórmulas complejas. Para los términos básicos los valores son denotaciones del dominio (p.e., dada una función como El lugar donde nació $x$ y la asignación Cortázar a la 
variable, se obtiene que el valor de la función es la denotación de un lugar, Bruselas ${ }^{18}$ ). Para fórmulas complejas, el valor de la función es un valor de verdad. Esto se debe a que la definición de los operadores lógicos es veritativo-condicional pues en un sistema lógico lo que interesa es garantizar la inferencia válida. Así, se asume desde Frege (1892) que la denotación de una fórmula compleja es su valor de verdad, resultado del modo de combinación veritativo-condicional de las partes simples que la integran. Esta idea se mantiene en la Teoría de modelos según la cual los términos (constantes y variables) denotan individuos, los predicados denotan conjuntos de individuos y las oraciones valores de verdad. La Semántica formal se construye en definitiva a partir fundamentalmente de denotaciones, como valores semánticos, y funciones ${ }^{19}$.

Más allá de los detalles técnicos, lo que interesa es mostrar tres conclusiones: 1) en un lenguaje formal sintaxis y semántica están en correspondencia y ésta es transparente, de modo que no cabe ambiguiedad ${ }^{20}$, 2) lo que aporta el significado son las denotaciones, que deben darse previamente y definirse mediante una asignación precisa ${ }^{21}$ y 3) hay una conexión directa entre la verdad y el significado. El significado es, en último término, una función que conecta expresiones con denotaciones y la verdad, entendida como validez semántica, consiste en la correspondencia entre los símbolos y el dominio; así, la verdad está expresada en la función de asignación semántica. En consecuencia, el lenguaje formal se caracteriza por ser un lenguaje esencialmente preciso y transparente.

El lenguaje natural en cambio es el resultado de un proceso de evolución histórica de los seres humanos, un producto vivo que cambia constantemente sin que los cambios introducidos

\footnotetext{
${ }^{18}$ Ejemplo tomado de Deaño (1974, p. 91).

${ }^{19}$ Conviene recordar aquí la distinción establecida por la semántica clásica que se vio en el capítulo anterior entre valores de verdad y condiciones de verdad. Desde la concepción fregeana de las oraciones como aplicación de función se entiende que la referencia de una oración es su valor de verdad mientras que las condiciones de verdad remiten al criterio con el que identificar esta referencia para lo que se han utilizado recursos como el sentido fregeano o las intensiones en la semántica formal. Desde la concepción davidsoniana, aunque se verá esto con detalle un poco más adelante, baste por ahora aclarar que las condiciones de verdad son una especie de regla semántica para definir recursivamente el significado como valor de verdad.

${ }^{20}$ La correspondencia se construye bajo lo que se ha llamado con la teoría de Montague la hipótesis regla por regla. Según ésta debe haber una regla semántica por cada regla sintáctica (o categoría sintáctica). De esta forma la composicionalidad que restringe la sintaxis se mantiene en la semántica (Dowty et al., 1981).

${ }^{21}$ Recuérdese que la definición de las intensiones es extensional.
} 
respondan a reglas específicas. Esto hace que tenga una gran riqueza expresiva pero también una acusada ambigüedad. Los hablantes tenemos libertad expresiva para hacer la comunicación efectiva y esto produce que la ambigüedad en el lenguaje natural sea un fenómeno generalizado que se puede encontrar tanto en la estructura sintáctica como en la semántica.

En relación a la sintaxis, tal es la libertad que podemos violar las reglas sintácticas emitiendo palabras aisladas o frases sintácticamente incorrectas, en el sentido en que no se sigue la estructura especificada por las reglas de la gramática. Así mismo, la ambigüedad se da también en el caso de oraciones sintácticamente correctas. Esto ocurre en oraciones que pueden entenderse como formadas por dos estructuras sintácticas diferentes de forma que presentan lo que Valdés (1998) llama una ambigüedad estructural o derivacional. En la oración Ralph believes that someone is a spy (Quine, 1956, p.178) se pueden derivar dos formas lógicas distintas según se tome una lectura de dicto o de re. En la lectura de re Ralph cree que alguien concreto es un espía, mientras en la lectura de dicto simplemente cree que hay espías aunque no sabe quiénes son. Este tipo de ambigüedad afecta de forma simultánea a la sintaxis y a la semántica implicando la noción de forma lógica. En un lenguaje formal ésta se muestra en la sintaxis, sin embargo en los lenguajes naturales el asunto es un poco más complejo. Si el lenguaje natural tiene una forma lógica asociada a la sintaxis y a la semántica, ejemplos como el anterior muestran que la forma lógica en el lenguaje natural es distinta a la sintaxis (superficial) y que el lenguaje es ambiguo en la derivación de la misma.

En cuanto a la semántica, a través del lenguaje expresamos el mundo con una amplia variedad de formas. La ambigüedad léxica, que incluye fenómenos como la polisemia o la homonimia, es un fenómeno que se da con alta frecuencia. Por otra parte, podemos utilizar el lenguaje de una forma más o menos convencional, utilizando recursos figurativos, e, incluso, dentro de nuestra libertad expresiva podemos encontrar paradojas, como el caso de la conocida oración Soy un mentiroso. Además, hay expresiones intrínsecamente vagas, como el caso de los términos que expresan conceptos abstractos. Es usual mencionar como un caso relevante de ambigüedad semántica 
algunos adjetivos gradables como calvo cuya definición implica la paradoja de sorites, i.e., no hay un punto exacto de demarcación de lo que entraría dentro del concepto CALVICIE. Igualmente, una gran parte de los sustantivos y adverbios que derivan de adjetivos arrastran la misma ambigüedad. Es fácil ver como para sustantivos deadjetivales (riqueza) o para adverbios (lentamente) tampoco contamos con un punto preciso de demarcación para la decisión sobre qué entidades caen bajo cada concepto. En el caso de los adverbios que no derivan de adjetivos, estos implican matices temporales, espaciales o modales de una forma indefinida (piénsese en la indefinición del matiz de cantidad del adverbio en la oración Llovió mucho). En el fondo, una gran parte de las expresiones de nuestro lenguaje involucran la vaguedad. No hay un único criterio para decidir cuándo uno es rico, ni para decidir cuándo uno está corriendo lentamente o cuánto es llover mucho. La semántica del lenguaje natural es por naturaleza vaga y las relaciones (semánticas) que se establecen entre los símbolos y los objetos no parecen unívocas.

En base a lo expuesto, el lenguaje natural presenta una ambigüedad estructural que el lenguaje formal no tiene, en este último todas las fórmulas tienen una estructura precisada a través de definiciones recursivas, así como del uso de símbolos como paréntesis que contribuyen a la precisión. Así mismo, la ambigüedad semántica del lenguaje natural contrasta con la precisión matemática proveniente de la Teoría de conjuntos y la noción de función que garantizan una atribución semántica libre de ambigüedad. Para terminar, se podrían añadir otras diferencias, ya no en la línea seguida aquí de la confrontación entre la precisión y la vaguedad, en relación a otros elementos constitutivos de ambos lenguajes. Este es el caso de la ausencia en los lenguajes formales de las partículas del discurso propias de los lenguajes naturales ${ }^{22}$, implicaturas, usos lingüísticos diferentes del enunciativo o la diferencia del tratamiento de las conectivas oracionales en ambos lenguajes ${ }^{23}$.

Ahora bien, deben recordarse en este punto dos tesis importantes que se anunciaron en el primer capítulo: la Tesis de Chomsky -los lenguajes naturales pueden describirse como sistemas

\footnotetext{
${ }^{22}$ Para una reflexión del fenómeno ver Strawson (1981), Bach (1989), Escandell y Leonetti (2000) y Korta (2001).

${ }^{23}$ Un estudio del tratamiento de las conectivas puede encontrarse en Bach (1989), Blakemore (1987) y Neale (1999).
} 
formales- y la Tesis de Montague -los lenguajes naturales pueden ser tratados como lenguajes formales interpretados- (Bach, 1989). Desde esta perspectiva, no hay una diferencia teórica importante entre ambos lenguajes, sino que las diferencias son resolubles desde el uso del aparto formal. De ahí que, siguiendo estas tesis, los únicos hechos relevantes para la teoría semántica hayan sido las condiciones de verdad y las relaciones de implicación (Partee, 2011). A primera vista parece posible un tratamiento del lenguaje natural en términos de lenguajes formales puesto que en ambos lenguajes hay símbolos que representan cosas y la Teoría de modelos ofrece la posibilidad de formalizar la representación semántica. La idea básica entonces es especificar los símbolos y reglas sintácticas y asignar significados a las expresiones en consonancia con las reglas sintácticas. Así, la tarea de la Semántica formal ha estado encaminada a construir sistemas lógicos capaces de representar formalmente las expresiones del lenguaje natural de esta forma. Sin embargo, a pesar de que se ha conseguido dar tratamiento formal a muchos tipos de expresiones, persiste un hueco entre el lenguaje natural y el formal que desde este trabajo se mantiene como irrebasable. La cuestión no es cuántos tipos de expresiones es posible representar formalmente, sino que lo que hace que tal hueco sea irrebasable es que la representación formal en términos de semántica lógica del lenguaje natural no puede dar cuenta de la naturaleza de la semántica natural y esta incapacidad, como se argumenta en lo que sigue, es una imposibilidad por principio.

\subsection{La teoría de la referencia}

Es necesario recordar dos requisitos fundamentales de la Teoría de modelos: el significado está vinculado con la denotación y la atribución semántica se lleva a cabo a través de funciones. La causa de que un modelo sea satisfactorio es que cuenta con un dominio y una función de interpretación especificados. Si uno quiere dar un tratamiento formal de la semántica natural en términos de modelos debe especificar igualmente el 
dominio que está tras la interpretación semántica; es decir, debe especificar la información sobre la que habla el lenguaje natural. Sin embargo, esto es problemático.

\subsubsection{Cuestiones metafísicas y cognitivas}

Cualquier teoría semántica seria del lenguaje natural que se sustente en nociones como referencia o denotación debe encarar el problema de su estatus metafísico y cognitivo. El conjunto de las objeciones que se siguen a continuación llevan a concluir que no es posible contar con una teoría de la referencia para el lenguaje natural.

En primer lugar, hay muchas expresiones que carecen de referencia extensional definida: expresiones que denotan entidades de ficción, como las que hablan de unicornios, hadas o duendes, cuya contraparte extensional es inexistente (Katz, 1981) o dudosa, p.e., The god Apollo en The god Apollo was worshipped in the island of Delos (Seuren, 2009, p. 218); expresiones que denotan entidades imposibles como la conocida oración russelliana El rey de Francia es calvo o The average American has 2.3 children puesto que, al no haber nadie que pueda tener 2.3 hijos, denotaría una entidad con una propiedad imposible (Kennedy y Stanley, 2009, p. 587) ${ }^{24}$; expresiones no reductibles a objetos físicos como la Quinta sinfonía de Beethoven (Horgan, 1986, p.22); términos teóricos como Big Bang y expresiones de magnitudes físicas que se definen en función del marco teórico, a veces de forma incompatible como en el caso de masa y energía ${ }^{25}$, por lo que parece que para considerar la referencia se deben integrar los principios teóricos con los datos observacionales (Fleisner, 2011); por último, las palabras abstractas carecen también de una referencia extensional clara, p.e., language en la oración Chinese is the language of Beijing and Hong Kong, but not Melbourne (Chomsky, 2000, p.130). Quizá podría decirse, siguiendo a Strawson (1952), que todas las expresiones denotativas del lenguaje natural plantean el problema de la referencia vacía con mayor o menor agudeza.

\footnotetext{
${ }^{24}$ La discusión acerca de expresiones como average puede encontrarse en muchos autores. Para una discusión detallada del caso ver Kennedy y Stanley (2009) y Carlson y Pelletier (2002).

${ }^{25}$ En el contexto de la física clásica, masa y energía se definen como dos magnitudes distintas que se conservan de forma independiente; sin embargo, en el contexto de la relatividad restringida se definen como equivalentes de forma que la conservación de ambas se unifica pudiéndose transformarse una en la otra y viceversa (Fleisner, 2011).
} 
En segundo lugar, hay expresiones que no parecen tener una función exclusivamente referencial, sino que hay algo en su significado que va más allá de identificar sus referentes. Este es el caso del tratamiento de cortesía (Usted o vos), las expresiones de argot y los términos estéticos y morales. Como un caso de estos últimos, los términos despectivos pueden servir como ejemplo de la problemática. Expresiones como negrata o panchito tienen un contenido que va más allá de la predicación de una propiedad extensional (la inclusión de un individuo en un grupo). Si dos personas refieren a una tercera con una expresión despectiva (negrata) y otra éticamente más neutral (afroamericano), ambas expresiones identifican el mismo referente e incluso lo identifican como perteneciendo al mismo grupo (el grupo de personas que tienen la propiedad de tener la piel de color negra) pero indican algo distinto. Ese algo distinto puede ser un contenido emocional, moral o social. En este sentido, cuando uno escoge usar negrata en lugar de afroamericano, no parece que la función de dicha expresión sea únicamente referencial. Tratar este tipo de expresiones desde el punto de vista de la semántica extensional implica dejar de lado una dimensión del significado de las mismas.

Para la última objeción debe tenerse en cuenta la forma de entender la referencia en los sistemas formales y en la visión veritativo-condicional del lenguaje natural, lo que se conoce a menudo como lenguajes con estructura tarskiana. En estos se mantiene lo que Higginbotham (2001) llama la visión deflacionaria de la referencia, con nociones incorporadas desde la teoría matemática como la noción de satisfacción. Aunque más adelante se verá en detalle la concepción tarskiana en relación al vínculo entre verdad, referencia y lenguaje que se establece en torno a la noción de satisfacción, algunas ideas básicas son necesarias aquí para entender el argumento.

Para Tarski (1944) la función representacional del lenguaje se expresa extensionalmente a través del concepto semántico de satisfacción. Dada la asunción de que las expresiones lingüísticas significan objetos, satisfacción es la relación que se establece entre las expresiones de un lenguaje y los objetos que refieren. De forma sencilla, puede decirse que las expresiones simples refieren objetos y a partir de ellas, mediante modos de combinación, se establece la forma de satisfacer expresiones compuestas. La combinación es, como en el formalismo estándar, aplicación de 
función, de forma que la relación semántica fundamental es la predicación (función) a través de la que se satisfacen los predicados; es decir, una oración se entiende como la aplicación de una función a un argumento (o más de uno), expresando así el hecho de que el argumento es un elemento en el dominio de la función. Esto se ve fácilmente en la forma en que Tarski expresa esta relación a partir de las equivalencias $T$. El típico ejemplo para explicarlas es uno que él mismo ofreció: <La oración la nieve es blanca es verdadera si, y sólo si, la nieve es blanca>. En esta formulación hay una equivalencia entre una expresión y su correlato en la realidad, de forma que lo que expresa es que hay un objeto, la nieve, que satisface el predicado es blanca; en otros términos, que en el dominio de las cosas de las que habla el lenguaje hay una, la nieve, que pertenece a un subconjunto de ese dominio, el de las cosas blancas. De esta forma, satisfacción se usa para explicar la relación de referencia que en última instancia constituye el significado.

Ahora bien, en la teoría tarskiana, la noción de satisfacción está definida (en un metalenguaje) recursiva y composicionalmente. Para lo que interesa aquí conviene dejar claro que esto implica que los objetos que satisfacen las expresiones están indicados con anterioridad en un lenguaje teórico de forma que el dominio está estructurado en términos de conjuntos matemáticos de la misma forma que se vio en el apartado anterior, conjuntos precisos delimitados y definidos en función de características necesarias y suficientes. Siguiendo un ejemplo propuesto por Pietroski (2008, p. 334):

\section{(1) Pb es verdadero syss dos es primo}

En este caso es posible determinar las condiciones de satisfacción pues los objetos que satisfacen los predicados -los números naturales- pueden definirse con anterioridad de forma que, dadas ciertas convenciones, el número dos puede identificarse con un conjunto y sabemos qué es para un número ser primo.

Sin embargo, en el lenguaje natural no parece que las cosas funcionen de la misma manera. Como se vio en el apartado anterior, fenómenos como la polisemia, la sinonimia, los usos figurativos y la vaguedad en general muestran que los predicados del lenguaje natural no 
constituyen conjuntos precisos de individuos de acuerdo a la noción lógica de propiedad. Un ejemplo dado por Lakoff (1987, p. 74) en relación al concepto MADRE servirá para ilustrar la problemática. Desde la visión clásica podría tomarse como condición necesaria y suficiente para definir el concepto que una madre es una mujer que ha dado a luz a un niño. Si bien, en el uso del término por parte de los hablantes, ésta no parece ser una característica necesaria pues en la vida real hay madres que no dan a luz al no ser mamíferas, hay madrastas, madres "de óvulos", gestación subrogada y adopciones. Estas realidades proveen múltiples características que pueden definir a una madre: hembra que contribuye con material genético para la formación de un ser vivo, mujer que cría a un niño, la mujer del padre de un niño o el ancestro más cercano. La cuestión, como muestra el ejemplo, es que todas estas características o condiciones que debe tener alguien para ser una madre interactúan y se combinan, pero ninguna de ellas puede tomarse como necesaria para distinguir a una madre de otra cosa ni existe ninguna entidad que cumpla todas ellas. Como ya advirtió Wittgenstein (1954), los ahora llamados conceptos cluster son frecuentes por lo que en el lenguaje natural las relaciones referenciales no son unívocas, pueden variar en función del uso y de los criterios usados en la conceptualización.

Determinar la referencia de la mayor parte de las expresiones con independencia de los sujetos es una tarea problemática desde un punto de visto teórico pues obliga a entrar en consideraciones metafísicas y epistemológicas. Es inevitable recordar que ya el empirismo o el constructivismo kantiano, entre otros, advirtieron de cómo los objetos con independencia del sujeto son inaccesibles y de cómo nuestra cognición construye la realidad. Russell (1918) dedicó varias páginas a la aparentemente sencilla tarea de determinar la referencia de esta mesa; en nuestros días, Chomsky (2000, p. 37) ha mostrado que palabras como Londres tomadas en un sentido extensional producen la adscripción de propiedades curiosas a dicha entidad, como que pueda ser destrozada y reconstruida posteriormente en otro lugar y tiempo sin dejar de ser Londres:

We can regard London with or without regard to its population: from one point of view, it is the same city if its people desert it; from another, we can say that London came to have a harsher feel to it through the Thatcher years, a comment on how people act and live. Referring to London, we can be 
talking about a location or area, people who sometimes live there, the air above it (but not too high), buildings, institutions, etc., in various combinations (as in London is so unhappy, ugly, and polluted that it should be destroyed and rebuilt 100 miles away, still being the same city).

Exigir denotaciones extensionales a los términos lingüísticos puede retrotraernos al viejo problema metafísico de la esencia: ¿La referencia de Londres es una localización, un área, su población? El problema del conocimiento de los objetos y de su caracterización es un problema sin resolver de larga tradición filosófica del que uno no puede despojarse sin más asumiendo que hay objetos en el mundo, que los conocemos y que nuestras palabras los refieren como si estuvieran atados por un hilo invisible.

Frente a la visión clásica extensionalista, parece más bien que lo que tomamos como objetos y cómo los referimos depende de factores cognitivos de categorización. Referimos a objetos materiales y concretos pero, como se ha visto, también referimos a entidades de ficción, objetos geográficos, objetos virtuales, entidades sociales o entidades teóricas, entre otros. Al mismo tiempo, el modo en que se da la referencia puede variar en función de los criterios usados para conceptualizar estas realidades. Esto puede verse en los conceptos cluster, así como en los llamados dot-objects (Pustejovsky, 1995) -entidades que subsisten en el dominio de los objetos físicos y en el de la información- como libro o persona. Así, un libro y una persona son objetos físicos pero también son una historia y una identidad personal, respectivamente (Jackendoff, 2011). De forma que hablamos sobre ambos aspectos en función de la situación.

Esto indica que las expresiones del lenguaje natural están cargadas de categorías semánticas relativas a la categorización de las distintas propiedades que las entidades pueden ostentar (p.e. función, composición, origen, formas y colores, o las actividades en las que forman parte, entre otras). A grandes rasgos, puede decirse que categorizamos las entidades según distintos criterios y cuando usamos las palabras para referir a dichas entidades priorizamos alguno de estos criterios en función de las perspectivas y recursos disponibles a nuestra cognición, de forma que la asignación de referencias depende del entramado de información sobre el mundo, los intereses o las 
experiencias individuales. De ahí que uno pueda usar Londres para referirse a su población o, en otras circunstancias, para referir a una extensión de terreno y pueda usar madre para referirse a su madre biológica o a su madre adoptiva. Por ello, el estudio del significado léxico requiere, como se ha venido haciendo desde los años 60, la investigación en la categorización y una teoría de la descomposición léxica más rica de lo que la visión estándar de condiciones necesarias y suficientes sugiere. En este sentido, las expresiones no seleccionan sin más una entidad en el mundo.

En definitiva, no parece haber una noción robusta de referencia como base para la teoría semántica. La referencia en el lenguaje natural no se corresponde con la noción de denotación extrapolada desde los lenguajes formales ni cuenta con una definición canónica. Persistir en la idea de que los términos del lenguaje natural tienen extensiones lleva a enfrentarse a problemas metafísicos, epistémicos y cognitivos. En consecuencia, pueden extraerse algunas conclusiones para la explicación del hueco entre los lenguajes formales y el lenguaje natural: 1) el léxico es más rico, complejo y flexible de lo que la concepción heredada sugiere (Chomsky, 2000; Falkum y Vicente, 2015; Jackendoff, 2002; Lakoff, 1987; Pietroski, 2005) y 2) la forma en que la experiencia se conceptualiza no parece un isomorfismo de la manera en que es verbalmente expresado (Bierwise y Schreuder, 1992).

\subsubsection{Implicaciones para la el tratamiento formal del lenguaje natural}

Dar un tratamiento formal en términos de modelos de la semántica natural exige especificar el dominio que está tras la interpretación semántica. Esto quiere decir que se debe especificar la ontología que subyace al lenguaje natural, el conjunto de los objetos de los que habla el lenguaje, asignando referencias a cada término y definiendo las propiedades que estas tienen. De acuerdo con esto surgen varias cuestiones: ¿cómo se determinan las denotaciones que conforman la ontología?

¿Se puede definir una única ontología extensional o deben definirse múltiples ontologías? En el fondo, de lo que se trata es de definir los modelos para el tratamiento de la semántica del lenguaje natural; cómo son, cuántos son y si son estos una representación adecuada del lenguaje natural. 
En cuanto a la ontología subyacente al lenguaje natural deben distinguirse dos formas de encarar la cuestión de la determinación de las denotaciones. Desde un punto de vista, el lenguaje natural habla sobre el mundo por lo que si se quiere tomar seriamente la semántica natural debe aceptarse que en lo que respecta al lenguaje natural sólo hay una ontología. Sin embargo, como afirma Bach (1989), describir ésta no parece que pueda ser la labor de un lingüista, un lógico o un filósofo, sino más bien la labor de un dios omnisciente. No es posible especificar un único dominio para el lenguaje natural en términos de denotaciones, funciones y conjuntos matemáticos dados los problemas vistos anteriormente. Por ello, la semántica en los enfoques estándar es más bien una “semántica para Dios" (ibid., p. 135). Desde otro punto de vista, lo visto en la sección anterior parece indicar que gran parte de la semántica del lenguaje natural es relativa a perspectivas conceptuales, categorías léxicas y comunidades lingüísticas. Esto indica que tras la semántica natural hay diferentes ontologías, entendidas éstas como diferentes formas de clasificar el mundo (Higginbotham, 1985; Robinson, 2009; Strawson, 1981). En este sentido hay muchos discursos descriptivos que representan el mundo, incluso de una forma incompatible (piénsese en las diferencias descriptivas entre la física newtoniana y la cuántica).

En relación a esto, la Teoría de modelos no dice cómo se determinan las denotaciones que conforman el dominio (Montague dejó esta tarea a la ciencia y a la psicología), sino que más bien dice cómo aplicar una estructura y, una vez dados los elementos, cómo son las relaciones entre ellos. La elección de los objetos que son candidatos a denotaciones es previa e independiente del sistema (Bach, 1989 y 2012; Dowty et al., 1981).

En este sentido, uno puede elegir la ontología que considere: hay quien postula escenas, de modo que uno puede admitir que en el mundo -dominio- hay perros, un perro concreto de nombre Fido y también escenas de perro -manifestaciones limitadas temporal y espacialmente de perros(Carlson, 1977; Barwise y Perry, 1981); se pueden tomar los objetos físicos como entidades simples o como cantidades (estructuradas) de materia de forma que se admita que hay objetos que son materiales y cuyo dominio tiene un subconjunto en el que se encuentran átomos, entendidos 
como cantidades de materia que mantienen relaciones de la parte al todo (Link, 1983); los números pueden ser conjuntos o, en cambio, entidades individuales como en la teoría de Montague (1973); se puede optar por una concepción en la que los elementos del tiempo sean puntos en una línea o intervalos, incluso puede tomarse el tiempo como relaciones entre eventos (Bach y Chao, 2012); se pueden aceptar clases, funciones, mundos, etc. (Bach, 1989, Bach y Chao, 2012; Dowty et al., 1981). Otro ejemplo en el que se deben tomar decisiones sobre la ontología es el caso de las eventualidades, en el sentido genérico del término usado por Bach (1986). En relación a estas, se puede optar, o no, por postular eventos, en el sentido davidsoniano de particulares concretos, de forma que la caída del Muro de Berlín tiene una referencia y ésta es un evento (Davidson, 1967b). La cuestión además se complica si se atiende a las distintas propiedades que puede tener un evento en relación a cómo se desarrolla y distribuye en el tiempo, pues no parece lo mismo ser alto que correr una carrera a pesar de que ambas cosas se consideran eventos. Puede haber diferentes tipos de eventos en función fundamentalmente de propiedades como la dinamicidad -si hay progreso en la acción- o la telicidad -si la situación no se realiza hasta cumplido un límite-, que remiten en última instancia a un criterio sobre la duración del evento, desde los que son máximamente duraderos (p.e., Antonio es alto) hasta los que apenas duran instantes (p.e., el policía atrapó al ladrón). Esta reflexión acerca del aspecto léxico de las eventualidades ha dado lugar en la literatura relevante a distinguir diferentes tipos de eventualidades: estados -no dinámicos y atélicos-, procesos -dinámicos y atélicos- y eventos -dinámicos y télicos- (Dowty, 1979; Vendler, 1957) ${ }^{26}$.

Con independencia de los detalles técnicos, puede verse que en la semántica formal lo que hay son distintos modelos en los que se han llevado a cabo ciertas decisiones previas sobre las cosas de las que habla el lenguaje natural. Cada una de estas decisiones implica una forma distinta de dar estructura al dominio estableciendo, en términos de conjuntos, las entidades que hay, sus

\footnotetext{
${ }^{26}$ En lo que respecta a los eventos, existe también una subclasificación entre realizaciones y logros desde la clasificación de Vendler (1957). Ambos son eventualidades dinámicas y télicas. Sin embargo, se entiende que las realizaciones (Alicia camina un kilómetro) tienen cierta duración temporal, lo que lleva a distinguir en ellas algunas fases de progreso, mientras los logros (p.e., Tomás alcanzó la cima) se identifican con cambios momentáneos de estado sin duración temporal. Para una caracterización más exhaustiva y una visión de las distintas teorías de las eventualidades ver Bach (1989), Maienborn (2011) y Filip (2011).
} 
propiedades y las relaciones entre ellas. De esta forma, los distintos modelos representan diferentes ontologías para el lenguaje natural.

Para la cuestión sobre cuáles de estos modelos son los adecuados para la caracterización del lenguaje natural no hay una respuesta disponible. Es problemático establecer criterios de identidad y demarcación para todas estas entidades desde el punto de vista metafísico, por lo que las distintas decisiones que se toman en lo que concierne a la estructura del dominio no parecen corresponderse con distinciones metafísicas sino más bien responden a un interés teórico, representar formalmente las distintas expresiones del lenguaje natural (como los verbos, los plurales genéricos o los términos masa, entre otras). Para entender esto servirán algunas observaciones sobre las eventualidades.

En relación a estas, es problemático establecer un criterio de demarcación entre las distintas categorías que se establecen. Siguiendo a Filip (2011), es posible entender algunos verbos como expresiones de eventualidades de distintas categorías. Desde un punto de vista conocer es un verbo de estado que expresa una eventualidad no dinámica, la eventualidad no transcurre sino que simplemente se da (p.e., Antonio conoce a María); mientras que, desde otro punto de vista, puede entenderse que conocer es un verbo que representa un proceso, una eventualidad dinámica con cierto progreso temporal (Antonio está conociendo a María). De la misma forma, verbos que se clasifican típicamente como eventualidades atélicas pueden expresar eventualidades télicas. Así, entender se concibe como un verbo de estado, pero en And then suddenly I knew! expresa una eventualidad télica (ibid., p. 1191). En general, las distinciones que se establecen, como se indicó anteriormente, remiten en última instancia a un criterio acerca de la duración de las eventualidades, sin embargo, como pone en evidencia Maienborn (2011), metafísicamente hablando todos los eventos requieren un tiempo para tener lugar, por lo que todos son durativos en algún grado y la distinción metafísica en estos términos es controvertida. 
Puede decirse entonces que las distinciones que se establecen no corresponden estrictamente con distinciones metafísicas, establecer esta correspondencia implicaría una compleja investigación metafísica y epistémica previa, sino que se establecen en términos de lo que expresamos lingüísticamente:

Consider 'the setting of the sun.' We can count sunsets, and there is a sense, I suppose, in which this is an existential change. But of course the sun doesn't really go out of existence; it simply goes out of an observer's range of perception in a certain kind of way. Should this be considered an event or a process? Perhaps it would be appropriate to say that, strictly speaking, it is a process; it's just convenient for us to speak as though it were an event. (Gill, 1993, p. 379).

De esta forma la clasificación en estos términos resulta en una simplificación metalingüística de su carácter metafísico en base a la necesidad teórica de establecer límites en las categorías para representar formalmente las expresiones. A pesar de que es indudable que los recursos formales tienen utilidad técnica y teórica para la representación formal de las expresiones e incluso que la reflexión metafísica que les subyace es muy interesante, lo es también que estas decisiones implican cierta arbitrariedad y un compromiso ontológico fuerte que está lejos de estar suficientemente justificado más allá del interés y muy lejos del uso ordinario del lenguaje por parte de los hablantes. Por ello, no hay una forma de decidir cuál de estos modelos es más adecuado para el tratamiento del lenguaje natural, lo que nos deja con una colección de modelos.

A este respecto la siguiente pregunta que ha de hacerse es si el tratamiento formal del lenguaje natural en términos de un conjunto de modelos es una representación adecuada del mismo. En este sentido, una concepción del lenguaje natural como un conjunto de modelos más pequeños implica que los valores semánticos y la noción de verdad son relativos a dichos modelos, pero esto no corresponde del todo con las intuiciones de los hablantes sobre los significados. En el lenguaje natural parece que hay valores absolutos. Así, los hablantes predicamos la verdad en un sentido absoluto de forma que tomamos Leticia Santos es la autora de esta tesis o $1+1=2$ como teniendo 
un valor absoluto (Schiffer, 2005, p. 71). Un tratamiento adecuado de la semántica del lenguaje natural parece requerir una ontología unificada.

Sin embargo, las diferentes ontologías no pueden unificarse en un cuadro consistente. El intento de unificación amenaza dos condiciones relativas a los sistemas lógicos, la consistencia y la formalidad. Por un lado, la vaguedad junto al hecho de que el lenguaje natural tiene la máxima capacidad expresiva permiten la inconsistencia generando paradojas (Barba, 2007; Robinson, 2009; Tarski, 1944) ${ }^{27}$. Por otro lado, el lenguaje natural cuenta con implicaciones léxicas. Así, implicaciones como (Glanzberg, 2015, p. 77):

(2) John is Bill's mother's brother's son, therefore, John is Bill's cousin.

No dependen de una relación formal sino del significado (en el ejemplo, del significado de cousin). Estas implicaciones léxicas deben tratarse desde una semántica del lenguaje natural, no hacerlo y restringirse a las implicaciones lógicas da como resultado una teoría superflua para el lenguaje natural pues explicar el mismo requiere explicar cómo somos capaces de entender fenómenos como éste (Schiffer, 2015). Así, el requisito de formalidad se ve amenazado dado que las implicaciones léxicas no pueden sistematizarse formalmente (a menos que, como dice Glanzberg (2015), tomemos cada palabra como constante lógica, lo que haría a la restricción de formalidad trivial). A su vez esto conlleva que en un modelo formal para el lenguaje natural no puedan deducirse todas las consecuencias dadas ciertas premisas y, por tanto, afecta en último término a la noción de consecuencia lógica ${ }^{28}$. En definitiva, como algunos han mostrado (Barba, 2007; Robinson, 2009), no puede haber un modelo universal para el lenguaje natural.

\footnotetext{
${ }^{27}$ Existen sistemas lógicos para el tratamiento de la vaguedad, las llamadas lógicas alternativas a la clásica. Sin embargo, hay evidencia de los problemas al abandonar la lógica clásica bivalente. Hampton (2006) ha mostrado que el mismo efecto de vaguedad se da en lógicas polivalentes al producir vaguedad de alto orden. Williamson (1992) mostró que negar la bivalencia lleva a contradicción. Como Robinson (2009) dice, la vaguedad del lenguaje natural no amenaza a la lógica ni representa la necesidad de una lógica desviada, sino que indica dónde están los límites de su aplicación.

${ }^{28}$ Es posible argumentar que el uso de los sistemas lógicos para el estudio del lenguaje natural no tiene por qué coincidir con el estudio de la inferencia para el que es clave la noción de consecuencia lógica. Sin embargo, aunque esto fuera así no anula el argumento presente. El no cumplimiento del requisito de la formalidad expresa de por sí el hueco existente entre ambos tipos de lenguajes.
} 
Siguiendo a Glanzberg (2015), puede decirse que las distintas ontologías subyacentes al lenguaje natural pueden armonizarse intuitivamente pero no formalmente, puesto que los movimientos de unas a otras están basados en consideraciones semánticas que no son asunto de la validez formal. Sin embargo, los hablantes pasamos continuamente de unas a otras y establecemos relaciones entre ellas de una forma intuitiva. En este sentido, una semántica del lenguaje natural debe explicar la habilidad de los hablantes para llevar a cabo estas tareas puesto que son esenciales a la comprensión y al uso del lenguaje por parte de los hablantes reales. El lenguaje natural consiste en gran medida en esas relaciones entre ontologías que parece que sólo pueden explicarse analizando el léxico y el sistema conceptual de los hablantes.

En definitiva esto significa que o bien tenemos un sistema formal que no cumple los requisitos de la lógica en cuyo caso pierde su fuerza explicativa, o bien que, como ya afirmó Traski (1944), la lógica no puede explicar el significado del lenguaje natural. La regimentación del lenguaje natural en un sistema lógico no implica que el lenguaje natural tenga propiedades lógicas, lo que implica es que el lenguaje natural deja de ser natural. La formalización no es lo que garantiza el proceder científico pues la lógica sólo es un conjunto de procedimientos para el estudio de la inferencia, no tiene una seguridad epistémica especial ni tiene que ver con cómo es el mundo real (Haack, 1978; Seuren, 2009). Los sistemas lógicos sólo pueden explicar las relaciones entre conceptos construidos a través de definiciones estipulativas y, dado que el lenguaje natural no tiene este carácter, usar el lenguaje formal o recursos derivados del mismo en su descripción resulta inadecuado. La Semántica formal parece que intenta describir la ontología a partir de lo que puede construir con las herramientas lógicas disponibles. El formalista de la semántica natural es "un metafísico reformador" (Strawson, 1981, p. 608) pues la construcción de sistemas lógicos para el lenguaje natural no nos ayuda a comprender cómo hablamos sino que se conciben otras situaciones, distintas de las reales, imaginando como podríamos (o deberíamos) hablar y simplificando con ello la cuestión del significado. Esto definitivamente no es lo mismo que tener un modelo para el lenguaje natural pues para tenerlo es necesaria una teoría de la referencia que nos diga cuáles son los 
referentes de las expresiones y cómo es la conexión entre estos. Lo contrario no es más que un modo de hablar formal superficial. El hueco entre el lenguaje natural y el lenguaje formal se muestra insalvable sin una metafísica del lenguaje natural.

\subsection{La forma lógica en el lenguaje natural}

La explicación veritativo-condicional requiere que haya una correspondencia transparente entre las estructuras sintáctica y semántica para que pueda darse la conexión entre el significado, la denotación y la verdad. Desde esta perspectiva, se asume que esta correspondencia se muestra en la forma lógica los enunciados. Sin embargo, como se muestra a continuación, no es posible trasladar esta noción al lenguaje natural.

En los lenguajes formales la forma lógica remite a la sintaxis de las fórmulas. Consiste en una estructura sintáctica especificada a través de definiciones recursivas que garantiza, por su carácter reglado, la preservación de la verdad independientemente de cuál sea la interpretación semántica. Ahora bien, dado que los lenguajes formales son interpretados según modelos y la interpretación semántica está en correspondencia con la sintaxis, la forma lógica es la estructura relevante para la representación semántica de contenidos (Creswell, 2006; Ludwing, 2012). En otras palabras, la forma lógica de una expresión representa objetos, sus propiedades y las relaciones entre ellos, de manera que describe el modelo que hace verdadera a una fórmula que contenga dicha expresión. Puesto que en los lenguajes formales la sintaxis y el modelo están dados de antemano, lo importante es determinar si dada una fórmula cualquiera ésta es verdadera (si representa el modelo) y esta información está contenida en la forma lógica. La forma lógica explica el comportamiento lógico de las expresiones, i.e., una explicación de su comportamiento en relación con la verdad. Está por tanto vinculada a la característica esencial de la lógica: el interés por la verdad y la inferencia válida deductivamente. 
El primer problema cuando se traslada esta noción al lenguaje natural lo constituye la ambigüedad inherente a él. Como se vio anteriormente, el lenguaje natural a menudo es ambiguo estructuralmente. Esta razón lleva a suponer, desde la tradición analítica hasta nuestros días, que en el lenguaje natural debe existir una estructura, distinta a la sintaxis superficial, que refleje la representación semántica y explique el comportamiento lógico de las oraciones ${ }^{29}$. Desde esta perspectiva, ha sido común tratar la forma lógica como una propiedad intrínseca de las oraciones que puede representarse mediante alguna paráfrasis formal (comúnmente en un lenguaje de primer orden). Como propiedad intrínseca implica que cada oración tiene su propia forma lógica y es generalmente aceptado que ésta es el resultado composicional de la sintaxis, el léxico y la desambiguación ${ }^{30}$. Esto significa que debe ser estable, independiente del uso y de otras oraciones. En la adscripción de la forma lógica no intervienen los procesos para la determinación del contenido veritativo-condicional puesto que para ello, en términos generales, es necesario determinar las referencias en contexto.

Sin embargo, como muestra Iacona (2013), esta concepción es problemática puesto que el rol explicativo de la noción en términos de intrinsecalidad entra en conflicto con la sensibilidad al contexto del lenguaje natural. Si la oración tiene una forma lógica intrínseca, entonces declarar (3) en dos contextos diferentes implica que podría haber argumentos en los que, estando involucradas dos proferencias de la misma oración que señalen dos referencias distintas para this, la verdad no se preserve (p. 441):

\section{(3) This is a philosopher}

\footnotetext{
${ }^{29}$ Esto ha llevado, desde finales de la década de los 60, a lo que se conoce como la guerra de las estructuras (Partee, 2015) en la interrelación entre las estructuras sintáctica y semántica. El debate ha estado centrado en cómo de cerca se encuentra la forma lógica al nivel sintáctico de superficie, así como de qué constituyentes están inarticulados en esta última. Para una discusión detallada de la caracterización histórica de la forma lógica y la guerra de las estructuras ver Cresswell (2006), Katz (1977), Ludwig (2012), Newmeyer (1980), Partee (2015) y Schiffer (2015).

${ }^{30}$ En general se toma el proceso de desambiguación como el proceso que da como resultado la asignación de una lectura a las oraciones. En algunas versiones (Borg, 2007; Stanley, 2000), se incluye la desambiguación formal de indéxicos. No obstante, para el argumento actual no es relevante si la desambiguación incluye o no la desambiguación formal de indéxicos.
} 
Esto no podría resolverse introduciendo en la representación formal dos constantes diferentes para ambas proferencias. Ningún análisis de la forma lógica en términos de propiedad intrínseca justificaría esta decisión puesto que para tener constantes diferentes es necesario conocer el contenido referencial en contexto, pero esta información va más allá de la forma lógica definida en dichos términos. Siendo así, la noción de forma lógica no puede cumplir el rol para el que fue postulada, explicar el comportamiento lógico de las oraciones.

Ahora bien, si forma lógica no es intrínseca entonces, siguiendo a Iacona, nos encontramos frente a dos problemas. En primer lugar, parece que la noción de forma lógica no es transparente. Por un lado, la forma lógica no es detectable gramaticalmente en la forma real de las oraciones. Por otro lado, como se acaba de ver, para conocer la forma lógica parece necesario incorporar información empírica acerca de los referentes. Sin embargo, puede que no conozcamos esa información. Esto hace que sea posible usar oraciones correctamente aún sin conocer la forma lógica de las mismas. De manera que la forma lógica no es detectable y es posible usar oraciones sin conocer su forma lógica. En segundo lugar, no parece haber una única forma lógica para las oraciones. Por un lado, si para determinar la forma lógica se necesita no sólo el proceso de desambiguación sino también la determinación del contenido o, en otras palabras, se necesita una interpretación que fije las referencias para evitar los problemas derivados de una noción puramente sintáctica, entonces la oración tiene una forma lógica relativa sólo a una interpretación. En este sentido, es controvertido que las distintas formas lógicas sean equivalentes. En el ejemplo siguiente pueden derivarse dos formas lógicas diferentes (Iacona, ibid., p. 445):

\section{(4) José is older than Max}

Es posible interpretar older than Max como una propiedad de manera que la forma lógica se representaría como $F a$-siendo $F$ la propiedad older than Max y $a$ el individuo José. Desde otra perspectiva, puede interpretarse la oración como involucrando una relación entre dos objetos de manera que la forma lógica correspondiente sería $R a b$-siendo $R$ la relación older than y $a$ y $b$ los 
individuos José y Max. La segunda forma lógica es una representación fina en el sentido en que hace explícito el carácter relacional de la propiedad adscrita a José, dotando de mayor estructura al contenido. Es por razones como ésta que no podemos asumir que existe la sinonimia entre las formas, ni entre las distintas formas lógicas, como en el ejemplo anterior, ni entre una forma lógica y la oración que representa:

Cuando parafraseamos una sentencia para resolver una ambigüedad lo que estamos buscando no es una sentencia sinónima, sino una sentencia que sea más informativa porque se resista a alguna otra interpretación antes posible. Lo normal es, realmente, que la paráfrasis de una sentencia $S$ del lenguaje ordinario mediante símbolos lógicos dé como resultado divergencias radicales. A menudo el resultado $S^{\prime}$ será menos ambiguo que $S$; muchas veces tendrá valores veritativos en circunstancias en las cuales $S$ carece de ellos (cfr. secs. 37 y ss.), y otras muchas veces suministrará referencias explícitas en casos en los que $S$ utiliza palabras indicadoras (cfr. sec. 47). Con bastante naturalidad puede en cambio afirmarse que $S$ ' será sinónima de una sentencia $S$ ” de lenguaje semiordinario que es el resultado del desarrollo mecánico de $S^{\prime}$ de acuerdo con las explicaciones generales de los símbolos lógicos; pero no puede pensarse que sean sinónimas $S^{\prime}$ y $S$. La relación de $S^{\prime}$ con $S$ se limita al hecho de que el asunto concreto que el hablante intentaba satisfacer con la ayuda de $S$ entre otras cosas puede también resolverse adecuadamente con $S^{\prime}$ en vez de $S$. (Quine, 1960, p. 169)

Las distintas maneras de concebir cómo tiene que ser la forma lógica son producto del interés con el que se construya el sistema (Branquinho, 2001; Iacona, 2013). En palabras sencillas, si el interés del sistema es el estudio de la inferencia podemos contentarnos con un sistema que proporcione la forma lógica $F a$ para (4) puesto que no se necesita el significado de las oraciones sino su diseño sintáctico; si nuestro interés es semántico quizá es más conveniente elegir un sistema que opte por Rab como su forma lógica dado que constituye una forma con mayor riqueza expresiva ${ }^{31}$ o si nuestro interés es gramatical deberíamos escoger una forma lógica que capture las categorías gramaticales al estilo chomskiano. Como muchos

\footnotetext{
${ }^{31}$ En este sentido, puede haber muchas formas lógicas para las oraciones del lenguaje natural en función del poder expresivo del sistema que adoptemos para su representación formal. En algunas estará incluida una referencia temporal, operadores modales, operadores epistémicos, cuantificación sobre eventos, etc.
} 
autores han señalado (Davidson, 1973; Evans, 1976; Iacona, 2013; Ludwing, 2012; Martí, 1998; Quine, 1960; Szabó, 2012), la elección de la forma lógica adecuada es una elección arbitraria que depende de qué decisiones se tomen en la construcción del sistema formal usado para representarla y, como dice Evans (1976), es una perversidad que atribuyamos a los hablantes ordinarios los compromisos que pertenecen sólo al teórico.

Forma lógica es una noción relativa al punto de vista matemático de los lenguajes lógicos y a la interpretación en el sistema de regimentación preferido, está unida a las características esenciales de la lógica y sólo dentro de ésta tiene sentido. Postular la existencia de una forma lógica para el lenguaje natural como una noción teórica desvinculada del uso real del lenguaje por parte de los hablantes no tiene una justificación clara y lleva a la búsqueda arbitraria de múltiples estructuras lingüísticas no sujetas a comprobación empírica ni provistas de un criterio único de individuación, modificando el modo de hablar normal según criterios lógico-matemáticos. En este sentido, la existencia de una forma lógica en el lenguaje natural es una hipótesis teórica fundamentada exclusivamente en la analogía de que los lenguajes naturales se comportan como lenguajes formales interpretados. Sin embargo, la única muestra objetiva y accesible de las propiedades de la práctica lingüística real son las oraciones y sus proferencias, que constituyen el comportamiento lingüístico público de los hablantes. En este sentido, la práctica lingüística real no ofrece formas lógicas puras que permitan estudiar las propiedades lógicas (ni semánticas) del lenguaje natural, así la identificación de una forma lógica genuina en el lenguaje natural a través de las oraciones reales simplemente no es posible ${ }^{32}$.

\footnotetext{
${ }^{32}$ El Pragmatismo hace hincapié en la necesidad de postular una forma lógica más rica en base a la existencia de constituyentes inarticulados en la forma gramatical de las oraciones. Más adelante se verá esto en detalle, baste por ahora aclarar que, dado que los constituyentes inarticulados no están sujetos a evidencia sintáctica, el Pragmatismo se encuentra frente a los mismos problemas enumerados en esta sección para la justificación de la noción.
} 


\subsection{La verdad en la semántica natural}

Lo que se intentará mostrar aquí es que no es posible una teoría semántica veritativocondicional porque no hay conexión entre la verdad y el lenguaje en los lenguajes naturales. La línea general de la argumentación es como sigue: una teoría semántica debe definir las nociones que explican el significado; la semántica veritativo-condicional utiliza la verdad como noción semántica, por lo que se necesita una teoría de la verdad; no hay una teoría de la verdad que sustente la noción semántica de verdad para el lenguaje natural. Por tanto, una teoría semántica veritativo-condicional es inadecuada explicar el significado del lenguaje natural. Asimilar el significado con la determinación de las condiciones de verdad conduce a dos alternativas: convertir la noción de verdad en un concepto técnico desvinculado del uso ordinario por parte de los hablantes o utilizar un concepto de verdad sustantivo desvinculado del lenguaje.

\subsubsection{La noción semántica de verdad}

El primer paso entonces es mostrar que una teoría semántica veritativo-condicional necesita contar con una teoría previa de la verdad. Este es un paso obvio dado que no es deseable una teoría semántica cuya noción explicativa principal sea una noción oscura y no definida, pues sería en estos términos una explicación deficitaria e insuficiente. Se necesita una aclaración teórica de la noción de verdad. La cuestión de la definición de la verdad constituye históricamente uno de los grandes problemas de la filosofía. No es la intención del presente trabajo elaborar una definición exhaustiva del concepto sino la de mostrar los presupuestos de fondo de la teoría semántica del lenguaje natural.

Los hablantes ordinarios manejan una noción intuitiva de verdad según la cual algo es verdadero si se corresponde con la realidad. En este sentido, la verdad tiene implicaciones metafísicas y epistémicas para los hablantes. Predicar la verdad de Mañana lloverá conlleva que 
los hablantes asuman que mañana se dará un hecho (la lluvia), lo que modificará sus conductas. En este sentido, los hablantes ordinarios entienden de forma intuitiva la verdad como una noción sustantiva en su sentido como correspondencia que les guía en las acciones cotidianas. De aquí se siguen apuntes relevantes para el estudio de la semántica. Por un lado, si se quiere contar con una teoría semántica sensata, adecuada a la práctica real del lenguaje, que haga uso de la noción de verdad, debe descartarse cualquier noción técnica de la misma. Postular un concepto técnico que no tenga las implicaciones que la verdad tiene en la vida de los hablantes no es deseable para una teoría semántica del lenguaje natural. Esto equivaldría a no tener teoría de la verdad alguna. Por otro lado, para incluir un concepto sustantivo en la teoría semántica no cabe dejar de lado los hechos relativos al uso normal del lenguaje puesto que hacerlo implicaría tener una teoría semántica de algún lenguaje (uno ideal) pero no una semántica del lenguaje natural. En este sentido, si se atiende a criterios empíricos del modo de usar el lenguaje y la verdad no cabe aceptar otra noción de verdad que la verdad como correspondencia.

En relación con lo anterior, la historia de la semántica ha sido la historia de la discusión en torno a la correspondencia. No es posible explicar aquí tal historia por lo que se pondrá la atención en los desarrollos teóricos vinculados con la semántica veritativo-condicional desde la perspectiva mantenida en el trabajo. En lo que sigue se argumenta que la teoría semántica veritativo-condicional se sustenta en la noción de verdad como correspondencia, incluso en aquellas teorías que han mantenido un rechazo a la misma. Para ello será necesario hacer un breve repaso de las concepciones relevantes que han dado lugar a las teorías semánticas veritativo-condicionales actuales.

De las concepciones relevantes hay especialmente dos que mantienen de una forma más o menos explícita el sentido de la verdad como correspondencia entre los objetos y las expresiones lingüísticas, la Semántica formal y la concepción tarskiana. La primera mantiene que la verdad, desde el punto de vista semántico, consiste en la correspondencia entre los símbolos y el dominio a través de la función de interpretación del modelo, como se vio anteriormente. Por tanto, la verdad 
en este sentido semántico consiste en la relación de correspondencia entre objetos y sus expresiones lingüísticas. Por su parte, Tarski (1944) asume que la correspondencia se establece entre las expresiones del lenguaje y los objetos del mundo y ofrece una forma de expresar esta correspondencia a partir de las equivalencias $T$, cuyo ejemplo típico es $<\mathrm{La}$ oración la nieve es blanca es verdadera si, y sólo si, la nieve es blanca>. En esta formulación hay una equivalencia entre una expresión y su correlato en la realidad. Sin embargo, esto por sí sólo no constituye una definición de la verdad extensional pues para obtenerla se necesita especificar todas las equivalencias -expresiones parciales de la verdad- correspondientes al esquema $<x$ es verdadero syss $p>$. Ahora bien, debe decirse que la definición no es una definición de la verdad per se (para todo lenguaje) sino una definición relativa a un lenguaje objeto regimentado, como él mismo señala. Esta relativización se debe a los dos criterios que Tarski impone para la definición, uno material y otro formal.

El criterio de adecuación material exige que todas las expresiones tengan su correlato y que esta relación esté estipulada pues sólo de esta forma puede garantizarse que todas las equivalencias se sigan de la definición y, por tanto, que sea posible una definición materialmente adecuada. Por otra parte, Tarski da una advertencia importante: si queremos garantizar la corrección formal de la definición y evitar las antinomias surgidas de la autorreferencialidad, la definición ha de darse en un lenguaje especificado y regimentado (como el de la lógica clásica de primer orden). Así, para una definición correcta formalmente se necesita de un metalenguaje en el que estén definidos recursivamente los términos semánticos. De esta forma, las equivalencias son equivalencias para un lenguaje, de lo que resulta el llamado esquema de la convención $T:\langle x$ es verdadero en $L$ syss $p>$ donde $x$ es el nombre de un enunciado en el metalenguaje, $L$ está por el lenguaje objeto al que se relativiza la definición y $p$ es la traducción en el metalenguaje de la expresión del lenguaje objeto. Siendo así, lo que tenemos entonces es que la correspondencia, estrictamente hablando, es una relación de correspondencia entre dos enunciados, cada uno de un nivel distinto de lenguaje. 
A pesar de la aceptación de la verdad como correspondencia en la Semántica formal y la teoría tarskiana, como se anunció al comienzo, no todas las teorías la han aceptado. Al contrario, dos teorías, estrechamente conectadas con las anteriores, se han opuesto frontalmente a la noción: la semántica fregeana y la davidsoniana. Sin embargo, un análisis más cercano puede revelar que, a pesar de su rechazo, en ambas se mantiene de forma implícita la noción de verdad como correspondencia.

En El pensamiento. Una investigación lógica (1918) Frege rechaza la noción de verdad como correspondencia en base a un doble fundamento, ontológico y lógico. Desde el punto de vista ontológico, Frege presupone que la verdad es algo objetivo que se predica de los pensamientos, tomados estos como hechos. Desde este presupuesto, tras examinar los posibles términos de la correspondencia (entre pensamientos y hechos o entre pensamientos y sus representaciones), descarta la noción de verdad como correspondencia. No cabe correspondencia con los hechos del mundo dado que los pensamientos son en sí mismos hechos. De la misma forma no cabe correspondencia con las representaciones puesto que, para que hubiera correspondencia, los pensamientos y las representaciones deberían coincidir, sin embargo son diferentes. La verdad es algo objetivo, como lo puede atestiguar el hecho de que los hablantes concordemos en nuestros juicios de verdad, pero, si los pensamientos fueran representaciones, la verdad sería algo subjetivo e interno a la conciencia de cada sujeto que tenga dichas representaciones ${ }^{33}$. Desde el punto de vista lógico, el problema se encuentra en la propia definición de la verdad como correspondencia. Si hubiera correspondencia entre los pensamientos y las representaciones (ya no porque coincidan plenamente sino incluso sólo parcialmente) entonces no habría diferencia entre ellos y esto llevaría a un regreso al infinito. Si no hay diferencia entre el objeto y la representación, entonces preguntar por la verdad de un objeto es preguntar por la verdad de su representación; de forma inversa, preguntar por la verdad de la representación de un objeto es preguntar por la verdad del objeto. De

\footnotetext{
${ }^{33}$ Para Frege la representación que nos hacemos de los objetos a que refieren las expresiones es subjetiva constituyéndose como una imagen "a menudo impregnada de sentimientos" (1892, p. 30).
} 
manera que, según Frege, la noción de verdad es indefinible en su versión como correspondencia. Sin embargo, no parece que Frege pueda escapar de la correspondencia cuando se sitúa en la teoría semántica. Es en ésta donde puede encontrarse ese término de la correspondencia que anteriormente había cuestionado. Las oraciones son expresiones de pensamientos y, en este sentido, las oraciones son verdaderas cuando expresan pensamientos verdaderos. Debe recordarse que para Frege el significado de una oración comprende el sentido, su condición de verdad, y como referencia un valor de verdad, el valor de verdad que tiene el pensamiento que expresa. En la semántica fregeana la verdad parece tener el sentido de correspondencia entre los pensamientos y sus expresiones.

Por su parte Davidson, en su intento de no comprometerse ontológicamente, rechaza la teoría de la verdad como correspondencia sobre la base de su crítica a la referencia como elemento semántico. Sin embargo, tampoco parece poder escapar de ella. Davidson (1974) reconoce que no tenemos un único concepto de verdad pero, cualesquiera que sean estos conceptos, todos ellos parecen, a la vista de la teoría davidsoniana, compartir una misma característica: la verdad del lenguaje depende de la realidad. Para entender el argumento conviene recordar que, dado que Davidson pretende construir una teoría semántica empírica a través de hechos relativos a la conducta lingüística de los hablantes, necesita dotar a la verdad, como ya hizo Tarski, no sólo de un criterio formal sino también de un criterio material. Así, el criterio material tiene una doble función: garantiza la corrección adecuada de la definición, según sus intereses en el estudio de la comunicación humana, y aleja la teoría de la verdad de la crítica deflacionista quineana. Para evitar la objeción de que la verdad es, desde el punto de vista tarskiano, un simple proceso de desentrecomillado por el que se traducen enunciados de un lenguaje objeto a un metalenguaje (Quine, 1977), Davidson defiende que los enunciados tienen contenido empírico verificable por la experiencia a través del asentimiento de los hablantes (Davidson, 1974 y 1977a). En la visión davidsoniana, determinadas causas reales, externas al lenguaje, producen una creencia en la mente del hablante, una creencia acerca de cómo es el mundo. Ahora bien, bajo mismas circunstancias 
puede producirse la misma creencia en distintos hablantes y esto es verificable, según Davidson, a través del asentimiento. El asentimiento constituye un acuerdo intersubjetivo sobre la verdad de las creencias e implica que hablante y oyente comparten la misma visión del mundo ${ }^{34}$. Es este hecho, para Davidson (1977a), el que dota de contenido empírico al lenguaje puesto que esa visión del mundo compartida está expresada en el lenguaje. Sin embargo, esto significa en definitiva que las oraciones son representaciones lingüísticas de creencias sobre el mundo y en la medida en que son compartidas, hecho verificable a través del asentimiento, demuestra que hay una realidad en correspondencia.

En conclusión, a pesar de que en la literatura sobre semántica es frecuente hablar de la verdad como siendo un atributo de las oraciones (o proposiciones), esta caracterización es engañosa. El uso ordinario que hacen los hablantes de la noción tiene el sentido de correspondencia. Además, una mirada atenta a las concepciones relevantes que están en la base de las teorías semánticas veritativo-condicionales muestra que la verdad con fines semánticos debe considerarse en este sentido. Si una teoría veritativo-condicional necesita de una teoría de la verdad como correspondencia, se vuelve necesario examinar la posibilidad de dar tal teoría para el lenguaje natural.

\subsubsection{Problemas de la noción semántica de verdad para el lenguaje natural}

Examinar si es posible una teoría de la verdad como correspondencia para la semántica natural exige en primer lugar resolver una cuestión que queda abierta tras el análisis anterior: si la verdad es una relación de correspondencia ¿cuáles son los términos involucrados en la relación? Para esta cuestión pueden encontrarse tres alternativas de forma que la correspondencia se da 1) entre

\footnotetext{
${ }^{34}$ El externismo de Davidson y su pretensión de construir una teoría empírica del significado y la comunicación lingüística le hace sustituir la teoría de la correspondencia por una suerte de teoría probabilística según la cual, tras una evidencia continuada, lo que hace que se relacionen expresiones con objetos no es en sí que las primeras se correspondan con los segundos, sino el hecho de que sistemáticamente se observe que las expresiones aparecen, bajo mismas circunstancias, correlacionadas con los objetos (Corredor, 1999).
} 
pensamientos y sus expresiones lingüísticas, 2) entre los objetos y las expresiones lingüísticas y 3) entre expresiones de un lenguaje (el lenguaje objeto) y expresiones de otro lenguaje (metalenguaje). De estas tres alternativas debe rechazarse la última pues la definición tarskiana no captura la idea de que la verdad consista en una robusta correspondencia con la realidad (Field, 1972) ni es compatible con nuestro uso ordinario del predicado de verdad (Kripke, 1975) y, por tanto, como dice Strawson (1969) reducir la verdad a verdad-en- $L$ es rechazar enfrentarse a la cuestión de la verdad. De esta forma, para el estudio semántico del lenguaje natural se debe elegir la relación de correspondencia como una correspondencia entre las expresiones lingüísticas y pensamientos u objetos. Las teorías veritativo-condicionales han tendido a eliminar las ideas en la explicación del significado debido a su interés cientificista, lo que ha llevado a una explicación extensional para correlacionar lenguaje y realidad.

Como se vio en el capítulo primero, Davidson se sirve de la definición semántica de la verdad tarskiana para construir una teoría recursiva del significado del lenguaje natural. Lo que determina el significado de una oración son las condiciones de verdad (intersubjetiva) de dicha oración que pueden ser formalizables siguiendo el modelo extensional tarskiano de las equivalencias $T$. El problema fundamental tiene que ver con la indefinición de la noción semántica de verdad. Debe recordarse en este punto que para la corrección de la definición han de cumplirse los criterios de corrección formal y material. Sin embargo, si uno quiere extender la definición tarskiana al lenguaje natural se enfrenta a problemas irresolubles en relación tanto al criterio de corrección formal como al criterio de adecuación material.

Para que la definición sea formalmente correcta se necesita un metalenguaje especificado en el que definir los términos semánticos pues de lo contrario topamos con paradojas. Tal definición sólo es posible si se distinguen con precisión sucesivos niveles de lenguajes objeto y metalenguajes en los que los últimos deben ser más ricos en expresividad que los primeros (al menos deben incluir al lenguaje objeto). El problema estriba en que deberíamos contar con un metalenguaje para el lenguaje natural pero esto no es posible. En nuestro lenguaje, como afirma Kripke (1975, p. 695), 
la noción de verdad es sistemáticamente ambigua en el sentido en que sólo hay una palabra para ella y no diferentes palabras cada una de las cuales estuviera ligada a un dominio restringido; en el lenguaje ordinario usamos la palabra verdad como siendo verdad per se y no verdad-en-unlenguaje. No existe un metalenguaje del lenguaje natural sino que el mismo lenguaje natural contiene a la vez oraciones, los nombres de éstas y las definiciones de los conceptos semánticos, entre ellas la definición del predicado es verdadero. El lenguaje natural es un lenguaje semánticamente cerrado y este hecho, como explica Tarski, es incompatible con la validez de las leyes de la lógica pues la conjunción de ambos produce sistemas inconsistentes. Ésta es la razón por la que Tarski rechaza la posibilidad de dar una definición de la verdad para el lenguaje natural en su totalidad. Podría pensarse, y así lo sugiere Tarski, que la definición pueda ser aplicable a ámbitos concretos del lenguaje con fines científicos, pero éste no sería nunca el caso de la investigación lingüística puesto que si bien en la investigación científica no hay porqué introducir nociones semánticas, no cabe no hacerlo en la investigación sobre la semántica. En conclusión, siguiendo a Tarski (1944, p. 309): “El problema de la definición de la verdad adquiere un significado preciso y puede resolverse en forma rigurosa solamente para aquellos lenguajes cuya estructura se ha especificado exactamente".

Por otro lado, la definición de la verdad para el lenguaje natural tampoco puede ser materialmente adecuada puesto que no se cumplen las dos condiciones impuestas. i.e., todas las expresiones deben tener un correlato y de la definición han de seguirse todas las equivalencias $T$. Para empezar, es conveniente volver nuevamente sobre el concepto de las equivalencias $T$ y la forma de entender la estructura semántica en la teoría tarskiana. En la teoría tarskiana la noción de satisfacción, no solo explica la relación de referencia sino que además se constituye como una noción primitiva para definir la verdad, pues ésta se produce cuando hay satisfacción de predicados:

ciertos objetos satisfacen una función dada si ésta se convierte en una oración verdadera cuando reemplazamos sus variables libres por nombres de los objetos dados. En este sentido, por ejemplo, la 
nieve satisface la función proposicional $<<x$ es blanca $>$ porque la oración $<<$ la nieve es blanca $>$ es verdadera. (Tarski, 1944, p. 315)

La verdad entonces es función de asignación de referencias o, en términos tarskianos, satisfacción de predicados y las condiciones de verdad de las oraciones son condiciones de satisfacción de los predicados. Este vínculo que se establece entre la referencia y la verdad a partir de la noción de satisfacción se expresa en las equivalencias $T$, que en este caso al ser extendidas al lenguaje natural tienen la forma < La oración La nieve es blanca es verdadera en LN si, y sólo si, la nieve es blanca>. La equivalencia establece una correspondencia entre el lenguaje y la realidad de forma que el hecho de que la nieve sea blanca constituye la condición de verdad de la oración La nieve es blanca. Esto implica que para tener todas las equivalencias $T$ debería ser posible especificar las condiciones de verdad de todas las oraciones del lenguaje natural. Sin embargo, en lo que sigue se verá que esto no es posible precisamente porque la primera de las condiciones, que todas las expresiones tengan un correlato, no se da.

En la definición tarskiana el valor de verdad depende de que haya un dominio especificado y estructurado en términos de conjuntos matemáticos que contribuya a establecer la relación de correspondencia unívoca entre el lenguaje y los objetos. Sin embargo, como se sigue de lo visto a lo largo del capítulo, en el lenguaje natural esto no es posible. Por un lado, no es posible tener un correlato para todas las expresiones puesto que carecemos de una metafísica para el lenguaje natural que garantice una teoría robusta de la referencia. Por otro, las expresiones del lenguaje natural no tienen condiciones de satisfacción tarskianas. Los predicados del lenguaje natural no se definen siguiendo un criterio de condiciones necesarias y suficientes, sino que se definen en función de criterios de categorización conceptual; de modo que los predicados no constituyen conjuntos precisos de individuos y las referencias varían en función de qué criterio se esté usando. Esto hace que en el lenguaje natural a menudo encontremos oraciones con condiciones de verdad indefinidas, así como oraciones a las que no es posible atribuir un valor de verdad. 
Uno de los casos en los que no es posible dar un valor de verdad es el de las oraciones con referencias vacías, como el conocido ejemplo de la oración russelliana:

(5) El rey de Francia es calvo

Para las semánticas bivalentes este tipo de expresiones que incluyen expresiones con referencias vacías son expresiones anómalas semánticamente en las que falta algún elemento para hacer posible la asignación de verdad. Este enfoque, derivado de las semánticas lógicas fregeana y russelliana, en el que se presupone que todas las oraciones deben ser verdaderas, falsas o sin sentido, es problemático. Por un lado, dado que parece que cualquier hablante competente diría que esta oración no es una oración asignificativa, este enfoque lleva a la búsqueda de constituyentes inarticulados (en el ejemplo, la teoría russelliana incluye un cuantificador existencial en la forma lógica) y con ello al problema de la búsqueda e identificación de la forma lógica visto en el apartado anterior. Por otro lado, la atribución de verdad o falsedad para una oración como (5) no encaja con la práctica habitual del lenguaje. Como explica Strawson (1952), ante una proferencia de (5) no respondemos diciendo que la oración sea falsa o negándola de forma ordinaria sino diciendo simplemente No hay rey de Francia. Las expresiones con vacíos referenciales carecen de valor de verdad pues para la asignación de verdad son necesarias las referencias (Acero, Bustos y Quesada, 1982; Higginbotham, 1985; Seuren, 2009; Strawson, 1952).

No es posible tampoco asignar condiciones de verdad ni valores de verdad determinados para las expresiones con referencias múltiples o predicados vagos:

(6) Let's read an italian book together (Sainsbury, 2001, p. 106)

(7) The mushroom is poisonous (Bach, 2008) 
La proferencia (6) es un caso de modificación adjetival ${ }^{35}$ en el que se necesita establecer la relación que mantiene el adjetivo con el nombre -si el libro es sobre Italia, si está escrito en italiano, si está hecho en Italia, etc.- para poder establecer condiciones de verdad determinadas, así como un valor de verdad ${ }^{36}$. De la misma forma, casos como (7) tampoco pueden ser evaluables. En el lenguaje natural a menudo usamos expresiones que necesitan de una relativización para determinar sus condiciones de verdad y su valor de verdad. Así, (7) literalmente no puede ser verdadera ni falsa a menos que se explicite un argumento para relativizarla (p.e., venenosa para los humanos). Lo mismo ocurre en afirmaciones sobre la hora del día que son relativas a la zona horaria, sobre la legalidad que es relativa a un código concreto, sobre el tamaño, la altura, etc. En todos estos casos, podría objetarse que no son oraciones significativas genuinas pues carecen de lo necesario para la atribución de verdad, sin embargo esto es contrario a las intuiciones de los hablantes y su uso real. Incluso con dudas sobre la relación que mantienen italian y book en (6), no puede decirse que la oración es asignificativa ni que no pueda entenderse puesto que la oración es completamente inteligible (Sainsbury, 2001). Así mismo, en el uso normal los hablantes utilizamos proferencias como (7) como si no fueran relativas, por lo que sería necesario admitir que los hablantes hablamos mal y, por tanto, desvincular la explicación semántica de la práctica real del lenguaje. Más bien lo que parece es que tales expresiones son genuinas pero sin atribución de verdad (Bach, 2008).

Así mismo, existen otros muchos casos donde no es posible determinar condiciones de verdad definidas ni valores de verdad: el uso artístico del lenguaje (Frege, 1892), así como el uso moral (Bach, 2008); las oraciones no enunciativas (desiderativas, imperativas o interrogativas); oraciones que expresan futuros contingentes (Peacocke, 2000); las bromas, los problemas pedagógicos y los

\footnotetext{
${ }^{35}$ Otros casos relacionados con el mismo problema para las semánticas veritativo-condicionales, como el caso de los genitivos entre otros, pueden verse en Sainsbury (2001).

${ }^{36}$ Muchas teorías contemporáneas han apelado al contexto como medio para definir las condiciones de verdad de las oraciones supliendo los vacíos referenciales y resolviendo las ambigüedades. Sin embargo, esto no invalida la presente argumentación pues lo que está aquí en cuestión es el criterio de adecuación material para la posibilidad de dar una teoría semántica extensional de la verdad en el lenguaje natural. En este sentido, la apelación al contexto de emisión y a las intenciones (referenciales) del hablante hacen inviable una definición recursiva, por lo que apelar al contexto no resuelve el problema de la adecuación material de la definición.
} 
insultos (Jackendoff, 2002), así como el lenguaje peyorativo (Camp, 2013; Richard, 2008; Saka, 2007); fenómenos lingüísticos como la connotación o la distinción uso-mención (Saka, 2007).

De lo anterior se sigue que la indefinición de las condiciones de verdad y la ausencia de valores de verdad no son una excepción en el lenguaje natural ${ }^{37}$. En el fondo, todos los casos se reducen a una misma cuestión, la verdad en el lenguaje natural es demasiado indeterminada como para dar una respuesta clara en innumerables ocasiones. Esto trae como consecuencia que no sea posible deducir todas las equivalencias $T$, requisito necesario para una definición extensional de la verdad. En conclusión, la definición de la verdad como correspondencia en el lenguaje natural siguiendo el modelo tarskiano no puede cumplir el requisito de ser materialmente correcta ${ }^{38}$.

En resumen, usar la noción de verdad como noción semántica para el lenguaje natural exige una teoría de la verdad a partir de la que pueda definirse la noción. Sin embargo, la definición de la verdad como correspondencia para el lenguaje natural es problemática. No es posible una definición extensional al modo tarskiano pues la definición no cumple con los requisitos necesarios para que cuente como una definición formal y materialmente correcta. Así, no hay una teoría de la verdad para el lenguaje natural. Esto muestra que las teorías semánticas veritativo-condicionales del lenguaje natural son teorías pobres del significado pues se construyen a partir de la noción de verdad como noción semántica sin definir.

\footnotetext{
${ }^{37}$ Las semánticas no bivalentes no parece que ofrezcan tampoco una solución satisfactoria a estos fenómenos. Para éstas, tales oraciones no son anómalas y sí tienen una asignación de valor, sólo que el valor es indeterminado. Sin embargo, cualquier valor alternativo a verdadero o falso, ya sea en cualquiera de las versiones de las distintas lógicas polivalentes, que asignemos a una oración está sustentado en la ignorancia epistémica (Acero et al. 1982; Schiffer, 2005; Williamson, 1992). Postular valores indicativos de ignorancia epistémica puede tener utilidad en ciertos campos, pero no contribuye en modo alguno a construir una teoría de la verdad para el lenguaje natural pues persiste aún el hecho de la incapacidad de dar un valor de verdad a todas las expresiones y, en este sentido, continúa sin ser posible dar todas las equivalencias $T$. ${ }^{38}$ Es usual encontrar en la literatura sobre semántica una objeción a esta conclusión. Se apela al hecho de que la semántica, a pesar de especificar el significado lingüístico a través del recurso a condiciones de verdad, no está comprometida con la verificación de las oraciones y, por tanto, el hecho de que no podamos atribuir un valor de verdad definido para las oraciones no es problemático. Sin embargo, ésta es una objeción meramente aparente que resulta de una reflexión superficial acerca del significado e implicaciones de la noción de equivalencia $T$ y de la noción de condiciones de verdad. Especificar las condiciones de una oración es en definitiva especificar cómo es la realidad; en otras palabras, identificar las condiciones de verdad de una oración equivale a identificar las referencias que posibilitan decidir la verdad o la falsedad de dicha oración y esta atribución de verdad es necesaria para poder tener las equivalencias $T$. Si no se da la atribución de verdad, no hay equivalencias $T$ y, por tanto, no hay adecuación material de la definición.
} 


\subsection{El dogma extensionalista}

Las semánticas veritativo-condicionales han intentado trasladar la concepción extensional del lenguaje formal al lenguaje natural. Sin embargo, este enfoque incurre en lo que Pietroski (2005) denomina el dogma extensionalista, la asunción de que en los lenguajes naturales hay un vínculo entre la verdad y el significado.

En una caracterización formal extensional referencia y verdad son dos caras de una misma moneda. La explicación de la relación de verdad como relación de correspondencia entre el lenguaje y la realidad a través de las equivalencias $T$ muestra que el significado es, desde esta perspectiva, la referencia y, por tanto, en la medida en que la relación de verdad expresa la correspondencia entre las expresiones y sus referentes, se asimila el predicado es verdadero a su equivalente significalrefiere. De manera que el problema de la determinación de las condiciones de verdad de las oraciones consiste en el problema de determinar referencias dejándonos, como dijo Strawson (1969) con las nociones de verdad y referencia señalándose la una a la otra inútilmente, forzándonos a explicar qué son la verdad y la referencia.

En los lenguajes formales esto no es problemático dado que ambas nociones se definen de forma coherente a través de la noción de satisfacción dentro de un sistema regimentado. Como se ha explicado, en los sistemas lógicos tanto la sintaxis como la asignación semántica están especificadas y esto posibilita que el significado, entendido como denotación, esté conectado a la verdad. En tales lenguajes se puede definir el significado como funciones bien definidas y, gracias a esto, se pueden asignar valuaciones a las fórmulas y determinar sus valores de verdad como siendo sus referencias puesto que la verdad es un término técnico que sirve para representar la validez. Determinar la verdad de las expresiones en estos lenguajes es más bien un ejercicio de capacidades lógicas dadas las restricciones anteriores. Una vez elegidas las denotaciones y hecha la asignación semántica en términos de funciones, la verdad de las fórmulas es independiente de la realidad y de los agentes epistémicos (Haack, 1978; Quine, 1948). Como dice Seuren (2009), la 
lógica no tiene que ver con cómo es el mundo real, de forma que el valor de verdad de Está lloviendo en Nueva York es una propiedad intrínseca de la expresión con independencia que de uno sepa el tiempo en Nueva York. Puesto que verdad y falsedad no tienen implicación epistémica ni metafísica sino que son términos técnicos, es un asunto sin importancia cómo etiquetar las valuaciones de los enunciados; en lugar de verdadero y falso podrían utilizarse sin perjuicio 1 y 0 pues la regimentación del sistema asegura la validez (McGee, 2006; Pietroski, 2003).

En el lenguaje natural las cosas no funcionan de la misma manera. Por un lado, en el lenguaje natural no es deseable un concepto técnico pues la verdad en el lenguaje natural sí tiene implicaciones epistémicas y metafísicas. Ahora bien, usar una noción sustantiva de verdad para el lenguaje natural es problemático puesto que la verdad debe entenderse como una relación de correspondencia y no es posible definir ésta para el lenguaje natural. Por otro lado, para el lenguaje natural no contamos con una teoría de la referencia mediante la que especificar el dominio que está tras la interpretación semántica ni con una teoría de la forma lógica con la que establecer una correspondencia transparente entre las estructuras sintáctica y semántica El lenguaje natural es fundamentalmente ambiguo y los valores semánticos en el lenguaje natural no son valores en un modelo teórico para una sintaxis especificada lógicamente, sino que son valores relativos a conocimientos léxicos dependientes del sistema conceptual, del conocimiento general del mundo y de los usos en contexto. Esto implica que a menudo las expresiones involucren algún tipo de fallo referencial que imposibilita asignarles un valor de verdad. Como afirma Haack (1978), no contrastamos nuestros enunciados con una realidad idealizada en la que reina la bivalencia sino con una información disponible que es fragmentaria y parcial y en la que carecemos de muchos datos para afirmar o negar multitud de afirmaciones. La defectividad sintáctica y semántica produce un hueco entre la verdad y el lenguaje natural de manera que no se cumple el principio de independencia cognitiva de la verdad. 
A menudo nuestros juicios de verdad no son robustos puesto que están basados en implicaciones subjetivas. Como en el siguiente ejemplo, los hablantes solemos afirmar que (3) es verdadero, a pesar de que solo sea intuitivamente verdadero:

Suppose that Inma and Tarek went to a certain party, to which Maria could not go. Maria now wants to know how the party went. She asks Inma, who says:

(1) Oh, I shouldn't have gone. 'Twas better to stay home and do some needle-work.

Later, Maria asks Tarek, and he tells her:

(2) My goodness! I don't think I've ever been more bored in my whole life.

Maria might well reply:

(3) Yes, Inma said that, too.

Or, talking yet to someone else about the party, Maria might report:

(4) Both Inma and Tarek told me that the party was really boring.

Although the intuitions are not very robust in the case of (3) and (4), it is still true that in everyday life, we often report people as having said the same thing when all that their utterances have in common is a certain implication, and that implication is relevant in the context of the report. Thus, while Inma does not literally say in (1) that the party was boring, what she does say, viz. that instead of going, she should have stayed home to do needle-work, implies, given enough contextual background (such as the assumption that needlework is not a particularly exciting activity), that the party was boring. And similarly for (2). (Stojanovic, 2007, p. 126-27)

Siguiendo a Stojanovic (2007), los estándares sobre qué es verdad (en este caso, sobre qué es decir lo mismo) pueden cambiar de manera que a veces tener una implicación similar puede ser suficiente, mientras otras puede exigirse más precisión. En lo relativo al lenguaje parece mejor hablar de juicios de verdad entre hablantes como un ajuste mutuo entre sus conceptualizaciones del mundo. Estas son las razones que han llevado a varios autores a conectar la verdad con la cognición (Horgan, 1986; Jackendoff, 2002; Pietroski, 2005; Seuren, 2009; Yalcin, 2014). 
En este sentido, la definición del significado lingüístico a través de la especificación de las condiciones de verdad presupone una manera de entender la verdad y la relación referencial que proviene de convenciones surgidas en el seno de la visión estándar del formalismo semántico (Seuren, 2009). Sin embargo, denotación, satisfacción y verdad son términos técnicos de la teoría lógica que no tienen contraparte en la semántica natural.

Como explica Schiffer (2015), el lenguaje natural es un lenguaje de comunicación interpersonal y en este sentido las oraciones deben tener algún tipo de propiedad que consista en reflejar significados (sean lo que sean) y, aunque no sea fácil decir en qué cosiste esta propiedad, sí podemos saber que algunas propiedades no pueden realizar esta tarea. De lo visto anteriormente, puede decirse que tomar la verdad como propiedad semántica no puede realizar la tarea que se le presupone: no explica el significado de muchas expresiones ni explica cuestiones relevantes como el léxico y su composición para formar significados. De la misma forma, referir no parece ser equivalente a significar, sino más bien un tipo concreto de función lingüística ligada a los actos de habla (Bach 2005; Strawson, 1950). En algunas ocasiones los hablantes usamos las palabras para llamar la atención del oyente sobre las cosas y ayudarle a identificarlas pero esto no es lo mismo que decir que las palabras signifiquen referencias en el sentido clásico (Heck, 2014; Rayo, 2013; Stojanovic, 2007; Yalcin, 2014). Es por ello que los hablantes pueden no saber quién ha escrito (8) o a quién refiere pero aún entienden su significado, la oración es perfectamente inteligible (Schiffer, 2015 p. 78):

(8) Is she a politician?

En definitiva, en el lenguaje natural no hay un vínculo entre la verdad, la referencia y el significado (Higginbotham, 1985; Pietroski, 2003 y 2005; Seuren, 2009; Strawson, 1981; Szabó, 2012), lo que muestra que la explicación del significado desde el enfoque extensional veritativo-condicional no es adecuada. La verdad y el significado deben desligarse de las 
extensiones al tiempo que se conectan con factores cognitivos. Así, los significados no son referencias, ni valores de verdad, ni condiciones de verdad sino algo mucho más conectado con la estructura conceptual. En definitiva: “the extensionalists' ideal of a mindless logic is thus seen to be illusory" (Seuren, 2009, p. 111). 



\section{Capítulo 3}

\section{El giro pragmático del supuesto veritativo-condicional}

Los problemas de la referencia y la verdad se han intentado acometer apelando al contexto como medio de salvaguardar el hueco entre la verdad y el significado. Se argumenta que el contenido lingüístico de las proferencias infradetermina el significado en el sentido en que la proposición mínima no aporta un contenido veritativo-condicional completo y, por tanto, no cumple ningún rol en el proceso de la comunicación. Esto ha llevado a la defensa de una amplia contribución contextual que desdibuja las nociones clásicas y elimina la distinción semánticapragmática, manteniendo una visión pragmática del significado. Desde esta perspectiva, solo cabe diferenciar el contenido codificado y el contenido comunicado al que se accede a través de procesos pragmáticos post-léxicos e inferenciales dentro de un modelo tripartito de la comprensión lingüística. Por ello, en el primer apartado se analizará la cuestión de la indexicalidad, mostrando que la forma generalizada de definir el significado como una función de contextos a valores de verdad está lejos de resolver el problema de la referencia para la determinación del contenido veritativo-condicional. Por otro lado, las nociones involucradas en el modelo de explicación pragmatista parecen inadecuadas a la luz de los problemas que suscitan. Así, se analizarán en los apartados siguientes las nociones de enriquecimiento, explicatura y contexto cognitivo, mostrando además algunas evidencias en contra del modelo inferencial que propone el Pragmatismo. 


\subsection{Sensibilidad al contexto e indéxicos}

El primero de los factores que contribuyen al argumento de la infradeterminación del significado por las características formales de las oraciones es la existencia de expresiones del lenguaje que son sensibles al contexto. El problema que plantean estas es que sus referentes varían con los contextos, lo que lleva a concluir que el contenido semántico de las proferencias en las que se encuentran es determinado por el contexto. Este es el caso de las expresiones indéxicas para cuya provisión de valores se requiere el llamado proceso de saturación ${ }^{39}$. Pragmatistas y minimalistas asumen que éste es un proceso necesario para determinar el contenido veritativocondicional de las oraciones. La diferencia entre ambas posturas estriba en que mientras para el Pragmatismo es un proceso de carácter pragmático en el que interviene un contexto amplio, el Minimalismo afirma que es un proceso semántico independiente de tales factores. Sin embargo, como se verá en lo que sigue, los problemas surgidos en torno a la cuestión hacen que la diferencia entre ambas posturas sea una cuestión del grado en que actúa el contexto para la determinación del contenido veritativo-condicional, moviéndose entre una contribución mínima o una máxima en lo relativo al proceso de saturación.

\subsubsection{El tratamiento de la indexicalidad en el Pragmatismo y el Minimalismo}

La visión contextualista de Recanati (2004) establece tres niveles de significado que se distinguen según sean afectados por un tipo diferente de procesos pragmáticos. El primer nivel es el significado lingüístico de la oración que consiste en el significado convencional de las expresiones simples asignado por las reglas del lenguaje y restringido por las características formales de la oración. Este nivel es el único al que no le afectan procesos pragmáticos pero no puede proporcionar una proposición completa puesto que en muchas proferencias faltan elementos para

\footnotetext{
${ }^{39}$ El caso de los llamados por Stanley (2002) indéxicos encubiertos se analizará posteriormente en conexión con las nociones de explicatura y constituyente inarticulado.
} 
determinar las condiciones de verdad: o bien hay elementos que requieren del contexto para proveer sus valores, o bien hay elementos que no están articulados en la forma lógica y sintáctica de la oración pero son esenciales para determinar las condiciones de verdad. Según Recanati, deben llevarse a cabo procesos pragmáticos primarios a nivel inconsciente para completar las proferencias con el material que falta en el primer nivel. Estos procesos pragmáticos primarios engloban dos tipos: obligatorios y opcionales. El primero comprende el proceso de saturación, mientras la modulación y el enriquecimiento libre constituyen los segundos. Como resultado de estos se obtiene el significado primario que corresponde a lo dicho por la proferencia de una oración. Tras éste, llevando a cabo procesos pragmáticos secundarios, se llega al significado secundario, ejemplo de no literalidad e implicaturas. De acuerdo con esto, hay procesos pragmáticos que actúan presemánticamente (su función es producir el contenido veritativo-condicional) y postsemánticamente (actúan sobre una proposición completa). Así, siguiendo esta visión la provisión de los valores de los indéxicos requiere de un proceso pragmático primario obligatorio que incorpore información del entorno físico de las proferencias y de la intención del hablante.

En relación a los indéxicos, el Minimalismo ofrece una explicación de carácter semántico para la asignación del significado de las expresiones indéxicas siguiendo la teoría de Kaplan. De acuerdo a Kaplan (1975), el análisis de los demostrativos tiene que desdoblarse tomando en cuenta su contenido y su carácter. El contenido de estos términos remite a las extensiones de los términos, que contribuyen a la proposición expresada. Los contenidos de los indéxicos varían con los contextos, lo que muestra su naturaleza dependiente del contexto. Sin embargo, hay algo en estos términos que es invariable a los contextos. Además del contenido tienen un carácter, que Kaplan equipara al significado lingüístico. El carácter de estos términos es una propiedad semántica que determina el contenido de la expresión dependiente del contexto en cada ocasión de uso. Es algo que, por convención, los hablantes conocen en virtud de su competencia semántica independientemente del contexto. Este aspecto independiente del significado de los demostrativos es el que el Minimalismo rescata como característico del significado semántico. 
Según el Minimalismo, estas expresiones tienen significados asignados independientemente de los contextos; es decir, tienen determinadas propiedades semánticas por convención que son invariables y que los hablantes conocen en virtud de su competencia semántica. Una de las propiedades semánticas de estas expresiones es el contener la restricción referencial necesaria para una futura identificación del referente en contexto puesto que el conocimiento de su entrada léxica implica el conocimiento suficiente para fijar sus referencias en contexto. Así, por ejemplo, el término yo refiere en cada ocasión de uso a una persona distinta y por tanto las condiciones de verdad de las proferencias en las que aparece varían con los contextos. Sin embargo, tiene un significado asignado independientemente de los contextos puesto que en cada contexto yo refiere siempre al hablante. Es posible que el oyente no pueda identificar el referente de la proferencia pero sabe, independientemente del contexto, que yo refiere a la persona que produjo la proferencia. De esta manera, el carácter toma la forma de una regla semántica que cumple la función de posibilitar la determinación del referente (contenido), ayudando a restringir entre las posibles interpretaciones. Por tanto, el significado de estas expresiones es invariable al contexto y se distingue del contenido referencial (Bach, 2001; Borg, 2004; Cappelen y Lepore, 2005; Perry, 2006; Stanley, 2002; Stojanovic, 2007).

El Minimalismo ha hecho uso de la noción de contexto estrecho (Perry, 1998) o contexto formal (Borg, 2004; Kaplan, 1975; Predelli, 2004). Siguiendo a Kaplan, se argumenta que la información contextual requerida para la determinación del contenido se recupera a través de funciones bien definidas desde parámetros objetivos que cuentan como hechos constitutivos de las proferencias. Es por esto que se distingue entre la información contextual en sentido amplio que es relevante para la pragmática y la información contextual en sentido estrecho que es relevante para la semántica. Ésta última es más restringida que la primera, refiere únicamente a los valores (semánticos) necesarios para fijar las referencias de los indéxicos y alcanzar el contenido veritativo-condicional en el proceso de saturación. Así, el contenido semántico de 
estas expresiones es relativo al contexto en el sentido estrecho, no dependen ni varían de acuerdo a las intenciones del hablante o a otro tipo de información extralingüística.

\subsubsection{Problemas en los modelos de explicación de la indexicalidad}

Las visiones pragmatista y minimalista encaran algunas dificultades en relación con la noción de contexto, el tratamiento de los indéxicos intencionales y el problema de explicar la inteligibilidad de las proferencias con independencia del contexto.

En primer lugar, la forma en que el Minimalismo explica cómo se fijan los referentes en contexto, lo que Heck (2014) llama la visión de la pista contextual, es problemática. Según ésta, para asignar referencias se necesita atender a parámetros objetivos del contexto de uso. Tradicionalmente para el contexto estrecho se han tomado como parámetros hablantetiempo-lugar (Frápoli y Villanueva, 2013; Perry, 1998) puesto que es generalmente aceptado que estos contribuyen al contenido veritativo-condicional. Si bien, esto plantea problemas en un doble sentido.

Por un lado, no está claro cómo deben definirse los parámetros. Cuando uno se dispone a establecer los parámetros de tiempo y lugar debe cuestionarse en qué consisten estos parámetros; es decir, debe decidirse en qué términos se definen el tiempo y el lugar: si la zona horaria debe tenerse en cuenta; si se toma el tiempo en un sentido absoluto o relativo; si, como cuestionan Bach y Chao (2012), los elementos del tiempo son puntos en una línea o intervalos. El habla sobre el tiempo en los lenguajes naturales es indeterminada y, en este sentido, deben llevarse a cabo previamente ciertas decisiones teóricas sobre la metafísica que subyace. Así mismo, Aquí puede referir al espacio ocupado por el cuerpo, la habitación, una parte de una ciudad, la ciudad o, incluso, el país (Carston, 2008). Todos estos parámetros podrían dar variaciones en el contenido veritativo-condicional, así como darían lugar a implicaturas diferentes. La decisión sobre cómo 
referir los puntos de localización, así como la temporalización, parece una decisión arbitraria que responde a intuiciones más que a criterios objetivos.

Por otro lado, hay innumerables parámetros con respecto a los que podrían darse variaciones en este sentido veritativo-condicional. Dado que la función del lenguaje en la comunicación es posibilitar que un hablante revele sus pensamientos a un oyente, lo que el hablante utiliza para asegurar esta comunicación no tiene límites, así hay muchos parámetros que podrían contar como pistas contextuales (entre otros, señalar u otros gestos, la saliencia de ciertos elementos, la entonación). En este sentido, como algunos autores (Bosch, 2007; Gauker, 2010; Heck, 2014) han mostrado, no parece posible establecer una lista finita y válida de parámetros contextuales que contenga todos:

The first idea, propounded by Montague, David Lewis, and others, is to think of contexts as simply $n$ tuples of specifications or parameters: one for the speaker, one for the addressee, one for the time, one for the world, and so on. Notice that on this view, worlds, times, and so on enter the picture two different ways: once as part of the context, once again as part of the semantic evaluation. (You can think of the assignment of values to variables as a context in the setup of $P T Q$.) Now the problem here is with the "and so on." This view makes it seem as if we can set up some prior fixed list of parameters for the context. Again it was Cresswell (1973, again!) who showed that this is an unreasonable expectation: In general, we do not know in advance what elements of the context we will need to get on with the semantic evaluation of a sentence. Cresswell gives a nice example to illustrate this point. Consider this request:

5. Please bring me another quart.

Do we need to have a "previous drinks parameter" to interpret such a sentence?! (Creswell, 1973. Tomado de Bach (1989, p. 105))

La especificación de los parámetros depende entonces de elecciones teóricas y metafísicas previas que son arbitrarias aunque necesarias si uno quiere tomarse en serio la relatividad de las proferencias a los contextos de uso. De lo anterior se sigue que nada puede contar como pistas 
objetivas del contexto para determinar las referencias y que la noción de contexto, en este sentido, es una noción ambigua para la que no hay una definición precisa, lo que hace que sea problemático identificar el contexto correcto.

En segundo lugar, el tratamiento en términos de funciones de contextos a contenidos parece insuficiente para la explicación de los indéxicos intencionales que podrían ser potencialmente $\operatorname{pragmáticos}^{40}$. En términos de Bach (2005, p. 40), sufren una deficiencia de carácter al no referir como una función del contexto. Para un indéxico como yo es fácil ver cómo puede tratarse su significado y el modo en que se da la referencia de una forma sistemática y automática puesto que yo refiere siempre al hablante y esto es independiente de las intenciones de los hablantes. Sin embargo, el ejemplo siguiente (Stojanovic, 2007, p. 20) muestra que esto no es tan sencillo en otros casos:

(9) She is dangerous

Si estando en una fiesta alguien declara (9) habiendo en la fiesta varias mujeres, la intención del hablante es necesaria para que el oyente identifique a la mujer correcta pues el contexto por sí solo no determina en este caso la referencia. Por lo que parece que habría que añadir a la noción de contexto kaplaniano un parámetro para las intenciones de los hablantes, sin embargo la noción kaplaniana no es operativa con un parámetro como éste (Schiffer, 2005).

La estrategia pragmatista pasa por ampliar el alcance del contexto. Desde el Pragmatismo se argumenta que en la mayor parte de los casos la identificación de referentes requiere de procesos pragmáticos que incorporan muchos tipos de información, entre estos las intenciones de los hablantes (Carston, 2012; Recanati, 2004). Así, el Pragmatismo, dado el problema que presentan los demostrativos intencionales y el problema anterior en relación al límite de parámetros del contexto estrecho, anula la distinción entre contexto estrecho y contexto amplio en favor de una noción de contexto como contexto cognitivo (Carston, 2008). En adelante se verá con más detalle

\footnotetext{
${ }^{40}$ Se sigue aquí la distinción de Perry (1998) entre indéxicos automáticos e indéxicos intencionales.
} 
esta noción, baste por ahora aclarar que se sugiere el contexto cognitivo como un producto de la combinación de los factores circundantes a las proferencias, así como de los procesos cognitivos y comunicativos involucrados en la producción y comprensión lingüísticas.

Sin embargo, la defensa de una contribución amplia del contexto para la determinación de las referencias de los indéxicos conlleva la dificultad de explicar la inteligibilidad de las oraciones con independencia del contexto. Para entender esto puede pensarse en un juego de yincana para niños en el que un grupo de niños encuentra un sobre con una tarjeta en su interior donde se encuentra escrito:

(10) Este objeto tan deseado por las plantas tiene la forma de una larguísima serpiente

Podría uno imaginar que los niños saldrían corriendo en busca de la manguera que está tirada en el jardín para encontrar la siguiente pista. En este caso la noción de contexto no sirve para la identificación de la referencia del demostrativo complejo. Hay varias referencias posibles pero ni el contexto situacional ni el dominio del discurso en el que está inmersa la proferencia determinan la referencia, para ello se requieren las intenciones del hablante que los niños desconocen, de lo contrario no habría juego. Ahora bien, ¿podría decirse que los niños no han comprendido el significado de la expresión este objeto tan deseado por las plantas antes de adivinar que se trataba de una manguera? ¿Debe decirse que la proferencia no tiene significado hasta que los niños infieren las intenciones del hablante y la referencia? Parece difícil asumir tal cosa, los niños comprenden el significado porque la oración es perfectamente inteligible y ésta, de hecho, es la razón por la que encuentran la solución al juego, la referencia. En este sentido, el Minimalismo pone énfasis en la distinción entre el contenido semántico y el contenido referencial. El hecho de que el referente se determine por la intención del hablante no implica que el contenido semántico esté determinado por el contexto en el sentido de estar constituido por factores contextuales. 


\subsection{Explicatura y enriquecimiento}

El segundo factor que contribuye a la objeción de la infradeterminación del significado se basa en que a menudo se necesita más de lo que está expresado en las oraciones para especificar sus condiciones de verdad. El Pragmatismo objeta que hay oraciones incompletas en el sentido en que carecen en su estructura sintáctica (superficial) de algún elemento que es necesario para determinar las condiciones de verdad de las mismas, p.e., la oración Está lloviendo en la que sin una especificación de la localización no parece posible producir nada evaluable. En conexión con esto, el argumento se refuerza con la que Bach (2001) llama la objeción intuitiva ${ }^{41}$ que se construye sobre un argumento acerca de la impropiedad del contenido veritativo-condicional determinado sobre la base de los elementos lingüísticos en abstracción del contexto de uso. Según este, la semántica sin la apelación al contexto falla al determinar el significado intuitivo; en otras palabras, que la condición de verdad recuperada formalmente parece demasiado general, de forma que no acomoda nuestros juicios intuitivos de lo que las proferencias expresan. Este es el caso de proferencias como Aún no he desayunado o todas aquellas que contienen cuantificadores como No hay nada para comer. En estos casos parece que si sólo se toma en consideración los elementos representados formalmente en las oraciones se obtiene un valor de verdad falso para ellas, mientras nuestras intuiciones nos dicen que son verdaderas.

De los argumentos anteriores se extrae la idea de que los constituyentes formales de las oraciones son insuficientes para determinar proposiciones completas y, por tanto, cualquier teoría que pretenda caracterizar el significado en base a las características formales de las oraciones infradetermina el significado. En cambio, se argumenta que las proferencias deben enriquecerse pragmáticamente para proveer el contenido veritativo-condicional que porta el contenido informativo invocando lo que se llamarán aquí procesos pragmáticos de enriquecimiento ${ }^{42}$. La

\footnotetext{
${ }^{41}$ Otra versión de la objeción aparece en Borg (2004 y 2007) y Carston (2002b).

${ }^{42}$ A este respecto cabe apuntar un par de cuestiones. Por un lado, existe una controversia en el seno de las teorías pragmatistas sobre si debe distinguirse entre dos tipos de procesos -primarios y secundarios- (Recanati, 2004) o si por el contrario, como afirma la Teoría de la relevancia, el procesamiento pragmático es un sistema unitario (Carston, 1997, 2002a y 2007). Por otro, a menudo se distinguen entre los procesos la modulación y el enriquecimiento libre. Mientras el
} 
argumentación pragmatista, como se verá en los siguientes apartados, sigue la misma línea que en lo relativo a la explicación del proceso de saturación. Para la recuperación de la explicatura se requiere acceder a múltiples recursos de información entre los que la noción de intención del hablante cobra un lugar predominante.

\subsubsection{El modelo pragmatista}

El Pragmatismo define lo dicho a través de la noción de explicatura como una proposición comunicada explícitamente entre cuyos constituyentes algunos son conceptos que no están verbalizados, sino que se han construido pragmáticamente a partir de los elementos codificados en la forma lógica (Carston, 1997 y 2002a; Sperber y Wilson, 1986). Esto quiere decir que en ocasiones el hablante comunica explícita y directamente contenidos que no están verbalmente expresados en sus proferencias y que el oyente recupera a través de procesos pragmáticos incorporando información del contexto de las proferencias. Si esto es así, entonces el significado es radicalmente dependiente del contexto.

Para entender el modelo pragmatista conviene recordar algunos ejemplos típicos de explicaturas ofrecidos por el Pragmatismo, donde el material entre corchetes indica el material enriquecido que da lugar a la explicatura ${ }^{43}$ :

\footnotetext{
último remite a la recuperación de elementos no articulados en la forma lógica de las oraciones, la modulación actúa sobre elementos que están articulados pero cuyo contenido semántico debe ajustarse en función del contexto para proporcionar el contenido correcto que contribuye al contenido veritativo-condicional de las oraciones. Así, al contrario que el enriquecimiento libre, la modulación no consiste propiamente en un desarrollo de la forma lógica al no añadir elementos nuevos. En este sentido cabrían ciertas objeciones sobre su contribución a la explicatura (Borg, 2004). A pesar de ello, en un sentido general la modulación expresa la misma idea que el enriquecimiento libre: el contenido comunicado (la explicatura) de las proferencias es más rico que las formas lingüísticas de las mismas. Esta es la razón por la que ambos procesos se tratarán aquí como procesos de enriquecimiento en este sentido general obviando la discusión sobre si forman parte de un subtipo de procesos primarios o no. Las distinciones al respecto no afectan a los argumentos que se exponen en adelante.

${ }^{43}$ Algunas versiones del MTA aceptan la existencia no explícita de los constituyentes de tiempo y lugar de las proferencias, pues entienden que para obtener el contenido veritativo-condicional se necesita la provisión de un valor para la localización de la proferencia. La diferencia con el Pragmatismo es que, mientras el MTA trata el material no explícito como un tipo de indéxicos encubiertos trazables en términos de funciones kaplanianas desde el contexto estrecho en el proceso de saturación (Stanley, 2002), el Pragmatismo los trata como material enriquecido pragmáticamente desde el contexto amplio en procesos posteriores a la saturación.
} 
(11) It's raining [here/in location x] (Perry, 1998, p. 8; Recanati, 2002, p. 300)

(12) I've had a very large breakfast [today] (Recanati, 2002, p. 300)

(13) Every bottle [that Mary bought yesterday] is in the fridge (Carston, 2008, p. 334)

(14) She gave him her key and [then] he opened the door (Carston, 2002a, p. 127)

(15) Most species have members that are small [for that species] ${ }^{44}$ (Recanati, 2002, p. 310)

(16) There wasn't enough [alcoholic] drink [to satisfy the people at the party] and [so] everyone[who came to the party] left [it] early (Carston, 2009, p. 35) ${ }^{45}$

Así, las explicaturas engloban casos en los que se enriquece el contenido para concretar el dominio del cuantificador, el contenido pragmático de las conectivas, los valores de indéxicos encubiertos (Stanley, 2002), la infradeterminación paramétrica en relación a la clase de comparación de los adjetivos (Recanati, 2002), así como el enriquecimiento destinado a resolver otros tipos de vaguedad. Por último, otro tipo frecuente de constituyentes inarticulados es el caso de los eventos en el fenómeno de la metonimia lógica. En la metonimia lógica los sintagmas nominales que acompañan a los verbos parece que requieren una interpretación en términos de eventos, pero esta interpretación no está fijada. Así, una proferencia de (17) puede interpretarse como que el escritor empezó a leer un libro o empezó a escribir un libro, entre otras:

(17) El escritor empezó un libro

\footnotetext{
${ }^{44}$ El material enriquecido entre corchetes no se encuentra en el ejemplo original de la proferencia.

${ }^{45}$ Aquí se están presentando los componentes añadidos como productos de procesos de enriquecimiento, no obstante debe aclararse que Carston (2009) señala que en esta proferencia se combinan el enriquecimiento libre y la modulación. Éste último sería el caso del contenido añadido para drink. Para la Teoría de la relevancia en este caso no hay un constituyente inarticulado propiamente dicho, sino que el concepto DRINK genera un concepto ad hoc DRINK* que reúne solo las características relevantes de la entrada léxica drink para el contexto de la proferencia (en este caso el concepto creado incluiría solo las bebidas alcohólicas). Pese a que aquí se toma la modulación como parte del proceso de enriquecimiento en general cabe mencionar el problema que genera esta explicación. Para llevar a cabo la modulación se aplica una relajación del concepto para lo que, según Bezuidenhout (2001), intervienen todo tipo de presuposiciones extralingüísticas. En base a esto, en cada contexto hay diferentes presuposiciones que harían diferencias en los conceptos ad hoc de DRINK, por ejemplo, incluso en el mismo contexto declarada la misma proferencia por dos personas diferentes. Como muestra Stern (2006), desde el momento en que entran en juego este tipo de presuposiciones se convierte en una tarea difícil establecer qué características cuentan como el contenido de las proferencias y cuáles se deben tomar para determinar su valor, por lo que parece que hay una sobregeneración de conceptos ad hoc que dificulta una clara determinación del contenido veritativo-condicional de las proferencias.
} 
Para el Pragmatismo debe recuperarse el evento que está encubierto en la forma superficial de las proferencias para resolver la inespecificidad de las mismas y alcanzar el contenido comunicado por el hablante. Siguiendo esto, el constituyente no articulado debe recuperarse desde el contexto de la proferencia pragmáticamente a través del proceso de enriquecimiento libre ${ }^{46}$ (Carston, 2002b; Recanati, 2002).

Desde esta perspectiva, cobra máxima importancia la noción de constituyente inarticulado. A este respecto, debe distinguirse la noción pragmatista de otros constituyentes que también están inarticulados. En este sentido deben distinguirse dos tipos de elementos no articulados que la literatura sobre el tema ha diferenciado. Por un lado, es posible recuperar algunos constituyentes que son obligatorios, en el sentido en que están demandados sintácticamente, y se explican desde los principios generales de la gramática, p.e., los elementos no expresados lingüísticamente en la anáfora. Por otro lado, se encuentran otros constituyentes que no están demandados sintácticamente (por tanto, no son obligatorios) pero que se defiende que contribuyen a la proposición expresada, siendo necesarios para determinar las condiciones de verdad (intuitivas) de las proferencias. Así, se acepta en general que los llamados constituyentes inarticulados son constituyentes opcionales y proposicionales. Además, el Pragmatismo (Carston, 2009; Recanati, 2002) caracteriza los constituyentes inarticulados como constituyentes comunicativos. Esto quiere decir que para tomar un constituyente como no articulado debe darse el requisito de que éste sea parte de lo que el hablante tiene en mente y comunica con su proferencia. Desde este punto de vista puede decirse, como hace Carston (2009), que son constituyentes obligados lingüísticamente, de forma que sin ellos las proferencias son incompletas en el sentido en que no expresan el contenido comunicado por el hablante ${ }^{47}$. El debate entre el Pragmatismo y el MTA ha estado centrado en los últimos años en la discusión

\footnotetext{
${ }^{46}$ De Almeida y Dwivedi (2008) tratan la recuperación pragmática de los eventos encubiertos en la metonimia lógica como parte del proceso de saturación al entender que el hueco en estas construcciones es estructural, aunque igualmente suplido vía inferencias pragmáticas.

${ }^{47}$ No se toman como incompletas aquellas proferencias donde el hablante no hubiera pretendido comunicar el constituyente, p.e., una localización, por estar comunicando un contenido en relación a un concepto y no un evento de habla. Ver Recanati (2004).
} 
acerca de si estos constituyentes inarticulados se recuperan a través de procesos semánticos, formando parte del proceso de saturación, o a través de procesos pragmáticos, como parte del enriquecimiento libre (Hinzen, 2015; Perry, 1998; Recanati, 2002; Sennet, 2011; Stanley, 2000).

Así, una de las ideas más fundamentales del Pragmatismo es entonces la advertencia de la existencia de contenido comunicado no articulado en las proferencias que forma parte del contenido de lo que se dice y que es necesario para la determinación del contenido veritativo condicional. Cuando uno dice que existen constituyentes no verbalizados que el hablante expresa directa y explícitamente, debe explicar qué constituyentes no verbalizados forman parte (o no) de tal contenido comunicado y por qué unos constituyentes, y no otros, deben tomarse como constituyentes de dicho contenido. En definitiva, se debe justificar algún tipo de criterio de individuación de lo que constituye una explicatura frente a otro tipo de contenido en el que también se encuentran constituyentes no verbalizados directa y explícitamente, como es el caso de la implicatura. Siguiendo a Borg (2016), pueden resumirse las características funcionales de la explicatura como: i) un desarrollo inferido pragmáticamente desde la forma lógica, ii) el primer contenido que el oyente recupera (a través de procesos pragmáticos), iii) la premisa para implicaturas añadidas, iv) el contenido veritativo-condicional y v) lo que el hablante pretende comunicar.

Partiendo de estas ideas, puede verse como el modelo tripartito del Pragmatismo elimina la distinción clásica entre sintaxis, semántica y pragmática a favor de una distinción entre sintaxis y pragmática (Carston, 2008). Desde este punto de vista, la proposición mínima no tiene realidad psicológica, no aporta un contenido completo ni es informativa y, por lo tanto, no cumple ningún rol en los procesos de comprensión lingüística ${ }^{48}$. En definitiva esto implica que apenas hay una distinción entre el contenido codificado y el contenido comunicado en forma de explicaturas e implicaturas al que se accede a través de procesos pragmáticos post-léxicos e inferenciales.

\footnotetext{
${ }^{48}$ Debe recordarse que se sigue aquí la acepción de proposición mínima de Cappelen y Lepore (2005).
} 


\subsubsection{Objeciones al modelo de explicatura}

Las características funcionales de la explicatura tienen el objetivo de constituir un criterio de individuación que la demarque de la forma lógica y las implicaturas. De las cinco caracterizaciones, hay especialmente tres que sirven a este propósito puesto que distinguen la explicatura como un desarrollo inferido pragmáticamente de la forma lógica, el primer contenido que el oyente recupera y la premisa para implicaturas añadidas. En lo que sigue se analizan los problemas surgidos desde estas características mostrando que las mismas no sirven como un criterio claro de individuación de lo que cuenta como una explicatura.

\section{El problema de la demarcación en relación a la forma lógica}

La primera de las características funcionales atribuidas a la explicatura como criterio de demarcación consiste en que la explicatura está restringida por la forma lógica de las oraciones. Se asume la explicatura como un desarrollo pragmático de la forma lógica que actúa como un tipo de restricción en su derivación, frente a la derivación de implicaturas, resultado de inferencias completamente nuevas, indeterminadas y relacionadas con consideraciones extralingüísticas (Carston, 1997 y 2002a).

El primer problema que se plantea es la indeterminación de la noción de forma lógica. Ya en el capítulo anterior se explicaron los problemas que plantea dicha noción, si bien el recordatorio en este punto aclarará el problema que conlleva en relación al criterio de individuación de la explicatura. Es posible resumir las características atribuidas a la forma lógica como i) la estructura relevante para la representación de contenidos, ii) la estructura en la que se determinan las condiciones de verdad de las oraciones, iii) la estructura profunda, distinta de la estructura sintáctica (dada la ambigüedad derivacional y los problemas derivados de las concepciones que adoptan por una noción intrínseca de forma lógica) y iv) el producto de la descodificación lingüística. Las características (i) y (ii), como se ha visto, por un lado, dependen para su validez de 
la aceptación del supuesto veritativo-condicional y, por otro, descansan en una elección previa del sistema formal usado para la representación de los contenidos. Por su parte, las dos características restantes no parecen que arrojen más luz. Si la forma lógica no tiene por qué coincidir con la sintaxis permanece abierta la cuestión de cómo identificar la forma lógica de las oraciones, lo que lleva a un debate infructuoso sobre cuántas estructuras deben individuarse en cada oración, la llamada guerra de las estructuras.

Si uno quiere evitar la guerra, puede optar, como se hace de forma general en la literatura más reciente, por hablar de forma lógica en términos del producto de la descodificación lingüística, algo así como la representación semántica o el conjunto estructurado de los conceptos léxicos de una proferencia (Carston, 1997). Sin embargo, esta caracterización es igualmente problemática. Por un lado, lleva a una reduplicación de las nociones teóricas. Lo que uno tiene en una proferencia son items lingüísticos, representaciones semánticas (significados o conceptos, según distintas visiones) codificadas en símbolos (palabras), por lo que descodificar no es sino asignar desde el símbolo codificado una representación. Por ello, se dice que la descodificación lingüística produce una representación semántica/conceptual (Hall, 2008). Ahora bien, parece que esto es algo a lo que cualquiera llamaría significado. Entonces, ¿qué distingue la forma lógica del significado? Por otro lado, el conocimiento del sistema interno a la comprensión del lenguaje está lejos de ser entendido y queda sin explicar en qué consiste ni cómo se lleva a cabo esa descodificación: ¿tiene cada expresión asignada una representación específica y definida en nuestro léxico mental? ¿Cómo se combinan los elementos descodificados en un ítem lingüístico complejo como es una oración? Qué es el léxico, cómo se estructura en nuestra cabeza y se vincula con la sintaxis y cómo es el proceso de composición de significados son asuntos que están lejos de resolverse. En este sentido, es cuestionable que a esa forma, que es el producto de la descodificación, puede atribuírsele el calificativo lógica, pues, si bien las representaciones tendrán algún tipo de estructura, no puede decirse que tengamos una concepción clara de cómo es esa estructura y sus propiedades. Por ello, parece teóricamente más neutral hablar estrictamente de formas (o inputs) lingüísticas. 
Por tanto, la caracterización de la forma lógica tanto en términos sintácticos como desde un punto de vista semántico es problemática. El concepto de forma lógica parece indeterminado por lo que resulta difícil establecer una línea divisoria entre qué es la forma lógica de una proferencia y qué un desarrollo de la misma.

\section{La arbitrariedad del enriquecimiento}

El segundo problema está en conexión con el concepto de enriquecimiento. Los procesos de enriquecimiento en la derivación de la explicatura son problemáticos. No parece haber un criterio claro para decidir qué desarrollos de la forma lingüística cuentan como contenido de la explicatura. Los procesos invocados son arbitrarios e irrestrictos dando como resultado un error en la demarcación de las explicaturas.

Parece curioso que el pragmatista acepte que proferencias, como las de los ejemplos (11)-(16) anteriores, se enriquezcan con material como el provisto, mientras que haya otros elementos que no se permitan introducir. El siguiente ejemplo de Stanley (2002, p.162) ilustra una proferencia que, sin la contribución del constituyente entre paréntesis, contaría como una proferencia anómala gramaticalmente:

(18) Everyone has had the privilege of having John greet (her)

Entonces, ¿qué impide tomar her como un constituyente inarticulado para deshacer la anomalía? ¿Por qué éste no es un caso de explicatura mientras los anteriores sí? Desde la visión pragmatista nada lo impide dado que una explicatura es un desarrollo de la forma lingüística de la proferencia y se da por hecho que esta forma lingüística es incompleta. De ahí que, como señala Stanley, éste podría ser un caso de explicatura pero esto resultaría contrario a las intuiciones de los hablantes. Parece evidente que los hablantes aceptarían que esta proferencia no es gramatical, sin embargo no podría explicarse la falta de gramaticalidad dado que los hablantes podrían enriquecer 
la proposición automáticamente de forma pragmática, deshaciendo con ello la anomalía. En la misma línea, en los ejemplos siguientes, aparece el contraste entre proferencias gramaticales y no gramaticales:

(19) Al has finished

(20) Al has completed

Como señala Bach (1994, p. 128), una proferencia de (19) aceptable pragmáticamente debe ser declarada bajo ciertas circunstancias que permitan inferir el contenido enriquecido (speaking), pero nada impide que este mismo criterio se siga para el enriquecimiento de (20), de modo que las circunstancias apropiadas permitieran inferir lo que Al ha completado. Siendo así, no habría explicación a la apariencia y los juicios de los hablantes sobre la no gramaticalidad de (20). Así mismo, Vicente y Groefsema (2013, p. 115) muestran cómo la visión del enriquecimiento no puede explicar por qué (21) no es gramatical si puede enriquecerse como en (22):

(21) John brought the sandwiches but Ann didn't eat -- she ate the cakes instead

(22) John brought the sandwiches but Ann didn't eat them -- she ate the cakes instead

El proceso de enriquecimiento en los términos pragmatistas permite flexibilidad para alcanzar la interpretación correcta, pero no puede funcionar en casos como los anteriores puesto que no es posible la flexibilidad. En ningún caso, el intérprete puede derivar lo que $\mathrm{Al}$ ha completado en función de la proferencia. Por tanto, como explica Del Pinal (2018), el modelo de enriquecimiento predice flexibilidad en todos los casos, incluso en los que no la hay. Por lo que tomar unos enriquecimientos como dando lugar a la explicatura y otros no en estos casos parece una decisión arbitraria puesto que la diferencia no puede explicarse pragmáticamente. En cambio, la explicación puede provenir del léxico involucrado.

En este sentido, Groefsema (1995) apela a la necesidad de una explicación semántica de las condiciones en que un argumento puede dejarse implícito basada en las restricciones que impone el 
léxico. En el capítulo cuarto se verá un poco más acerca de estas restricciones que impone el léxico, por lo que ahora basta una idea sencilla aquí para comprender el argumento. Hay verbos, como beber, cuyo significado restringe el tipo de entidad que puede ser su argumento (cosa de tipo líquido); mientras otros verbos, como acabar o completar, no codifican ninguna restricción para las entidades de lo que serían sus argumentos. Siguiendo a Groefsema, sólo pueden dejarse implícitos aquellos argumentos cuya interpretación está suficientemente restringida como para que pueda recuperarse inmediatamente. De forma que el argumento que puede dejarse implícito está mucho más restringido de lo que la visión del enriquecimiento sugiere (Groefsema, 1995; Vicente y Groefsema, 2013).

Así mismo, hay también otros casos de carácter arbitrario, liberal e irrestricto del enriquecimiento. Uno de estos casos es el conocido ejemplo de Carston (2009, p. 35) en el que se dan varios de los tipos de enriquecimiento para la explicatura, los encaminados a la resolución del dominio del cuantificador, el contenido pragmático de las conectivas y la resolución de vaguedad:

(16) There wasn't enough [alcoholic] drink [to satisfy the people at the party] and [so] everyone [who came to the party] left [it] early

Pero como advierten Stanley (2002), Borg (2016) y Carston (2012), este contenido quizá no sea suficiente: ¿Y si hubiera habido bebida alcohólica pero no del tipo que comúnmente suele beber la gente? ¿Y si hubiera habido bebida alcohólica dentro de un armario cerrado con llave? Quizá también habría que especificar que los anfitriones no abandonaron la fiesta, el tipo de fiesta que era y la duración, dado que no parece lo mismo temprano aplicado a una fiesta con niños que a una fiesta nocturna de adultos. Como resultado se obtendría una explicatura como la siguiente (Borg, 2016, p. 351):

(20.1) There was not enough [easily available and attractive alcoholic] drink [to satisfy the people at the party] and [so] everyone [who came to the party as the result of an invitation] left [the party] [after an hour] 
Parece que no hay un criterio claro acerca de cuántos constituyentes son necesarios para finalmente obtener la explicatura. No hay un criterio para decidir si (16), (16.1) o un contenido aún más rico son el contenido correcto de la explicatura.

Dos casos más bastarán para comprender el carácter arbitrario de la noción. En un intercambio comunicativo como el siguiente, el Pragmatismo (Sperber y Wilson, 2015, p. 23) defiende que es razonable pensar que Pamela está comunicando algo más de lo que expresa la forma lingüística de su proferencia. Esto es así, debido a que tener dinero es verdadero de tener 50c., pero si Pamela tuviera 50c. su proferencia no sería relevante y en ese caso parece probable que hubiera escogido proferir que no tiene dinero:

\section{(23) Mark: We can't afford La Cantina \\ Pamela: I've got money}

Ahora bien, ¿el contenido añadido que comunica Pamela debe coincidir con lo que, según los pragmatistas, es lo que directa y explícitamente quiere expresar Pamela, es decir, la explicatura de la proferencia de Pamela? Según los autores es así debido a que para que la respuesta de Pamela pueda dar lugar a las implicaturas (que Pamela puede pagar la cena en La Cantina, que está dispuesta a pagarla y que pueden ir a cenar allí) el contenido de la forma lingüística debe enriquecerse. La siguiente cuestión que surge es ¿qué material debe aparecer como resultado del enriquecimiento? Según Sperber y Wilson (ibid., p. 24) "Basically, what she is referring to is an amount of money such that she is willing and able to pay for a meal at La Cantina, an amount which cannot be less than what the bill is likely to come to, but which may be quite a bit more". Como señala Borg (2016), el contenido enriquecido descansa finalmente en intuiciones (en este caso sobre cómo funcionan situaciones típicas) más bien que en criterios objetivos que aten de alguna manera el contenido enriquecido a la forma lingüística. Además, el contenido enriquecido no 
resuelve el problema de la vaguedad de la proferencia declarada puesto que de ser así sigue siendo tan vago como lo es la proferencia.

Por último, parece que la defensa de constituyentes inarticulados de tiempo y localización también descansa en decisiones injustificadas. En relación a estos se dan dos criterios para decidir la existencia del constituyente inarticulado. Por un lado, se apela a un criterio veritativocondicional. En este sentido, son constituyentes inarticulados aquellos constituyentes necesarios para determinar el contenido veritativo-condicional de las proferencias. Ahora bien, como se vio anteriormente, hay arbitrariamente muchos parámetros con respecto a los que podrían darse variaciones de significado en este sentido. Siendo así, a las explicaturas It's raining [in Paris] o I've had a very large breakfast [today] deberían añadirse parámetros como la zona horaria o los puntos exactos de localización y temporalización (podría ser que llueva en una zona de París mientras en otra no y puede que, como resultado del insomnio el hablante, haya desayunado a las cinco de la madrugada en la zona horaria $x$, lo que daría lugar a una implicatura diferente). Como dice Hinzen (2015), el hecho de que se tome que los pensamientos divergen de lo expresado resulta del intento de trazar las estructuras de pensamiento a través exclusivamente de intuiciones sobre las condiciones de verdad pero tales intuiciones no pueden decidir sobre los constituyentes de las proferencias. Por otro lado, se adopta un criterio comunicativo. Los constituyentes inarticulados deben tener un sentido comunicativo, más bien que uno metafísico, en correspondencia con el contenido que pretende comunicar el hablante. Siguiendo a Recanati (2002), la zona horaria es un constituyente metafísico de los eventos de habla, pero no es un constituyente comunicado puesto que con bastante probabilidad no es parte de la intención del hablante comunicar esta información que incluso podría desconocer. En contraposición, la localización en (24) debe ser un constituyente de la proposición expresada puesto que en realidad lo que pretendía comunicar el hablante es que ha llegado a un sitio concreto:

\section{(24) I have arrived}


Sin embargo, involucrar las intenciones de los hablantes como determinantes de lo que cuentan como constituyentes de las proferencias es problemático. Más adelante, se volverá sobre los problemas que implica la noción de intención del hablante, no obstante para seguir el argumento baste por ahora ver que no siempre los hablantes tienen un contenido concreto en mente para comunicar. Como advierte Hinzen (2015, p. 282), en (24) pudiera ser que mientras el oyente, que espera al hablante para pasar la Navidad en New York, enriquece la proferencia añadiendo una localización (p.e., I have arrived [in New York]) puede que el hablante no pueda referir su localización porque no sepa dónde ha llegado, puede que sepa que ha llegado a New York pero no sea capaz de identificar dónde está o puede que su vuelo se haya redireccionado y no sepa si está en la ciudad o no. Por tanto, la proferencia es compatible con la adición de la cláusula but I have no idea where.

En cambio, es posible ofrecer una explicación semántica de los constituyentes inarticulados de tiempo y localización, para lo que se seguirán los argumentos de Hinzen (ibid.). Por un lado, es evidente que hay cierto sentido en el que, cuando llueve, llueve en un lugar, o, cuando uno desayuna, desayuna en un momento determinado del tiempo. Ahora bien, pasar de este sentido metafísico a implicaciones en nuestra teoría del lenguaje parece un paso ilegítimo que responde a intereses teóricos. Siguiendo a Hinzen, cuando uno declara una proferencia realiza un evento (de habla) y, como todos los eventos, está sujeto a unas coordenadas espacio-temporales (en términos de Hinzen, el aquí y ahora de la proferencia) que se constituyen como aspectos intrínsecos del evento. Las lenguas cuentan con mecanismos gramaticales para expresar la referencia a las coordenadas espacio-temporales de los eventos a través del tiempo verbal y la persona gramatical. Suele ocurrir que el tiempo y la localización del evento de habla coinciden con el tiempo verbal y la persona gramatical de la proferencia. Así, por ejemplo, si uno dice (25) el tiempo verbal indica que está comiendo un bocadillo en este preciso instante de tiempo:

\section{(25) Estoy comiendo un bocadillo}


Cuando esto ocurre los hablantes tendemos a omitir información añadida sobre las coordenadas temporales en beneficio de una mayor eficiencia comunicativa pues dicha información resultaría redundante al estar ya codificada gramaticalmente. En cambio, cuando los aspectos espacio-temporales del evento de habla no coinciden con los de la proferencia, los hablantes añaden la información necesaria para que el oyente comprenda el desajuste entre el plano metafísico y el plano lingüístico. Como resultado, si uno declara (26) sin añadir una especificación temporal al tiempo verbal, su proferencia, no es que sea incompleta o que no sea gramatical, sino que estará violando la máxima de cantidad griceana:

\section{(26) Probé las lentejas}

En casos como éste, no hay posibles constituyentes inarticulados recuperables por el oyente que sirvan para los propósitos para los que fueron diseñados. El oyente no puede por sí mismo recuperar una fecha en que el hablante probó las lentejas y añadir un constituyente genérico como ayer no provee una solución mejor. El proceso de enriquecimiento que debería dar lugar a la interpretación correcta no puede generarla.

En los ejemplos en los que estaría involucrado un constituyente inarticulado de referencia de la localización la explicación es similar. La localización está codificada en la persona gramatical y referenciada en relación al hablante. Cuando un hablante declara (24), el aquí del evento del habla se establece en relación al propio evento de habla y su productor de forma que añadir here resultaría redundante si la localización de la proferencia coincide con la localización del evento de habla y de su productor.

En definitiva, la gramática codifica los constituyentes de tiempo y localización y cuando se produce un desajuste los constituyentes necesarios para referir a dichos aspectos metafísicos se dan explícitamente. Por tanto, no hay constituyentes inarticulados en proferencias como (11) y (12), 
éstas son proferencias completas y gramaticales ${ }^{49}$. Al contrario, los constituyentes explícitos pueden ser suficientes para que el oyente alcance una interpretación correcta de las proferencias a través de la información gramatical y léxica. Cuando esto no ocurre no parece que sea tarea del oyente recuperar la información no codificada explícitamente sino que es el hablante quien debe hacer explícito el contenido necesario.

De lo visto en este apartado puede concluirse que el proceso de enriquecimiento implica problemas en un doble sentido puesto que parece un proceso arbitrario que además no soluciona el problema de la determinación del contenido veritativo-condicional. Hay muchos parámetros que podrían contar como constituyentes añadidos, cada uno de los cuáles daría variaciones veritativocondicionales. Sin embargo, la decisión sobre cuántos y cuáles son esos parámetros necesarios para la explicatura parece arbitraria, haciendo descansar el criterio en último lugar en un criterio comunicativo acerca del contenido que el hablante pretende comunicar; es decir, en la noción de intención del hablante. No obstante, a pesar de ello, el contenido enriquecido, como se vio en el ejemplo de La Cantina, puede continuar siendo vago. Por otro lado, parece que algunos fenómenos para cuya explicación se apela a constituyentes inarticulados podrían explicarse no pragmáticamente mediante la gramática y la composición léxica. En consecuencia, el mismo concepto de enriquecimiento, así como el criterio veritativo-condicional para la demarcación de la explicatura se ven comprometidos.

\section{La demarcación entre la explicatura y las implicaturas}

El problema para demarcar la explicatura de las implicaturas gira en torno a dos cuestiones. Por un lado, las explicaturas parece que contienen contenido de lo que contaría como implicatura.

\footnotetext{
${ }^{49}$ Vicente y Groefsema (2013) presentan una visión alternativa en la que los constituyentes de lugar no son constituyentes inarticulados, sino que están disponibles en los esquemas de selección de los predicados de evento que codifican los verbos; es decir, los verbos codifican una representación conceptual del evento que incorpora sus argumentos, por lo que el lugar y el tiempo están en el escenario conceptual cuando se activa la representación. Sin embargo, sólo se especifican cuando se requiere contextualmente. De manera que usamos las palabras que creemos indispensables para que el oyente cree escenarios conceptuales en su mente, mientras las demás las omitimos.
} 
Por otro, no se necesita de la explicatura como garantía para activar las inferencias que dan lugar a las implicaturas, incluso la explicatura no tiene por qué ser recuperada por el hablante.

Para la primera cuestión, si se vuelve sobre el ejemplo (23) puede verse claramente que la explicatura contiene contenido de lo que contaría como implicatura. En (23), las implicaturas de la proferencia I’ve got money son que Pamela puede pagar la cena en La Cantina, está dispuesta a pagarla y pueden ir a cenar allí. Para alcanzar este contenido implicado se debe enriquecer la proferencia con algún contenido en relación a la cantidad de dinero que exprese la idea de que es una cantidad con la que se puede pagar un menú en La Cantina, que no puede ser menor de lo que probablemente será la cuenta aunque podría ser mayor. El problema es que este contenido enriquecido contiene parte del contenido implicado puesto que esa idea de una cantidad indeterminada pero suficiente no es más que la idea de que Pamela puede pagar la cena.

Parece difícil distinguir qué cuenta como explicatura y qué como implicatura. Desde el Pragmatismo se ha argumentado que una inferencia pragmática provee una explicatura si su alcance es local, i.e., si modifica una subparte del significado codificado lingüísticamente; mientras que si la inferencia pragmática tiene un efecto global (opera sobre una forma completamente proposicional) contribuye a una implicatura (Carston y Hall, 2012). Sin embargo, Borg (2016, p. 344) ha señalado que algunos enriquecimientos locales pueden capturar contenido de implicaturas. En el ejemplo siguiente:

(27) A: Do you want to have dinner?

B: I'm going to the cinema

La opción más plausible desde el Pragmatismo es establecer como implicatura de la proferencia de B que B no va a cenar con A esta noche y como explicatura para alcanzarla un enriquecimiento local desde GOING-TO-THE-CINEMA a GOING-TO-THE-CINEMATONIGHT. Sin embargo, no hay ningún mecanismo de restricción que impida que enriquezcamos 
también localmente desde GOING-TO-THE-CINEMA a GOING-TO-THE-CINEMA-AT-ATIME-THAT-MAKES-HAVING-DINNER-WITH-A-IMPOSSIBLE. Este último enriquecimiento, sin embargo, contiene contenido de las implicaturas.

A este respecto, Jary (2016) muestra que a menudo el contenido enriquecido que uno adscribiría con las intenciones de los hablantes se asemeja más a lo que se tomaría como implicatura que a lo que cuenta como explicatura. Jary ejemplifica esto partiendo del modelo de explicación pragmatista basada en conceptos ad hoc en el siguiente intercambio (p.36):

(35) Peter: Will Sally look after the children if we get ill?

Mary: Sally is an angel

Explicature: Sally is an ANGEL*

Implicatures: Sally is exceptionally good and kind

Sally is watchful and will help when needed

Sally will look after the children if Peter and Mary get ill

Para Jary, en lugar de entender ANGEL como un concepto que debe modificarse siguiendo el proceso pragmático del habla laxa, puede entenderse que el significado léxico de angel activa mecanismos de asociación dentro de la red conceptual que dan lugar a una inferencia dentro del proceso que deriva en la implicatura final. Por lo que es posible integrar el contenido de la explicatura dentro del proceso inferencial que da lugar a las implicaturas. Lo importante entonces es ver que este proceso inferencial parte de la información que hace disponible el léxico en el nivel de lo dicho, siendo éste la premisa para el proceso (ibid.):

(35') Sally is an angel.

Angels are good and kind.

Sally is good and kind.

Someone who is good and kind will look after the children if they get ill.

Sally will look after the children if they get ill. 
En la misma línea, Vicente y Groefsema (2013) argumentan que algunos ejemplos de enriquecimiento se corresponden mejor con implicaciones contextuales. Para ello discuten un ejemplo de Sperber y Wilson (2002, p. 607) en el que se toma (22b) como el contenido enriquecido de la proferencia de Lisa (p. 111):

22a. Alan Jones: 'Do you want to join us for supper?'

Lisa: 'No, thanks. I’ve eaten.'

22b. Lisa has eaten [supper] [this evening]

El proceso de enriquecimiento que se propone parte del contenido de la proferencia de Lisa que, junto a ciertas asunciones, da lugar a la explicatura en (22b). Simplificando un poco, para los autores el proceso es como sigue:

a) Lisa ha dicho No, thanks. I've eaten

b) Lo que dice Lisa debe ser relevante para Alan

c) Es relevante para Alan si explica el rechazo a la invitación

d) Una buena explicación para el rechazo es que Lisa ya haya cenado

e) Explicatura: Lisa ya ha cenado esta noche

f) Implicatura: Lisa está rechazando la cena porque ya ha cenado esta noche

Sin embargo, como explican Vicente y Groefsema (p. 112), en el ejemplo no está claro qué justifica la explicatura ${ }^{50}$ :

Alan has derived the assumption not because of Lisa's words 'I have eaten', but solely on the basis of her declining his offer of supper, expressed by 'no thanks' (i.e. Lisa does not want to join them for supper), together with his assumption in (d), so rather than (e) being an enriched interpretation of Lisa's utterance 'I have eaten', it would be a contextual implication of Lisa's utterance 'No thanks'.

\footnotetext{
${ }^{50}$ Otra discusión del ejemplo puede verse en Jary (2013, p. 649) donde la reconstrucción racional de la interpretación de (22b) incluye una inferencia material; es decir, la derivación de la implicatura realmente se realiza a partir de la asunción en (d) sin la intervención de principios pragmáticos sino sobre la base del contenido conceptual.
} 
No solo es posible integrar el contenido de lo que contaría como explicatura dentro del proceso inferencial de las implicaturas, sino que además no se cumple el requisito de la necesidad de la explicatura para derivar las implicaturas. Camp (2006) muestra que el hecho de que una interpretación pueda servir como input para posteriores interpretaciones no puede en sí mismo demarcar el límite de lo dicho, o de lo que cuenta como un significado primario, porque puede hacerse tanto desde el sarcasmo como desde la implicatura como muestran los ejemplos a continuación (p. 291):

For instance, suppose that Bill asks Alice whom they should invite for dinner; Alice could respond with a sarcastic utterance of:

(21) Well, Jane is always so utterly charming,

in order to implicate that Jane should absolutely not be invited. Similarly, suppose that Bill and Alice have a long- established routine of going to the movies on Thursday nights, and that the following exchange takes place between them early one week:

(22) Alice: So, which movie we should go see on Thursday?

Bill: Actually, I was thinking I might grab a beer with the guys from work.

Bill's utterance responds to Alice 's question by implicating that he doesn't plan to go to the movies on Thursday (and so has no reason to offer an opinion about which movie they should see). At the same time though, the obvious lameness of Bill' $s$ excuse combined with mutual knowledge of their routine, further implicates that he is intentionally breaking that routine, and perhaps even breaking up with Alice altogether.

En base a lo anterior, no parece necesario postular la explicatura como medio para garantizar las implicaturas ${ }^{51}$. Incluso, como muestran los dos ejemplos siguientes dados por Borg (2016), la existencia psicológica de la explicatura es cuestionable, de forma que puede no ser el primer contenido que el hablante recupera. Como primer ejemplo, la proferencia (30) ejemplifica una

\footnotetext{
${ }^{51}$ Cabe mencionar que Camp ofrece un requisito para que una interpretación indirecta pueda funcionar como input para posteriores implicaturas. El requisito es que para que una implicatura $Q$ sea activada desde una interpretación $P$ de una proferencia $U$, la intención del hablante de que $U$ sea interpretada como $P$ tiene que ser no sólo insinuada sino abierta y obvia. Este requisito lo pueden cumplir tanto las proferencias metafóricas como las sarcásticas. Cuando este requisito de obviedad falla, como ocurre con las metáforas de la alta poesía, entonces no es posible inferir una interpretación añadida.
} 
situación en la que una madre dice esto a su hijo que está montando una escena típica de berrinche tras haberse hecho un corte en un dedo:

(28) You are not going to die $e^{52}$

El argumento pragmatista remite a la necesidad de enriquecer el contenido (You are not going to die [inmediately] o You are not going to die [from that cut]) principalmente para obtener un contenido veritativo-condicional completo y adecuado a las intenciones del hablante sobre el que el niño pueda inferir la implicatura de que debe calmarse. Ahora bien, parece que el niño puede perfectamente realizar la implicatura sin necesidad de añadir el contenido enriquecido. En otro caso, cuando preguntas ¿Quieres ir a cenar? y tu acompañante responde Voy al cine, con mucha probabilidad inmediatamente piensas que tu acompañante no va a cenar a contigo, sin mediación de una proposición enriquecida (Voy al cine [esta noche]). Como afirma Borg (2016), lo único que hay en estos casos es el significado de la oración, el contexto conversacional y la implicatura producida por ambos. En muchas ocasiones, para alcanzar la implicatura puede ser suficiente seguir alguna pauta social general, p.e., cuando me responden con algo irrelevante a una invitación están rechazando mi invitación, sin necesidad de llevar a cabo los pasos que serían deductivamente necesarios (Borg, 2017).

Por tanto, los ejemplos anteriores muestran que no hay necesidad de la existencia psicológica de la explicatura. Así, la explicatura no es la premisa para las implicaturas ni tiene por qué ser el primer contenido que el oyente recupere. Al contrario, los contenidos enriquecidos propuestos se asemejan más a inferencias racionales en la derivación de la implicatura. En este sentido, parece mejor tomar las explicaturas, siguiendo a Jary (2013 y 2016), como implicaturas materiales, derivadas inferencialmente a partir del contenido explícito de la proferencia; a diferencia de las implicaturas conductuales que incluyen premisas para las que se usan datos extralingüísticos sobre la conducta verbal y los estados mentales del hablante.

\footnotetext{
${ }^{52}$ Recanati (2002) y Stern (2006).
} 
En conclusión, ninguno de los requisitos para demarcar la explicatura son explicativamente satisfactorios. En primer lugar, no parece posible definir qué cuenta cómo forma lógica y qué cuenta como explicatura, por lo que caracterizar la explicatura como un desarrollo de la forma lógica no ofrece garantía explicativa. En segundo lugar, el proceso de enriquecimiento es excesivamente arbitrario, no pudiendo identificar cuántos constituyentes inarticulados son necesarios y dejando en ocasiones el contenido igualmente vago a pesar del enriquecimiento; lo que compromete la caracterización de la explicatura como el contenido veritativo-condicional y relega el criterio para la decisión del material enriquecido a la noción de intención del hablante. En tercer lugar, la explicatura puede incluir contenido de lo que se tomaría como implicatura, siendo plausible una concepción del contenido enriquecido como parte del proceso inferencial que deriva en las implicaturas. Por último, el contenido enriquecido no sólo no es necesario para activar el proceso inferencial que da lugar a las implicaturas sino que tampoco es necesario que se procese. La noción de explicatura parece descansar en última instancia en las nociones de contexto e intención del hablante.

\subsection{Un contexto muy amplio}

Según el Pragmatismo, para acceder al contenido semántico se necesita determinar las referencias de las expresiones sensibles al contexto y suplir los huecos semánticos de la estructura superficial de las oraciones con constituyentes a través de información del contexto. Hecho esto, el oyente obtiene un contenido más rico que el codificado en las proferencias. En este sentido se dice que la semántica sin la apelación al contexto falla en determinar el contenido semántico. A este respecto cabe preguntarse dos cuestiones importantes en la visión pragmatista ¿Cómo contribuye el contexto al contenido semántico? ¿Qué es el contenido semántico?

En relación al contexto, en el apartado sobre la indexicalidad se mostró que la cuestión de los indéxicos intencionales y el problema en relación al límite de parámetros contextuales llevó al 
Pragmatismo a ampliar el alcance del contexto adoptando la noción de contexto cognitivo y anulando con ella la distinción minimalista entre contexto estrecho y amplio. Las teorías actuales subrayan la importancia de establecer el contexto correcto para la interpretación de las proferencias y la elección de éste, desde esta perspectiva, se sugiere que proviene del producto de la combinación de procesos cognitivos, de los factores circundantes a las proferencias y los aspectos comunicativos que están involucrados. Atendiendo a esto, como factores de contexto se incluyen el conjunto de asunciones de background (Recanati, 2002; Sperber y Wilson, 1986), las coocurrencias de experiencias previas (Mazzone, 2015), el contexto situacional y las intenciones del hablante. En definitiva, el contexto es visto como una construcción psicológica que incluye un amplio (si no total) conjunto de las representaciones mentales (Carston, 2008 y 2012; Recanati, 2004; King y Stanley, 2005; Hall, 2008).

De los múltiples recursos de información necesarios para la recuperación de la explicatura la intención del hablante cobra un lugar predominante. Para el Pragmatismo las intenciones del hablante no son más que estados mentales representacionales ${ }^{53}$. Cuando un hablante declara una proferencia se encuentra en un estado mental que representa las cosas de una forma determinada e informa al oyente de esta representación, quien a su vez debe identificar esa información con los recursos que tenga disponibles. Siguiendo esto, el objetivo fundamental en la comunicación es interpretar las proferencias a través de un proceso inferencial (subpersonal) identificado la intención del hablante, por lo que el contenido semántico y la explicatura corresponden en definitiva al contenido que tiene en mente el hablante. En otras palabras, el significado descansa en el contenido que tiene en mente el hablante y que comunica a través de su proferencia; mientras que la explicatura descansa en la capacidad del oyente para construir el contexto correcto con el que identificar la intención del hablante, de forma que el criterio que rige el enriquecimiento es un criterio comunicativo acerca de los constituyentes que el hablante pretende comunicar (Carston,

\footnotetext{
${ }^{53}$ La Teoría de la relevancia distingue dos niveles de intención: la intención informativa que corresponde al conjunto de proposiciones que informa el hablante sobre su representación del mundo y la intención comunicativa que remite a la intención del hablante de que el oyente reconozca la primera (Sperber y Wilson, 1986). En adelante se utilizará intención del hablante para referir al nivel de la intención informativa.
} 
2002a y 2008; Sperber y Wilson, 1986 y 2015). Sin embargo, este modelo es problemático, tanto en relación a la noción de contexto propuesta como a la noción de intención del hablante como base para caracterizar el contenido semántico.

En primer lugar, la noción de contexto cognitivo es excesivamente amplia no permitiendo distinguir los distintos tipos de información involucrados en la comunicación (Stanley, 2002). Por un lado, una composición enriquecida que utilice toda la información que cuenta como contexto cognitivo es más compatible con la propia definición de implicatura que con la de explicatura desarrollo inferido de la forma lógica. Por otro lado, para el Pragmatismo, todos los recursos de información están implicados en la recuperación de la explicatura, sin embargo apelar al contexto en este sentido equivale en definitiva a no explicar en qué consiste el contexto. Las proferencias son eventos de habla particulares en situaciones concretas. Por esta razón debe poderse distinguir lo que particularmente comunica una proferencia, que debe ser variable en algún sentido, de la información que cuenta como el conocimiento compartido entre los hablantes, que debe ser en cierta medida estable (Gerrig y Littman, 1990). Si se toma toda esta información como parte de un todo entonces se deja sin efecto la misma noción de contexto (Jackendoff, 2002). Es decir, una noción de contexto tan excesivamente amplia equivale a no tener contexto. Por tanto, se necesita algún tipo de demarcación entre los diferentes tipos de información.

Ciertamente cuando estamos inmersos en una conversación a menudo accedemos a información no codificada en las palabras de nuestro interlocutor. En (29) el oyente tiene que acceder al conocimiento genérico sobre restaurantes y los eventos que se dan en ellos para entender por qué la conducta de los camareros es relevante para elegir un restaurante (Gerrig y Littman, 1990, p. 331):

(29) I'll never eat at the Stewpot again. The waiters there are terribly rude

Ahora bien, esto no implica que tal conocimiento forme parte del significado de las proferencias; más bien, lo que indica es que hay unas estructuras de conocimiento compartidas 
entre los hablantes. Tampoco implica que este conocimiento forme parte de lo que cuenta como el contexto de la proferencia; aunque sí indica que en los procesos de comprensión y producción lingüísticos está involucrado el sistema conceptual de alguna manera. En (29), el significado léxico de waiters incluye la información que define la función, características y conducta de los camareros tipo puesto que el significado léxico no tiene por qué ser idéntico a la entrada de diccionario. Este contenido rico de la entrada léxica waiters es lo que conecta con el conocimiento acumulado.

En segundo lugar, una defensa del contenido semántico como asunto radicalmente dependiente del contexto en este sentido amplio se enfrenta al problema de explicar ciertos hechos semánticos. Para empezar, se encuentra con la dificultad de explicar la inteligibilidad de las oraciones sin contexto o en ausencia de los datos contextuales que efectivamente lleven a conseguir identificar la intención del hablante. En relación a esto, puede recordarse la proferencia (10) del juego de yincana en el que parece evidente que los niños comprenden el significado de la proferencia y ésta, de hecho, es la razón por la que encuentran la solución al juego:

(10) Este objeto tan deseado por las plantas tiene la forma de una larguísima serpiente

Además, algunos estudios (Briscoe, Copestake y Boguraev 1990; Verspoor, 1996, 1997; Zarcone, 2014) sobre la metonimia lógica entrañan problemas en esta misma línea. En primer lugar, muestran que en muchos casos hay un acuerdo intersubjetivo en las interpretaciones de oraciones con metonimia lógica con o sin contexto. En segundo lugar, los siguientes ejemplos (Zarcone, ibid., p. 45) muestran que hay ciertos cambios de significado que son regulares:

(30) She was enjoying the first coffee of the day

(31) She was enjoying the first cigarette of the day 
De forma que si los eventos encubiertos dependieran enteramente del contexto no podría explicarse ni esta regularidad ni el acuerdo intersubjetivo en las interpretaciones. ¿Cómo explicar fenómenos que implican cierta estabilidad apelando a una noción altamente variable como la de contexto? ¿Cómo se explica que haya cambios de significado regulares o la sistematicidad en la omisión de ciertos elementos en nuestras proferencias? Se necesita una explicación acerca de los procesos de recuperación de explicaturas que sea compatible con los fenómenos que reflejan sistematicidad en el lenguaje. Desde los estudios anteriores se observa que el acuerdo se produce en metonimias lógicas que tienden a la tipicalidad y la convencionalidad, así como que hay una gran cantidad de casos de metonimia lógica explicables desde un punto de vista semántico, donde los eventos encubiertos son compatibles con una explicación acerca de la composición léxica y según el cual los eventos se recuperan a través del léxico convencionalizado. Así, de la misma forma que hay metonimias regulares o metáforas muertas, hay también significados léxicos más o menos convencionalizados y usos sistemáticos de elementos omitidos. Estos casos muestran que el factor de convencionalidad es un factor importante en los procesos de producción y comprensión de las proferencias que el Pragmatismo no tiene en cuenta ni puede explicar.

En tercer lugar, no parece que el contexto pueda cumplir el rol constitutivo que se le supone. ¿Cómo puede el contexto, dada la asimetría epistémica entre hablante y oyente, determinar lo que el hablante realmente tiene en mente? Sólo el hablante tiene acceso directo a lo que tiene en mente. Si el hablante no explicita todo aquello que quiere decir, no es suficiente con la información contextual, se necesita la intención del hablante. Así, si en una fiesta hay varias mujeres y alguien declara (9) She is dangerous, no hay manera de que el contexto, ni amplio ni estrecho, ayude a determinar la referencia de she. Ésta sólo puede resolverla el hablante, por lo que se necesita incluir las intenciones del hablante como factor de contexto para que éste pueda suplir los huecos que se supone que debe suplir. Sin embargo, como explica Bach (2006a y 2006b) las intenciones del hablante no pueden contar como parte del contexto. Por un lado, para que el contexto pueda cumplir el rol explicativo que se le presupone éste debe ser algo compartido para 
hablante y oyente pero las intenciones del hablante no cumplen este requisito. Por otro lado, debe recordarse que la explicatura descansa en la capacidad del oyente de construir el contexto correcto para identificar la intención del hablante, por lo que no es posible añadir la intención del hablante al conjunto de los recursos de información que el oyente necesita para alcanzar la misma intención del hablante. La intención del hablante en todo caso sólo puede contar como conclusión y no como parte del conjunto de premisas.

No obstante, involucrar las intenciones del hablante en la teoría semántica, ya no como factor de contexto sino como una noción sobre la que hacer descansar el contenido semántico, no está exento de problemas.

Para comenzar, no está claro cómo debe caracterizarse la noción. Por un lado, si por intenciones comunicativas se entiende representaciones explícitas o conscientes de objetivos comunicativos como resultado de un razonamiento deliberado, entonces podrían no existir para muchas de nuestras proferencias. Al contrario, parece que nuestra conducta lingüística es una actividad bastante automática que ejecutamos en base a rutinas sociales o hábitos (Mazzone y Campisi, 2010). Los hablantes construyen sus producciones lingüísticas en muchas ocasiones imitando de forma espontánea la conducta lingüística de sus interlocutores en muchos niveles lingüísticos -léxico, gramatical, fonológico y semántico-, de forma que en los diálogos ordinarios los interlocutores repiten palabras, estructuras gramaticales y entonaciones producidas por interlocutores precedentes (Pickering y Garrod, 2006). Así mismo, como explica Borg (2017), los hablantes delegan en el conocimiento compartido y estándares sociales de la comunidad el trabajo de la deducción para alcanzar la implicatura, de forma que este mismo conocimiento permite que los oyentes no sigan los pasos deductivamente necesarios para su comprensión. De esta forma el proceso de comprensión descansa en gran medida en estas pautas sociales. Por otro lado, en muchas ocasiones ocurre que los hablantes no tienen un contenido concreto en mente para comunicar: 
Compare the case where we are in Oxford and I say 'I want to travel to London'. If you then tell me that there is a bus to London from the end of the street, I can then tell you that I don't want to take a bus. Given my others beliefs (about how slow buses are, etc.) and desires (I prefer train travel), I'm in position to sharpen up my original claim: I want to travel to London but not by bus. Yet none of this shows that the content of my earlier thought needed to contain something about buses -indeed just consider how great the cognitive burden would be if our thoughts needed to incorporate relevant possibilities at the very outset, we would be unlikely to be able to move beyond entertaining a single thought. (Borg, 2016, p. 347-348)

Si se analizan algunos de los ejemplos que han ido surgiendo en el trabajo puede verse que esta indeterminación es algo que ocurre con bastante frecuencia. Es improbable que si uno dice Miguel es calvo esto indique que tenga en mente un criterio preciso que resuelva la paradoja de sorites. En la proferencia (24) I have arrived, como ya se vio, pudiera ser que el hablante no pueda describir o referir su localización y, por tanto, la proferencia es compatible con la adición de la cláusula but I have no idea where (Hinzen, 2015, p. 282). En I've got money del ejemplo (23) no cabe la pretensión de que el hablante tenga en mente una cantidad precisa para pagar la cena. En relación a (13) Every bottle is in the fridge, mientras el oyente enriquece la proferencia para precisar el alcance del cuantificador a Every bottle [that Mary bought yesterday], puede que el hablante no sepa cuántas botellas hay, si todas las botellas que hay en el frigorífico son para la fiesta y quién las comprado ni cuándo; simplemente en un sentido más general, sabe que si hay algo interesante para beber en la fiesta estará en el frigorífico e incluso su conducta verbal puede ser el resultado de un modo automático de actuar en función de las convenciones y acciones rutinarias involucradas (no es difícil imaginar una situación en la que, en medio de una multitud de gente que se encuentra en tu casa para una fiesta y mucha gente te habla al tiempo, respondas (13) de forma bastante automática e irreflexiva a alguien que te pide bebida en medio del bullicio). Además, aún en el caso de que el hablante posteriormente admita haber pretendido comunicar el contenido enriquecido, de aquí no se sigue que éste haya sido el pensamiento expresado en la proferencia; más bien, parece que el contenido enriquecido responde a una racionalización post hoc 
de los datos (Gauker, 2010; Heck, 2014; Hinzen, 2015). Ante esto se puede optar, como hace la Teoría de la relevancia, por una noción débil de intención. Sin embargo, no parece que ésta sea una perspectiva mucho mejor puesto que si se entiende que las intenciones son subpersonales resulta difícil saber en qué consisten, por lo que la indeterminación persiste.

En segundo lugar, el papel de las intenciones en los intercambios comunicativos puede variar según las culturas y contextos de forma que en ocasiones las intenciones pueden no definir el significado. Así, hay quien puede pensar que un acto de habla pueda no significar un insulto, pese a la intención del hablante de significarlo, hasta que el oyente decida considerarlo como tal (Duranti, 1992). En otras situaciones, alguien puede proferir un término peyorativo sin la intención de afirmar un contenido despectivo, aunque a pesar de ello el contenido del término seguirá siendo peyorativo, como ocurre en las proferencias siguientes:

(33) Ángel le dijo a su compañero que era un marica

(34) "Nigger" es un término inglés para negros

(35) Mi vecino no es un panchito, es peruano

El contenido despectivo se mantiene a pesar de utilizar un estilo indirecto, un uso metalingüístico o pretender cancelar el contenido despectivo con la negación estándar ${ }^{54}$. Desde otra perspectiva, a pesar de que el hablante tenga la intención de adscribir el contenido despectivo sólo a la persona a quien se dirige, está adscribiendo el contenido despectivo a todo el grupo. En relación a los slurs hay un acuerdo general en que el contenido despectivo tiene autonomía respecto de las intenciones del hablante. Dicho contenido está inmerso en el significado codificado por las expresiones y éste no se determina completamente por el estado interno del hablante sino por las prácticas sociales externas de la comunidad, de forma que los

\footnotetext{
${ }^{54}$ En general, usamos la negación de una manera estándar para hacer falso lo verdadero y viceversa pero la negación en el lenguaje natural no se restringe a ésta (Horn, 2001). En casos como (35), la cancelación del contenido despectivo requiere, no sólo una negación metalingüística sino además una indicación precisa de que el término es moralmente inadecuado (Saka, 2007).
} 
slurs tienen cierta sistematicidad no explicable por la intención del hablante (Anderson y Lepore, 2013; Camp, 2013; Hom, 2008; Richard, 2008; Saka, 2007).

Por último, no parece posible exigir que la comprensión de las proferencias por parte del oyente precise la reconstrucción de las intenciones del hablante. Interpretar la intención del hablante requiere la intervención de funciones esencialmente pragmáticas como lo que la psicología cognitiva llama teoría de la mente, i.e., una representación de segundo orden de los estados mentales de uno mismo o de otros a través de un sistema inferencial (Premack y Woodruff, 1978). Sin embargo, no parece que todos los intérpretes tengan esta habilidad. Pacientes con daños cerebrales -tanto en el hemisferio derecho como en el lóbulo frontal-, así como pacientes con esquizofrenia (Langdon, Davies y Colthear, 2002; Mitchley, Barber, Gray, Brooks y Livingston, 1998), TDAH (Crespo, Manghi, García y Cáceres, 2007) o algunos pacientes con autismo ${ }^{55}$ (Baron-Cohen, Leslie y Frith, 1985) presentan problemas para percibir intenciones comunicativas. A pesar de ello, responden de manera adecuada en los intercambios comunicativos con respecto al nivel literal o explícito de las proferencias. Desde esta perspectiva, no puede decirse que no sean hablantes competentes puesto que, en cuanto conocen el léxico, la gramática y el funcionamiento de la sintaxis, son capaces de generar y comprender oraciones, así como comunicarse y expresar sus pensamientos. Esto entra en contraste con la visión que hace descansar el contenido semántico en la intención del hablante puesto que, si para acceder al contenido semántico de las proferencias se requiere inferir las intenciones del hablante, no se explica cómo estos sujetos pueden comprender las proferencias y mantener intercambios comunicativos teniendo problemas para representarse las intenciones del hablante.

Dados los argumentos anteriores, un modelo del contenido semántico que descansa en las nociones de contexto cognitivo y, en última instancia, en la noción de intención del hablante resulta

\footnotetext{
${ }^{55}$ En relación al autismo deben aclarase un par de cuestiones. Debido a la controversia que suscita la inclusión del síndrome de Asperger como una variante de autismo conviene señalar que para el presente argumento debe excluirse el síndrome de Asperger pues existen estudios que muestran que los afectados presentan, además de disfunciones pragmáticas, déficits en las habilidades semánticas (Martín-Borreguero, 2005). Debe mencionarse además que el estudio de Happé (1993) indica que algunos autistas son capaces de atribuir estados mentales a terceros.
} 
inadecuado. La noción de contexto cognitivo parece excesivamente amplia, no permitiendo distinguir los distintos tipos de información necesarios y debiendo incluir como factor contextual la propia intención del hablante para lograr su propósito. A su vez, la noción de intención del hablante es indeterminada, no determina el significado en algunos casos y requiere para su interpretación de la teoría de la mente.

En consecuencia, parece mejor caracterizar el contexto en un sentido clásico para explicar los procesos lingüísticos. El contexto, entendido como el campo común saliente, el estado de la conversación, los interlocutores y los aspectos ambientales, tiene un rol epistémico en el sentido en que proporciona la información para efectuar inferencias sobre las intenciones del hablante y llevar a cabo implicaturas. Pero, salvo determinar las referencias de los indéxicos puros, el contexto no cumple un rol constitutivo del contenido de las proferencias. Como afirma Bach (2006b), el contexto puede restringir lo que un hablante puede significar con una proferencia dada y lo que un oyente puede interpretar (lo que es plausible esperar de un intercambio comunicativo), pero en ningún caso puede contribuir con constituyentes al contenido semántico. Además, siguiendo a Bach, no es la intención del hablante la que dota de significado a una expresión, sino que la expresión ya tiene propiedades semánticas y es al ser declarada que el hablante provee al oyente con la parte semántica que es la base para representar su intención.

No se trata entonces de negar el rol que cumplen las intenciones de los hablantes en la comunicación sino de demarcar el ámbito en el que están inmersas. En este sentido, las intenciones de los hablantes deben quedar fuera del ámbito de la semántica. Si se quiere explicar el significado del lenguaje natural se necesita incorporar nociones normativas con cierta estabilidad más allá de la psicología de los hablantes. La visión pragmatista hace descansar la semántica en el contenido comunicado por el hablante aunque el enriquecimiento descansa finalmente en la capacidad del oyente de construir el contexto para la interpretación correcta, lo que quiere decir que en última instancia la explicatura recae en el oyente. Esto trae como consecuencia que el contenido semántico puede ser distinto para hablante y para oyente. 
Ciertamente el desacuerdo entre los hablantes en los intercambios comunicativos es frecuente. Por un lado, los hablantes a menudo tienen contenidos mentales para comunicar más ricos de lo que las palabras les permiten. Por otro, no necesariamente se tienen estructuras conceptuales idénticas en conexión con el lenguaje, lo que afecta a las asociaciones que se hagan al interpretar las proferencias (Jackendoff, 2002). Para reducir la divergencia, hablante y oyente hacen esfuerzos comunes. El hablante llevará a cabo su selección léxica en función de la audiencia que tenga en frente y el oyente intentará alcanzar la información comunicada utilizando la proferencia del hablante y el contexto, pero, dado que el contenido mental del hablante es más rico, probablemente entienda parcialmente los significados (Jackendoff, 2002; Johnson, 2007; Johnson-Laird, 1987; Putnam, 1975).

Si bien una completa convergencia en los estados mentales que subyacen a las producciones lingüísticas no está garantizada, una incompleta comprensión del significado puede ser suficiente en muchos casos para la comprensión de las proferencias. A menudo hacemos selecciones léxicas incorrectas e incluso, como explican Sanford y Garrod (1998, p. 178), si aparecen anomalías no las descartamos:

Such effects are generally known under the heading of the Moses illusion, in which individuals fail to notice that a word that is outside the linguistic focus of a sentence is inappropriate (e.g., Reder \& Kusbit, 1991; van Oostendorp \& Kok, 1990). In the classic case of asking "How many animals of each sort did Moses put on the Ark?" individuals often fail to notice that it was not Moses but Noah who built the Ark (Erickson \& Mattson, 1981).

De alguna manera el sistema de comprensión y producción lingüística es indulgente con los errores, teniendo en cuenta que, según algunos estudios (Ferreira y Patson, 2007; Fox Tree, 1995), los hablantes cometen errores hasta seis veces por cada cien palabras. A menudo nos manejamos con el error en la conversación a no ser que haya algo que haga que reajustemos la selección. Así mismo, es común que apliquemos términos, como los adjetivos gradables, en función de lo que 
esperamos como normal según juicios de tipicalidad y marcos sociales, sin necesidad de mayor precisión a no ser que, como en el caso anterior, haya algo que nos obligue a reajustar y precisar el contenido (Jackendoff, 2002). Como ponen de manifiesto algunos estudios (Ferreira, Ferraro, y Bailey, 2002; Ferreira y Patson, 2007), el sistema de comprensión puede no resolver las ambigüedades y los errores debido a que no todos ellos son relevantes comunicativamente, de forma que mantenerlos no es un problema para una comprensión suficientemente buena de los significados de las proferencias, y a que el sistema a menudo no tiene tiempo de considerar todos los recursos de información. La realidad de los intercambios comunicativos -rápidos, con abundante producción de expresiones, a menudo desestructurados- es más compatible con un sistema de producción y comprensión lingüística que no crea representaciones precisas y completas, que con un modelo en el que el oyente debe considerar todos los recursos de información, recuperar constituyentes e inferir el contenido que está en la mente del hablante. Un sistema lingüístico que considere todos los recursos implica una excesiva carga cognitiva, así como requiere de una teoría de la mente, por lo que parece biológicamente inviable o, al menos, poco ajustado a la ecología mental.

Siguiendo esto, la semántica no parece tanto una cuestión de enriquecimiento de un material no explícito que está en la mente del hablante sino más bien una cuestión de explicar un nivel de significado compartido entre los hablantes, con cierta estabilidad, que permita la convergencia necesaria como garantía de la comunicación.

\subsection{Algunas evidencias en contra del modelo de inferencia post-léxica}

En este apartado se proponen algunas evidencias que contradicen las tesis pragmatistas. Se argumenta que el proceso inferencial post-léxico que propone el Pragmatismo para la recuperación de la explicatura y la explicación del procesamiento lingüístico no encaja con los datos aportados desde otros estudios. En este sentido, no hay evidencias de la existencia de inferencias pragmáticas 
para la recuperación de eventos en el procesamiento de la metonimia lógica, así como que el procesamiento lingüístico es incremental y la integración con el conocimiento general es temprana.

En primer lugar, como se vio, un tipo frecuente de proferencias que el Pragmatismo defiende que deben enriquecerse pragmáticamente para proveer contenido no lexicalizado son aquellas en las que se da el fenómeno de la metonimia lógica. Una proferencia como (30) puede interpretarse como que el sujeto estaba disfrutando bebiendo el café, preparando el café, oliendo el café o moliendo el café. En estos casos, se argumenta que debe suplirse un evento encubierto en la forma superficial para alcanzar la interpretación correcta a través del proceso de enriquecimiento libre (Carston, 2002b; Recanati, 2002):

(30) She was enjoying the first coffee of the day

Sin embargo, esta perspectiva es problemática. Por un lado, implica un problema de sobregeneración de interpretaciones, al no contar con un mecanismo de restricción de las posibles interpretaciones. Por otro lado, una serie de experimentos recopilados en Zarcone (2014) que miden parámetros como las latencias de lectura en tareas de reconocimiento de oraciones metonímicas muestran que la influencia del contexto es bastante menor. En metonimias convencionalizadas, como disfrutar el café o comenzar el periódico, no parece que haya inferencias pragmáticas en la recuperación de los eventos encubiertos sino que la naturaleza del léxico que conforma el contexto oracional lingüístico ofrece una interpretación por defecto que el hablante tiende a omitir y el oyente recupera igualmente por defecto en función de su conocimiento léxico. Es decir, sabemos que los periódicos típicamente se leen o que los cafés se suelen beber y este conocimiento es parte de la entrada léxica de periódico y café. Los hablantes omiten el evento en estos casos precisamente porque están seguros de que el oyente comprenderá la proferencia sin necesidad de efectuar inferencias añadidas a su conocimiento léxico. Si ocurre que el evento es menos típico o no corresponde a las preferencias léxicas del verbo entonces se necesita expresarlo para que el hablante alcance la interpretación. De esta forma, los factores que determinan la 
recuperación de eventos encubiertos remiten a factores semánticos como la estructura y composición del léxico, el contexto lingüístico oracional o la tipicalidad de la metonimia (Briscoe et al., 1990; Verspoor, 1996 y 1997; Zarcone, 2014).

En segundo lugar, estudios recientes con experimentos realizados a través de técnicas electrofisiológicas de resolución temporal -electroencefalograma (EEG), potenciales relacionados a eventos (ERP) y magnetoencelografía (MEG)- que graban las respuestas eléctricas tras la lectura de oraciones han permitido mostrar que i) el procesamiento lingüístico se da incrementalmente palabra por palabra, ii) hay una integración del significado de las oraciones con el conocimiento general en el proceso de comprensión y iii) esta integración es temprana.

El procesamiento lingüístico se da incrementalmente palabra por palabra de forma que cada incremento de la oración influencia el análisis subsiguiente. Por un lado, el estudio del conocido como efecto $\mathrm{N} 400^{56}$-una gran amplitud de onda con un incremento de la latencia- ha mostrado que a mayor facilidad de conectar la semántica léxica de una palabra con el contexto semántico precedente de la oración, menor es la amplitud de onda de la respuesta eléctrica grabada y que, además, el efecto decrece con cada incremento de la oración (Petten y Kutas, 1990). Por otro lado, el estudio de la conexión entre el procesamiento del lenguaje y la memoria ha conducido también a la conclusión de que el procesamiento del lenguaje es incremental. En este caso, los experimentos realizados han mostrado que las oscilaciones theta, que miden la actividad en el hipocampo, son mayores y se dan de forma incremental en la medida en que las palabras van apareciendo, así como cuanto mayor es el contexto lingüístico (Covington y Duff, 2016; Piai et. al, 2016).

\footnotetext{
${ }^{56}$ A pesar de que el efecto $\mathrm{N} 400$ ha sido invocado en la literatura inmediatamente posterior a su descubrimiento como un índice de la contribución de factores contextuales en la comprensión lingüística, en la actualidad no parece que esté clara esta función. Se ha mostrado que el efecto se reduce debido a un mayor contexto lingüístico, la repetición de palabras y la condición de tipicalidad del léxico. En base a esto, se pueden encontrar diferentes visiones acerca de la funcionalidad que expresa el efecto: procesamiento post-léxico, análisis semántico al nivel de la palabra o integración del significado de la oración completa (Pickering y Garrod, 2006). Sin embargo, se ha comprobado que el efecto se produce no solo en lectura de oraciones sino también en discursos enteros y en ámbitos no lingüísticos como el reconocimiento de voces, escenas y fotografías (Kutas y Federmeier, 2011). Por ello, parece que aún queda mucho por entender acerca de los procesos implicados que dan lugar al efecto. No obstante, este desconocimiento no invalida las consecuencias argumentadas en el presente trabajo. Los datos revelan que la lectura de oraciones concretas fuera de contexto con violaciones semánticas y contradicciones con la información de conocimiento general producen la misma amplitud de onda, se integran al mismo tiempo y de forma temprana.
} 
Las respuestas grabadas confirman el procesamiento palabra por palabra pero también que hay una conexión entre el procesamiento de palabras entrantes y el conocimiento semántico acumulado y previamente adquirido. En este sentido, los mismos estudios evidencian una correlación entre la actividad producida en el hipocampo y el procesamiento lingüístico. Hay un aumento de la actividad en el hipocampo a medida que las palabras aparecen, así como en tareas de predicción de palabras. Este aumento de la actividad del hipocampo lleva a la idea de que una gran actividad en él está relacionada con la tarea de asociación semántica de palabras y que, por tanto, el procesamiento de las palabras se asocia con el conocimiento acumulado, de forma que el hipocampo ayuda a recombinar y restaurar elementos de la memoria en la comprensión lingüística representaciones individuales de palabras, patrones de coocurrencia léxica y probabilidades sintácticas-. Esto puede explicar que algunos estudios (Jastrzembski, 1981; Pexman, Hargreaves, Edwards, Henry y Goodyear, 2007) hayan registrado que el acceso a los significados múltiples y a palabras semánticamente ricas sea más rápido.

Además, parece que esta integración del conocimiento acumulado y el significado es temprana. En este sentido, Kutas y Federmeier (2011) han mostrado que las violaciones semánticas y las contradicciones con la información procedente de lo que se tomaría como el conocimiento general producen el efecto N400. Ahora bien, el tipo de efecto producido en ambos casos es muy similar, tanto en el inicio (en ambos casos se produce una latencia de $-300 \mathrm{~ms}$ ) como en picos de latencia y distribución topográfica (Hagoort, Hald, Bastiaansen, y Petersson, 2004). Por tanto, puede decirse que ambos tipos de información se integran al mismo tiempo y de forma temprana. Los experimentos recopilados en Zarcone (2014) vienen a confirmar lo anterior mostrando que la integración del conocimiento general sobre eventos es temprana en la interpretación de proferencias con metonimias lógicas. Según estos, el conocimiento general de eventos se activa inmediatamente produciendo un recurso de expectativa para inputs entrantes, contribuyendo a facilitar el procesamiento. Cuando el conocimiento general se asocia con los ítems lingüísticos de la oración, dando la pista para la determinación del evento encubierto, los participantes son más 
lentos en decidir si el evento ha sido o no mencionado, así como es más difícil que rechacen eventos con una alta tipicalidad a pesar de no haber sido mencionados. En otras palabras, ocurre a menudo que los ítems lingüísticos se asocian con elementos del conocimiento general y en estos casos los hablantes, dada su alta condición de tipicalidad, tienen dificultades para discernir si dichos elementos del conocimiento general estaban explícitos o no en las proferencias.

La cuestión entonces es que estas evidencias contradicen las tesis pragmatistas. Siguiendo el Pragmatismo, la comprensión lingüística se da en dos pasos, la descodificación léxica y el proceso inferencial que conduce, mediante enriquecimiento, a la explicatura ${ }^{57}$. Sin embargo, parece que el procesamiento lingüístico 1) es incremental, lo que contradice la secuenciación en dos pasos pragmatista, 2) está influenciado tempranamente por la integración del conocimiento general y por la actividad de asociación de palabras con la información que se activa en el hipocampo, mientras que siguiendo la visión pragmatista las inferencias para el enriquecimiento son post-léxicas y la integración del conocimiento general debería ser tardía, prediciendo también un acceso más lento a palabras semánticamente ricas debido a la realización de inferencias pragmáticas. Por tanto, el conjunto de las evidencias propuestas contradice la idea de que el contenido enriquecido es recuperado a través de procesos inferenciales post-léxicos desde la forma lingüística de las oraciones; en cambio, es compatible con una visión del contenido enriquecido propuesto como implicatura. No parece haber inferencias desde una proposición mínima a una enriquecida, sino que el proceso de comprensión es incremental y el rol de la semántica léxica parece mucho mayor de lo que la visión de la explicatura sugiere.

\footnotetext{
${ }^{57}$ La Teoría de la relevancia (Carston, 2002a) mantiene que éste proceso en dos pasos corresponde más bien a la descodificación y los procesos inferenciales que dan lugar a explicaturas e implicaturas. Desde este punto de vista, no hay un compromiso con la prioridad temporal de la explicatura, como sí lo hay en Recanati. Para la Teoría de la relevancia, el sistema inferencial es un sistema de ajuste mutuo entre explicaturas e implicaturas que no tiene por qué seguir un orden secuencial estrictamente lógico. Sin embargo, parece haber aquí alguna especie de contradicción o explicación confusa acerca de la naturaleza de este sistema. Por un lado, se mantiene que el proceso no tiene por qué seguir un orden lógico, que no hay una prioridad temporal de la explicatura y que ésta no tiene por qué ser el input para la implicatura; mientras, se afirma que las explicaturas son previas lógicamente a las implicaturas y, como se ha visto, uno de los criterios para la caracterización de la explicatura es que ésta es necesaria puesto que funciona como premisa para alcanzar la implicatura. Por otro lado, cuando se revisan los ejemplos dados por la Teoría de la relevancia para justificar la explicatura, es difícil ver cómo el proceso puede no ser secuencial dado lo que hay es realmente una secuencia inferencial lógico-deductiva.
} 
Ya en los apartados anteriores se apuntó a la idea de la conexión entre las entradas léxicas con contenido rico y el conocimiento acumulado. Además, como se ha mostrado en éste, el lenguaje y la memoria comparten mecanismos neurales por lo que el significado y el conocimiento general parece que están unidos, de forma que las conexiones asociativas entre representaciones semánticas que actúan como restricciones en el contexto lingüístico son provistas por la memoria. Así que no es que el contenido comunicado (explicatura) sea más rico que las formas lingüísticas sino que las expresiones son más ricas de lo que la visión estándar sugiere. Como se explica en el capítulo siguiente, de alguna manera el léxico está unido a la estructura conceptual. Esto parece algo con cierta prioridad frente a los intereses y objetivos comunicativos pues lo que está en juego son las formas en que la realidad se representa en nuestro sistema conceptual. Una teoría pragmática de la competencia comunicativa no elimina por tanto la necesidad de una teoría semántica que explique las conexiones entre las expresiones lingüísticas, la gramática, nuestro sistema conceptual y el cuerpo de conocimiento general con el que está en conexión. 



\section{Capítulo 4}

\section{Del contexto a la competencia.}

\section{Una semántica natural}

Los argumentos expuestos arrojan dudas sobre la existencia de constituyentes inarticulados y el proceso del enriquecimiento que da lugar a la explicatura. La existencia psicológica de la explicatura es dudosa y algunos fenómenos que la noción explica pueden explicarse sin ella. La explicatura se ve comprometida convirtiéndose en una noción teórica sin contraparte en los procesos reales de comprensión de las proferencias. Esto pone en entredicho la visión tripartita del modelo pragmatista y la caracterización del significado como un asunto radicalmente pragmático. En este capítulo se muestra que es legítimo adoptar una noción de significado independiente de los contextos. De forma que el significado de la oración, como significado lingüístico y convencional, está conectado con el léxico y la cognición. Un significado de este tipo cumple un papel en los procesos de comprensión. Sin embargo, dada la complejidad de factores que están involucrados en la comunicación, el rol que cumple es mínimo. Desde esta perspectiva, se defiende que en lo relativo al significado, la única distinción que puede establecerse es la distinción entre el significado lingüístico y el significado del hablante, donde deben englobarse los significados figurados (p.e., metáforas, ironías o sarcasmos) y las implicaturas, tomando como implicatura 
cualquier contenido enriquecido más allá de las expresiones lingüísticas. Esto no quiere decir que deba asumirse una vuelta al esquema griceano, sino más bien una modificación del mismo en la que se integre el conocimiento provisto por las evidencias. Debe adecuarse el modelo binario a los procesos cognitivos que están implicados en el procesamiento del lenguaje para poder explicar la competencia semántica desde un punto de vista natural.

\subsection{Roles para un contenido semántico mínimo}

Desde la concepción heredada se establecieron varios criterios para la individuación del significado lingüístico y la demarcación de los límites de la semántica. Sin embargo, los problemas surgidos en torno a la referencia y la verdad llevaron a la tensión entre el criterio veritativocondicional y el criterio de la carta anónima o de la independencia del contexto en el nivel de lo dicho. Desde el punto de vista del primero, el significado lingüístico o significado de la oración corresponde al contenido veritativo-condicional y, desde el punto de vista del segundo, el componente semántico representa sólo aquellos aspectos del significado de una oración que cualquier intérprete del lenguaje conocería en una situación como la de la carta anónima de Katz (1977). El debate contemporáneo resuelve esta tensión descartando la independencia del contexto mientras mantiene el criterio veritativo-condicional adoptando puntos de vistas más o menos moderados. El Minimalismo defiende un contenido semántico mínimo que se genera sobre la base de constituyentes léxicos y sintácticos. No obstante, el Minimalismo, llamado aquí de aptitud de verdad, mantiene la visión del contenido semántico como contenido veritativo-condicional, por lo que ha de admitir un mínimo aporte contextual que contribuya a la proposición mínima. Por su parte, el Pragmatismo, a través del argumento de la infradeterminación, redefine la noción de lo dicho como explicatura y descarta la proposición mínima al entender que ésta no tiene realidad psicológica ni cumple un rol en la comunicación. 
Sin embargo, la solución a la tensión entre los dos criterios puede resolverse de manera inversa, descartando el criterio veritativo-condicional mientras se mantiene la independencia del contexto. Como se ha visto a lo largo del trabajo, el enfoque estándar que asimila el contenido semántico como contenido veritativo-condicional no parece adecuado para el tratamiento del lenguaje natural y la propuesta de un modelo tripartito del significado sustentado en la noción pragmática de explicatura no resuelve los problemas. Por lo que, descartado el criterio veritativocondicional, queda abierta la posibilidad de restablecer un nivel de contenido semántico independiente del contexto, previo a ajustes pragmáticos y construido sobre la base del léxico y la sintaxis. Como se muestra a continuación, este nivel no solo tiene realidad psicológica sino que además cumple tanto un rol normativo como un rol explicativo.

En primer lugar, la semántica, como competencia para comprender el significado de nivel tipo independiente del contexto, ofrece un nivel normativo de significado que es necesario como garantía comunicativa ante diversos fenómenos habituales como las bromas pero también como malentendidos en nuestros intercambios (Cappelen y Lepore, 2005) y esto es especialmente relevante en proporción al nivel de responsabilidad y conflictividad a que esté sujeto el intercambio. Así, como se muestra a continuación, existen algunos intercambios comunicativos en los que este significado cobra especial relevancia.

El primero de los casos es un ejemplo típico de explotación del habla indirecta donde el material verbal empleado deja abierta la posibilidad de varias interpretaciones que dan lugar al efecto cómico cuando se revela como correcta la interpretación menos favorecida o esperada. En este sentido, para que algo se constituya como broma debe contener dos niveles detectables de significado (Dascal, 1985). Estos dos niveles de significado pueden ser de distintos tipos pero en algunos (quizá bastantes) casos, por lo que interesa aquí, se da una contraposición entre un significado no enriquecido, el contenido mínimo, y otro enriquecido de una misma expresión ${ }^{58}$. De

\footnotetext{
${ }^{58}$ Para una caracterización más exhaustiva de la formas de generar el doble significado en las bromas véase Dascal (1987).
} 
esta forma, el efecto cómico se produce al insistir sobre una interpretación mínima como ocurre en el ejemplo del siguiente intercambio:

(44) A: Yo he pagado todo, así que me lo como todo

B: También has pagado el envase del yogur y no te lo comes

En este caso, la respuesta insiste en una interpretación mínima con la intención de bromear. Ciertamente su declaración es absurda desde el momento en que el envase del yogurt no es algo comestible, pero es legítima en un doble sentido: en cuanto a la competencia lingüística y en cuanto a la función que cumple la proferencia, i.e., bromear. Siguiendo a Dascal (1987), los dos niveles de significado deben estar disponibles para el oyente en toda broma con el fin de que se produzca el efecto cómico; en caso contrario éste no se produce. De esta forma, el significado mínimo, no solo tiene realidad psicológica sino que no puede obviarse en tales intercambios comunicativos.

De la misma forma tampoco puede obviarse el significado mínimo en intercambios comunicativos conflictivos. Cuando los interlocutores sienten que de las palabras proferidas puede derivarse un perjuicio para ellos priorizan las interpretaciones y expresiones literales, en el sentido de no enriquecidas, así como exigen fijar en el curso de la interacción los significados de aquellas expresiones ambiguas y convencionalmente no literales. Así, en una comunicación conflictiva, como puede ser una discusión doméstica o una declaración en un juzgado, hay una tendencia al habla literal y a la explicitación (Hansen, 2008).

En nuestros intercambios muchas veces elegimos cuidadosamente nuestras palabras para no tener que comprometernos con ciertas cosas aunque éstas se puedan interpretar de las palabras proferidas. Siguiendo a Borg (2017), cuando Bill Clinton declara There is no improper relation en respuesta a las acusaciones de haber mantenido una relación sexual con Monica Lewinski, aunque la audiencia interprete el contenido enriquecido de que no hay ni ha habido relación impropia entre ellos, no puede adscribírsele a Bill Clinton la responsabilidad de tal contenido enriquecido puesto 
que, precisamente con este objetivo, Bill Clinton eligió cuidadosamente sus palabras. Es el contenido explícito de nuestras proferencias el que conlleva la responsabilidad estricta de los hablantes de las consecuencias de lo que dicen (Borg, 2017; Israel, 2002). Para distinguir el acto de habla de mentir de otros actos de habla parece que se necesita apelar al contenido mínimo y a un cierto principio de externalización, evitando enriquecimientos pragmáticos.

Nuestra práctica ordinaria de informar del habla es sensible a este principio de explicitación (Camp, 2006; Millikan, 2005). A la hora de informar a un oyente de lo que un hablante ha dicho sólo es apropiado informarle de aquellos contenidos a los que el hablante se haya comprometido abiertamente con sus proferencias. Los hablantes pueden oponerse legítimamente a informes que no hagan caso del requisito de la explicitación. Es fácil ver esto si se pone la atención en muchas de nuestras discusiones cotidianas con amigos o familiares. En estas discusiones solemos ponernos a la defensiva e interpretamos de las palabras del otro acusaciones personales a las que el amigo, o nosotros, contestamos con un No he dicho eso.

Aunque de una manera institucionalizada, lo mismo ocurre en la práctica de los juzgados como puede verse en el siguiente ejemplo donde un tribunal superior tuvo que revocar una condena anterior por perjurio al estar fundada en una inferencia pragmática (Solan y Tiersma, 2012, p. 15):

Samuel Bronston was the president of a movie production company. His company petitioned for bankruptcy. At a hearing, lawyers for creditors were allowed to question Bronston regarding the nature and location of his assets:

Q. Do you have any bank accounts in Swiss banks, Mr. Bronston?

A. No, sir.

Q. Have you ever?

A. The company had an account there for about six months, in Zurich.

In fact, Bronston had once had a large personal bank account in Switzerland, where over a five year period he had deposited more than $\$ 180,000$. 
Bronston was convicted of perjury. The prosecution apparently convinced the jury that although Bronston's reply to the second question was literally true (his company did once have an account there), it falsely implied that he had never had a personal Swiss bank account.

The Supreme Court admitted that people might indeed infer from Bronston's answer that he had never had a personal account in Switzerland. But Bronston never said so directly. The Court emphasized that the perjury statute refers to what the witness "states", not to what he "implies".

En este sentido, como afirma Borg (2017), la carga de perjurio, así como de la mentira, descansa sobre el contenido no enriquecido. En general, en los procesos de argumentación de nuestras discusiones, las respuestas que resultan admisibles, ya sean de ataque o de defensa de algún punto de vista u opinión, deben estar determinadas funcionalmente por la sintaxis y la redacción de las afirmaciones anteriores. Es decir, que nuestras respuestas sean legítimas es algo que dependerá de lo que ha sido dicho explícitamente y no en intenciones, creencias o enriquecimientos. De ahí que en casos especialmente conflictivos, como los de la lingüística forense, cobre especial importancia el uso del lenguaje. El abogado prepara junto a su cliente las palabras que dirá en su declaración en el juzgado (p.e., usará la voz pasiva si no quiere responsabilizar a nadie) o intentará minar la credibilidad de un testigo buscando inconsistencias en sus usos lingüísticos; así como cobra gran relevancia que la transcripción del procedimiento sea más o menos literal dado que, en la revisión de un posible recurso del fallo judicial, el nuevo juez no estará en presencia de las partes (Tiersma, 1993).

Gracias al lenguaje hacemos públicos nuestros pensamientos y los exponemos a la valoración de otras personas de forma que, como se ha visto, se establecen juicios acerca de la responsabilidad de los contenidos comunicados. Si bien, como explica Borg (2017), parece haber distintas nociones de responsabilidad en este sentido; en otros términos, la responsabilidad parece ser un asunto de grado, que se mueve desde una responsabilidad estricta a lo que Borg llama una responsabilidad conversacional. La idea general es que los hablantes asumen ciertos 
grados de responsabilidad sobre los contenidos que pueden comunicarse con sus proferencias. No obstante, parece que ambas nociones son relevantes:

\section{(36) Every bedroom in the hotel has its own bathroom}

Una expresión como (36) puede interpretarse como que cada habitación tiene un baño de uso exclusivo en su interior o que cada habitación tiene un baño externo asignado que es compartido con otras habitaciones. Cuando alguien utiliza una expresión ambigua como (36), se está comprometiendo conversacionalmente con las dos interpretaciones que pueden generarse puesto que es responsable de no haber resuelto la vaguedad; de la misma forma que cuando alguien habla irónicamente de alguna manera se compromete conversacionalmente con el contenido irónico a pesar de no ser explícito. En general, puede decirse que hay cierto nivel de responsabilidad sobre los contenidos que pueden comunicarse que no está sujeta al criterio de la no cancelabilidad.

Sin embargo, como se ha visto anteriormente, parece que también es necesario establecer un nivel de responsabilidad más estricta. Se necesita poder distinguir un nivel de responsabilidad que haga diferencias entre lo que contaría como un acto de habla de mentir o cometer perjurio de otro acto de habla como un malentendido, por ejemplo. En estos casos, los juicios de responsabilidad deben estar restringidos a nuestros compromisos externalizables. Tanto en nuestras discusiones cotidianas como en nuestros informes de habla y muy especialmente en la lingüística forense es necesario apelar a este principio de externalización y al contenido semántico no enriquecido pragmáticamente. De forma que el contenido semántico mínimo cumple un rol en función del nivel de conflictividad a que esté sujeto el intercambio.

Además de cumplir este rol normativo, un nivel de significado lingüístico independiente de los contextos parece necesario para explicar dos hechos fundamentales relativos al lenguaje: el hecho de que el lenguaje es una capacidad compartida por todos los hablantes y el hecho de la eficiencia en la comprensión lingüística. Como señala Schiffer (2015, p. 77), "Whatever constitutes the ability of a native speaker of a language to understand sentences of her language must be 
something shared by all native speakers of the language" $y$, dado que el lenguaje se usa para la comunicación, "it requires the ability to understand utterances of it".

Como se ha visto, muchas oraciones incluyen expresiones dependientes del contexto que son susceptibles de ser interpretadas de distinta manera en diferentes contextos. El modelo pragmatista ha insistido fuertemente en la idea de que la interpretación de las proferencias no puede depender solo del significado convencional de las palabras junto a sus relaciones sintácticas, sino que para una correcta interpretación de las proferencias es necesario que intervengan procesos pragmáticos y factores contextuales. Sin embargo, esto abre un gran conjunto de posibles interpretaciones que cada oración tendrá en función de los contextos en los que sea declarada, lo que resulta problemático en un doble sentido.

Por un lado, cada proferencia lingüística, como hecho, es única y esto implica que, de no tener una forma más o menos sistemática de restringir las posibles interpretaciones, así como de seleccionar el contexto apropiado, la comunicación resultaría realmente complicada. Una explicación de la comprensión de las proferencias fundamentalmente pragmática, donde se deje todo el trabajo al contexto, produce una sobregeneración de interpretaciones y dificulta la sistematización necesaria para explicar esta habilidad general compartida por todos los hablantes en todas las situaciones.

Por otro lado, un modelo en el que el sistema de comprensión tenga que construir un nivel de significado enriquecido, como resultado de procesos pragmáticos en los que intervienen todos los recursos de información, no parece acorde con la velocidad del procesamiento lingüístico ni con la realidad de los intercambios comunicativos. Es necesario que el sistema de comprensión pueda restringir las interpretaciones posibles que pueda tener una expresión de una forma más eficiente y acorde a la ecología cognitiva.

En este sentido, se necesita un conocimiento con cierta independencia del contexto para evitar la sobregeneración de interpretaciones y favorecer una comprensión económica de las proferencias. 
Este conocimiento debe extraerse sobre la base del significado lingüístico de la oración, el léxico y sus características formales y sintácticas (Rayo, 2013; Schiffer, 2015; Stern, 2000). Además, parece que solo a través de las características independientes del contexto, las restricciones y contenidos que impone el sistema sintacto-semántico, conocen los oyentes qué aspectos del contexto deben tomarse como relevantes (Dascal, 1987; Higginbotham, 1985).

A grandes rasgos puede decirse entonces que es precisamente la dependencia del contexto del lenguaje la que motiva la necesidad de apelar a nuestra competencia puramente linguiística, de forma que, de manera general, las palabras dichas restringen entre las posibles interpretaciones:

Example after example has been given over the last several years to show that one can say many different things by uttering even very simple sentences, such as "That ink is blue": One might mean that the ink appears blue in the bottle, or that it will appear blue upon drying, or yet other things. But little notice ever seems to be taken of how few things might be said by uttering this sentence, that is, of how many things there are that cannot be said by uttering it. For example, under no circumstances can one say, by uttering the sentence "That ink is blue", that the existence of a measurable cardinal implies that there are non-constructible sets. (Heck, 2014, p. 45)

Parece sensato contar con un nivel de significado independiente de las variaciones contextuales y las intenciones de los hablantes en favor de la eficiencia en la comprensión de las proferencias que esté en consonancia con la ecología cognitiva y la realidad de los intercambios comunicativos y que permita explicar el lenguaje como una habilidad compartida.

En resumen, el contenido semántico mínimo que se construye sobre la base del léxico y la sintaxis no sólo tiene realidad psicológica sino que, como se ha visto, cumple ciertos roles en relación a la explicación del lenguaje y los procesos de comprensión lingüística dentro de la comunicación. Aporta la estabilidad lingüística necesaria para que el lenguaje natural pueda utilizarse como medio de comunicación por una comunidad de hablantes restringiendo las interpretaciones, funcionando como garantía comunicativa en los intercambios y estableciendo un 
nivel de compromiso del hablante. Por último, se necesita un nivel tipo normativo porque de lo contrario solo tendríamos una teoría descriptiva de actos de habla y no una teoría semántica explicativa. El nivel tipo ofrece la única posibilidad de contar con una forma de explicación sistemática del significado. Éstas son las razones que llevan a un modelo de explicación de la comprensión lingüística ligado a las nociones de convención y prototipicalidad.

\subsection{Significado y cognición}

Los argumentos expuestos en la parte crítica llevada a cabo anteriormente muestran que el camino para la explicación de un nivel de significado lingüístico independiente de los contextos es la conexión con el sistema conceptual. No es que el contenido comunicado sea más rico que las formas lingüísticas, sino que las formas lingüísticas son más ricas de lo que la visión estándar sugiere. En este sentido se argumenta que el léxico es un sistema rico ligado al sistema conceptual y a los mecanismos cognitivos que organizan el conocimiento en términos de tipicalidad. Desde esta perspectiva, se explica el significado a través de una noción de convención en términos de tipicalidad adecuada a los procesos cognitivos que están implicados en los procesos de comprensión y producción del lenguaje. La noción de convención, en este sentido, es el nexo entre la cognición y la comunicación que se expresa en lo que llamamos significado de la oración o significado lingüístico. Ahora bien, dado el estado de desarrollo de los estudios cognitivos, este apartado no pretende ser un estudio riguroso sino más bien una defensa de la visión defendida, así como un esbozo de las líneas de investigación abiertas en este camino.

\subsubsection{Bases para un significado convencional}

Para empezar debe explicarse qué se entiende aquí por convención para entender cómo produce ésta el nexo entre la cognición y la comunicación. Cuando hablamos y escuchamos a otros 
codificamos o descodificamos estructuras conceptuales a través de signos lingüísticos, de forma que el lenguaje está conectado con los estados mentales internos de los hablantes. Los estados mentales de los hablantes no tienen por qué ser idénticos y, aunque lo fueran, no es posible contar con la garantía de que así sea. En este sentido la comunicación sólo es posible cuando estos estados son, si no idénticos, al menos similares (Chomsky, 2000; Jackendoff, 2002). En consecuencia, debe haber ciertos contenidos conceptuales compartidos y estabilizados.

Dichos contenidos se estabilizan empíricamente a través de las prácticas sociales observadas. Como explica Geurts (2018), las convenciones son regularidades conductuales o patrones en la interacción social que obtienen su estatus a través de la frecuencia de uso. De la misma forma se generan convenciones linguísticas. Los hablantes observamos y retenemos en la memoria cómo otros hablantes utilizan las palabras para lograr la convergencia en los significados y usamos los diccionarios como medio para asegurar la estabilidad y externalizar públicamente dicha convergencia (Barsalou, 1987; Hampton, 2006; Jackendoff, 2002). Así, en términos generales, categorizar una palabra de una forma dada depende de la experiencia (Lakoff, 1987) y refleja la frecuencia de esa práctica dentro de una comunidad; otras veces la forma en que se registra la convergencia se delega en expertos (Putnam, 1975) o puede que cohabite la categorización hecha por expertos con la alcanzada por experiencias comunes, en un intento de alcanzar la convergencia en los respectivos estados mentales de los interlocutores con objetivos comunicativos (Malt, 1994). Esto posibilita que las estructuras de conocimiento sean compartidas por la mayoría de los miembros de una comunidad (Gerrig y Littman, 1990). De esta forma, la convencionalidad se caracteriza principalmente como una cuestión de grado afectada por la regularidad estadística tanto de la frecuencia de uso como de la frecuencia en el procesamiento conceptual del léxico y las construcciones gramaticales.

La convencionalidad, en este sentido de regularidad estadística, se materializa en nuestro sistema conceptual en términos de tipicalidad. Parece que la maquinaria cognitiva mantiene una tendencia a la generalización de las experiencias para organizar el conocimiento acumulado 
formando estructuras de conocimiento. En este sentido la cognición usa mecanismos como la formación de schemata, scripts y prototipos.

Por un lado, el conocimiento genera estructuras de alto nivel conceptuales o representaciones de eventos y situaciones tipo, los llamados schemata. Según algunos estudios (Brewer y Treyens, 1981; Gureckis y Goldstone 2010; Rumelhart, 1980), la función de estos es organizar la experiencia previa favoreciendo un conjunto de expectativas en base a ella. Para entender esto puede pensarse en la percepción. Varios estudios (Barsalou, 1999; Brewer y Treyens, 1981; Jackendoff, 2002; Johnson-Laird, 2004; Minsky, 1974) han revelado que la percepción es un sistema basado en schemata donde las variables que no se proporcionan con la información perceptiva presente se acomodan por defecto en base a expectativas producidas por la experiencia pasada. Esta es la razón por la que cuando entramos en una habitación en la que vemos un escritorio con una silla, a pesar de que no veamos las patas de la silla, en nuestra percepción la silla tenga patas, por ejemplo. Se puede decir, simplificando un poco las cosas, que nuestra percepción pone unas patas por defecto a la silla. Para que esto pueda ocurrir, la información pasada, que constituye la experiencia sobre la que se construye el schema, debe estar acumulada en la memoria a largo plazo. Sin embargo, no parece posible acumular toda la información experimentada por lo que la memoria parece que debe estar mejor organizada en principios generales y reglas que podamos usar en diferentes ocasiones (parece más eficaz acumular un tipo de conocimiento general sobre patas de sillas que actúe como valor por defecto en situaciones variadas que acumular todas las patas de sillas particulares experimentadas en nuestra vida). De esta forma, la información episódica nueva interacciona con la información ya acumulada.

Además, para que la integración sea económica cognitivamente, la información que acumulamos en la memoria sobre la experiencia pasada debe estar organizada. En este sentido, los schemata utilizan lo que se han denominado scripts, paquetes de conocimiento sobre tipos particulares de situaciones frecuentes -culturalmente compartidos o idiosincráticos- (Bower, Black y Turner, 1979; Mazzone, 2014; Schank y Abelson, 1975). 
Por otro lado, a la vista de lo argumentado en el capítulo segundo, la semántica del lenguaje natural es por naturaleza vaga, no tenemos criterios precisos para definir la calvicie, la riqueza o la lentitud. Esto indica que las categorías conceptuales poseen estructuras de grado; en otras palabras, que sus miembros no son equivalentes sino que hay unos ejemplos "mejores" que otros, hay prototipos. Ciertamente parece que las categorías conceptuales no tienen límites precisos sino borrosos, por lo que resulta mejor definirlas en función de los juicios de los hablantes y las prácticas sociales estabilizadas y no siguiendo la forma clásica regida por conjuntos de características necesarias y suficientes (Barsalou, 1985 y 1987; Lakoff, 1987; Rosch, 1998). De esta forma, parece que las estructuras conceptuales generan juicios de tipicalidad de sus miembros. A pesar del riesgo que supone el aparente subjetivismo ha de mencionarse que la comunicación está garantizada en un sentido intersubjetivo dado que los juicios de tipicalidad de los hablantes suelen ser unánimes pues provienen del conocimiento común producido por contar con las mismas estructuras perceptivas, así como por experimentar las mismas prácticas sociales. No puede decirse, como afirman Yee, Jones y McRae (2017), que los hablantes refieran a las mismas cosas pero sí que los juicios de los hablantes serán suficientemente parecidos en contextos similares para lograr una comunicación satisfactoria.

En la literatura sobre el tema se han ofrecido varios factores determinantes de tipicalidad y prototipos: 1) la similaridad a ideales $^{59}$ - los miembros se ordenan en función del grado en el que sirvan a un objetivo asociado a la categoría, de forma que el miembro que mejor sirva al objetivo es el prototipo- (Barsalou, 1985); 2) el parecido de familia -los miembros de la categoría guardan un parecido entre sí, de forma que el prototipo es el miembro que más atributos comparte con los demás-; 3) la frecuencia de instanciación - los miembros de la categoría se ordenan en función de la frecuencia con la se experimentan, de forma que el más frecuente es el prototipo- y (4) la saliencia - los miembros de la categoría se ordenan en función de la relevancia que tienen en

\footnotetext{
${ }^{59}$ Uno de los ejemplos que Barsalou propone para entender la similaridad a ideales es la categoría de comidas para una dieta. Para esta categoría el objetivo asociado es perder peso, por lo que a menor cantidad de calorías que tenga una comida mejor sirve al objetivo asociado. Establecida la relación entre la categoría y el objetivo asociado, puede situarse el ideal en las comidas con cero calorías, de forma que los miembros de la categoría serán más o menos prototípicos en función de su similaridad a este ideal.
} 
nuestra interacción social, de forma que el prototipo es el miembro más relevante ${ }^{60}$ - (Seuren, 2009). De los cuatro, hay un acuerdo general (Hampton, 2006; Machery, 2010; Malt, 1994; Millikan, 2005; Rosch, 1998; Rosch y Mervis, 1975) sobre la importancia de los factores (2) y (3) en la determinación de la tipicalidad en la estructura conceptual, mientras los factores (1) y (4) son defendidos en menor medida. No obstante, la tipicalidad encaja mejor como un fenómeno afectado por los cuatro factores. Siguiendo un ejemplo de Seuren (2009, p. 328) puede verse la importancia de otros factores como la saliencia. Cuando a alguien se le indica que mencione un individuo de la clase de los animales, probablemente responda perro y no mosca, a pesar de que ver moscas es un hecho mucho más frecuente que ver perros. En resumen, el prototipo incluye las propiedades típicas de la categoría a la que pertenece. Estas propiedades típicas a su vez dependerán de los juicios de los hablantes en función de las prácticas sociales y culturales, de manera que se establecen de forma compartida pero podrían variar con cada comunidad de hablantes (el blanco puede ser el color típico de la piel en unas culturas, mientras no serlo en otras; las pipas de girasol pueden ser un aperitivo típico para los seres humanos en unos sitios, mientras en otros apenas son la comida típica de algunas aves).

A su vez, los prototipos se instancian en ejemplares (Smith y Medin, 1999; Vooorspoels, Vanpaemel y Storms, 2008). Los ejemplares son piezas acumuladas en la memoria a largo plazo que encarnan el prototipo; es decir, son ejemplos conocidos que materializan el prototipo de la categoría y que, en caso necesario, actuarán como valores referenciales por defecto en la

\footnotetext{
${ }^{60}$ La noción usada aquí no es equivalente a la utilizada por el pragmatismo. En la concepción pragmatista saliencia hace referencia a la relevancia relativa al contexto de la proferencia para la interpretación, mientras lo que se expresa aquí no está estrictamente conectado al contexto de la proferencia. La saliencia mental remite a un alto índice de retención en la memoria por factores que pueden ser diversos pero que tienen en común la necesidad de la atención por parte de los individuos y que afecta a nuestra forma de categorizar la realidad. La noción de saliencia no debe darse por definida simplemente como relevancia, una explicación de la saliencia debe incluir una explicación de la composición de las estructuras conceptuales, de las conexiones entre las distintas estructuras, así como de los factores que originan la atención necesaria que produce la saliencia. Estas explicaciones exigen un estudio de la composición del léxico, así como de las relaciones de éste con otros procesos cognitivos como la formación de schemata en la memoria a largo plazo. En este sentido, algunos experimentos en la investigación de schemata, que revelan estas interconexiones, muestran que la saliencia puede estar basada en tres factores muy dispares. En el escenario de una habitación con las características típicas de un estudio en el que se encuentran encima de la mesa una pistola de calibre 45 y un clip, la pistola es saliente debido a (1) una saliencia intrínseca del objeto en sí, el clip es saliente debido a (2) su conexión con el schema de estudio, aunque la pistola podría ser también saliente en este último sentido al (3) no acomodarse al schema (Brewer y Treyens, 1981). Por tanto, está por determinar si la saliencia depende del léxico, de la correlación con la expectativa de schemata, con la inadecuación a la misma o está causada por todos los factores.
} 
comprensión de las proferencias (Minsky, 1974). Ahora bien, no debe confundirse prototipo con ejemplar del prototipo. Como se ha dicho antes, el prototipo incluye las propiedades típicas de la categoría a la que pertenece. En este sentido, el prototipo es una especie de schema representacional abstracto que se define en términos de un conjunto de valores por defecto en función de las propiedades típicas de un objeto o evento (Johnson-Laird, 1987). Por su parte un ejemplar es una especie de referencia mental que sirve para materializar el prototipo conectando nuestras experiencias particulares en la memoria con nuestras estructuras conceptuales, así como para facilitar la comprensión de las proferencias (favorece la rapidez en la comprensión al ser mejor accesibles a la memoria, evita la creación de conceptos innecesarios y soluciona el problema del desconocimiento de las referencias del hablante). En relación a esta distinción, puede ocurrir que los ejemplares no ostenten el conjunto de propiedades típicas de los prototipos o que en nuestra memoria no contemos con ejemplares para algunos prototipos. Puede decirse entonces que en definitiva el conocimiento prototípico es un conocimiento generalizado y compartido mientras el conocimiento de ejemplares prototípicos es un conocimiento particular y privado ${ }^{61}$. Sin embargo, son dos tipos de información que se complementan dando estructura y aumentando la riqueza del sistema conceptual (Machery, 2010; Murphy, 2016; Yee et al., 2017).

La maquinaria cognitiva representada en los procesos de conocimiento relativos a la formación de schemata y prototipos posibilita una generalización de experiencias adecuada a la ecología cognitiva: reduce la carga cognitiva, permite predecir información desconocida en situaciones nuevas ayudando a interpretarlas, así como explica la velocidad de procesamiento, el aprendizaje en niños, quienes parece que aprenden antes como miembros de una categoría ejemplos que expresan propiedades típicas, y el aprendizaje general por reglas (Jackendoff, 2002; Pickering y Garrod, 2006; Rosch, 1998).

\footnotetext{
${ }^{61}$ En el presente trabajo se hace referencia a ejemplares en su sentido de particulares. Sin embargo, existe un sentido alternativo en la literatura sobre el tema. En este segundo sentido los ejemplares pueden ser un subconjunto de un concepto (las manzanas serían un ejemplar del concepto FRUTA), de forma que en este segundo sentido los ejemplares son abstractos (Smith y Medin, 1999).
} 
Parece que esta misma maquinaria cognitiva pudiera estar involucrada en lo relativo al lenguaje. La interpretación de las proferencias también requiere integrar la información nueva con la acumulada, por lo que en este proceso lo más probable es que intervengan los mecanismos antes descritos. Así, en consonancia con las evidencias que apuntan a que el procesamiento es incremental, puede entenderse que sobre el curso de la comprensión de una oración se construye un schema -una simulación representacional del evento o situación- donde el léxico, como se muestra en adelante, cobra especial importancia (McRae y Matsuki, 2009).

\subsubsection{Una competencia semántica rica}

Los argumentos expuestos en los capítulos anteriores llevan a conclusiones en una misma dirección. Por un lado, como se vio en el capítulo segundo, la semántica del lenguaje natural es relativa a perspectivas conceptuales, categorías léxicas y comunidades lingüísticas. Lo que lleva a la idea de que el léxico es más rico de lo que la visión estándar sugiere. Por otro lado, como se vio en el capítulo anterior, hay algunas evidencias desde los estudios en neuropsicología que apuntan a la conexión entre el lenguaje y el conocimiento acumulado. El lenguaje y la memoria comparten mecanismos neurales, de forma que hay una correlación entre la actividad producida en el hipocampo y el procesamiento lingüístico, aumentando la actividad en el hipocampo a medida que aparecen las palabras. El procesamiento lingüístico está influenciado tempranamente por la integración del conocimiento general y la actividad de asociación de palabras con la información que se activa en el hipocampo. Esto indica que el léxico y el sistema conceptual están unidos de alguna forma. Además, el hecho de que la comprensión de las proferencias sea incremental sugiere, siguiendo a Ferretti, McRae y Hatherell (2001), que nuestras estructuras de conocimiento están organizadas. En base a esto puede decirse que la semántica, como competencia, es un sistema rico ligado al sistema conceptual. 
No obstante, aún permanece abierta la cuestión de la naturaleza de la conexión entre el significado y el conocimiento del mundo. Resulta difícil establecer una línea divisoria entre qué es significado y qué estructuras conceptuales. En este sentido algunos autores han defendido que el significado es en sí mismo estructura conceptual (Bosch, 2007; Evans, 2006; Jackendoff, 2002; Lakoff, 1987; Vicente, 2017); hay quien distingue entre significados y conceptos (Bierwisch y Schreuder, 1992; Evans, 2006; Pustejovsky, 1995; Seuren, 2009) y algunos han afirmado que los significados y los ítems léxicos son indicadores para construir conceptos (Pietroski, 2008; Sainsbury, 2001) o formar estados mentales de interpretación (Zarcone, 2014). Esta tarea excede el ámbito del presente trabajo, si bien cabe apuntar que, aunque no parece posible discernir si esta estructura conceptual que está ligada a las expresiones lingüísticas es en algún sentido diferente del conocimiento general, esta conexión íntima entre el significado y la estructura conceptual deja a la vista la importancia de la caracterización del léxico y la función de las palabras en la conexión con el sistema conceptual. Quizá, podría decirse que, en términos generales, como afirma Jackendoff (2002), la semántica tiene que ver con la organización de los pensamientos que el lenguaje puede expresar y que la semántica léxica remite al estudio de la organización conceptual que está bajo la palabra.

Desde los años 60 muchos han sido los desarrollos teóricos que han puesto el énfasis en la necesidad de una teoría de la descomposición léxica en conexión con la idea de que el léxico es un sistema rico ligado a la categorización conceptual. En un sentido general, puede decirse que el léxico recoge y expresa nuestras formas de categorizar las realidades. Desde esta perspectiva, como mantiene Lakoff (1987), la categorización no parece responder a la visión estándar del modelo tradicional objetivista que caracteriza el pensamiento como manipulación de símbolos abstractos que adquieren significado a través de la correspondencia con el mundo y que se construye objetivamente con independencia de los sujetos. La categorización, influenciada por la experiencia humana, atiende a información relativa a asociaciones con conocimientos diversos, presuposiciones y convenciones. Por ello, las entradas léxicas no parecen representaciones atómicas que deban 
modularse con la información del contexto sino estructuras ricas de información en las que se establecen relaciones semánticas o relaciones de sentido con otros ítems léxicos. En este sentido, el léxico podría estructurarse de diferentes formas.

Por un lado, el significado de las palabras se establece en función de distintos criterios de conceptualización. Como ya se ejemplificó en el capítulo segundo en relación a la crítica a la noción de referencia, esto puede verse en los dot-objects, así como en la semántica de palabras como Londres o madre que remiten a conceptos cluster. Desde esta perspectiva, puede decirse que las palabras están cargadas de categorías semánticas que especifican diferentes aspectos de significado en consonancia con las diferentes formas de categorizar las entidades (Jackendoff, 2002; Lakoff, 1987; Pustejovsky, 1995).

Por otro lado, el sistema léxico también parece estar estructurado en torno a las relaciones que mantienen los ítems entre ellos, de forma que la organización conceptual que subyace al léxico incluye campos semánticos, así como lo que se ha llamado el conocimiento temático, i.e., un registro léxico y gramatical de cómo las cosas típicamente van juntas o juegan roles complementarios en las acciones (McRae, Ferretti y Amyote, 1997). En relación a esto, el sistema léxico incluye estructuras de evento en conexión con este conocimiento temático que incorporan información en un doble sentido. Desde un punto de vista, las estructuras generalizadas de evento incluyen información acerca del número y el tipo semántico general de sus argumentos, así como de su realización sintáctica. En términos generales, se asume que al menos algunos verbos imponen una restricción en el tipo semántico de sus argumentos en función de la adecuación temática para formar composiciones bien formadas gramaticalmente, de forma que ciertos verbos requieren complementos que denotan entidades mientras otros requieren complementos que denotan eventos $^{62}$. Así, por ejemplo, el verbo comprar restringe el tipo semántico general de lo que podrían

\footnotetext{
${ }^{62}$ La noción de restricciones selectivas tiene su origen en la idea de que la representación semántica deriva o se corresponde con la estructura sintáctica. Siguiendo una visión estricta de la composicionalidad, se asume que hay una conexión entre la representación sintáctica (las categorías gramaticales) y la semántica (los tipos semánticos generales). Desde este punto de vista, una composición bien formada es aquella en la que cada aspecto del significado proviene de una pieza en la representación sintáctica; de otro modo, que si hay piezas de significado que no están en la sintaxis
} 
ser sus argumentos de forma que lo que uno compra debe ser un objeto concreto y por tanto el verbo requiere un complemento que denota una entidad. Desde otro punto de vista, el conocimiento temático incluye un conocimiento semántico más fino sobre los participantes típicos ${ }^{63}$ (Lai, 2017; Zarcone, McRae, Lenci, y Padó, 2017). En el ejemplo anterior el objeto debe ser algo que sea típicamente aceptado en la cultura relevante como algo que se pueda comprar; en otro caso, recuperando un ejemplo de Groefsema (1995), el verbo drink impone la restricción de que su complemento sea una entidad pero además que esta entidad sea algo de tipo líquido. De esta forma, puede entenderse, como hacen algunos autores (Groefsema, 1995; Jackendoff, 2002), que esta información forma parte del significado de los verbos. En este sentido, los verbos se conciben como estructuras conceptuales, siguiendo el modelo Jackendoff (1990), o como activando estructuras representacionales que incluyen los argumentos típicos, una representación de quién hace qué a quién.

En definitiva, el sistema léxico no es una mera lista de entradas sino una estructura organizada de conocimiento donde se registran los valores semánticos de cada ítem, las presuposiciones del léxico y las asociaciones semánticas del mismo. Desde esta perspectiva, se sigue aquí el modelo provisto por Zarcone (2014), inspirado en el trabajo de Elman (2011), en relación a la función que cumplen las palabras en el sistema de comprensión lingüística. Zarcone propone que las palabras actúan como indicadores o estímulos para formar estados mentales de interpretación de forma que las palabras son "instrumentos" para que el sistema cognitivo recupere recursos de información. Siguiendo a Yee et al. (2017), el conocimiento episódico e implícito influencia la memoria semántica de forma que cada experiencia con una palabra establece un registro en la memoria episódica. Estas experiencias previas generan estructuras de conocimiento en relación a cómo

entonces hay constituyentes encubiertos que aseguran esta correspondencia. Para una consideración más detallada, así como para una visión de la evolución de la noción ver Ferretti et al. (2001) y McRae y Matsuki (2013).

${ }^{63}$ En la discusión sobre el fenómeno de la coerción donde la noción de restricciones selectivas de los verbos cobra un lugar predominante, Lai (2017), siguiendo el trabajo de Piñago y Deo (2012), desafía la asunción tradicional al mantener que no todos los verbos imponen restricciones en la selección de sus complementos pues dicha asunción no se cumple en todos los casos para los verbos aspectuales (p.e., empezar o acabar). Esto no implica que los verbos aspectuales no contengan restricciones, sino más bien que las restricciones que imponen no se explican suficientemente a través de los tipos semánticos generales. En estos casos parece que las restricciones provienen del conocimiento acumulado en términos de tipicalidad de los ítems léxicos. 
suceden las cosas. A su vez, este conocimiento se organiza siguiendo criterios de tipicalidad de forma que, como se ha visto, se generan prototipos, ejemplares y paquetes de conocimiento que incluyen el conocimiento temático en relación a eventos tipo. De esta forma, las palabras, en términos de Rayo (2013), llevarían asociadas maletas de información.

Este conocimiento influencia de vuelta el procesamiento y la interpretación de las proferencias. Cuando se recupera una palabra desde la memoria en la interpretación, ésta incorpora su información léxica codificada y activa la información asociada a sus contextos previos (Lai, 2017; Mcrae y Matsuki, 2009; Rayo, 2013; Yee et al., 2017), lo que está consonancia con la correlación mostrada entre el procesamiento de palabras y la actividad en el hipocampo. Así, por ejemplo, nombres como cafetería o policía activan verbos y tipos específicos de escenarios (McRae y Matsuki, 2009) y, como muestran Ferretti et al. (2001), al procesar un verbo resulta la computación inmediata de los roles temáticos de agente, paciente e instrumento. Este conocimiento prototípico activado por las palabras juega un rol importante en la comprensión puesto que genera expectativas acerca de las palabras y conceptos entrantes que facilitan la comprensión y favorecen la rapidez del procesamiento (Kuperberg y Jaeger, 2016; McRae y Matsuki, 2009; Zarcone et al., 2017)

Así, las palabras cumplen la función de activar una serie de procesos cognitivos y recuperar la información necesaria para la comprensión lingüística. De esta forma, la comprensión lingüística puede verse, siguiendo el modelo propuesto por Lai (2017), como una composición semántica incremental enraizada en la representación léxica donde los ítems léxicos que se recuperan de la memoria a largo plazo, incorporando su información codificada y asociada, generan una representación en la memoria de trabajo. En la construcción de esta representación el procesador intenta satisfacer los requisitos impuestos por cada ítem y predice lo que vendrá después usando el conocimiento prototípico activado ${ }^{64}$. De esta forma, parte del trabajo de la comprensión es una

\footnotetext{
${ }^{64}$ Conviene apuntar para Lai (2017) este proceso puede dar lugar a la construcción de múltiples representaciones en paralelo si fuera necesario, de forma que el procesador determina una apoyándose en el contexto. Si bien, este trabajo encaja mejor con un modelo en el que no hay representaciones en paralelo, sino que, como se verá más adelante, el
} 
acomodación de los requisitos impuestos por el léxico. Puede decirse entonces que el procesamiento y la construcción del schema en que consiste la comprensión lingüística, como se vio en el apartado anterior, están guiados por el conocimiento prototípico activado por las palabras.

En resumen, como se dijo al comienzo, el lenguaje es una cuestión de codificar y descodificar estructuras conceptuales por lo que la comunicación requiere que las estructuras conceptuales expresadas por el lenguaje sean similares entre los hablantes. La comunicación es entonces una cuestión de reducir la convergencia en los estados mentales de los hablantes y la semántica debe explicar cómo es posible que haya contenidos compartidos para que esto sea posible. En este sentido, se ha argumentado que el léxico es un sistema rico ligado al sistema conceptual y a los mecanismos cognitivos que organizan el conocimiento en términos de tipicalidad y que los juicios de tipicalidad suelen ser unánimes en contextos similares. Así, como se anunció al principio, la noción de convención en términos de tipicalidad produce el nexo entre la cognición y la comunicación. Esto hace posible que podamos hablar de un nivel de significado convencional y con cierta independencia del contexto que se expresa, como se verá a continuación, en la noción de significado de la oración.

\subsection{Un modelo binario de la comprensión lingüística}

Como se vio al inicio del capítulo, parece que es necesario contar con un nivel de significado independiente a los contextos que actúe como garantía en la comunicación y que permita explicar el lenguaje como una habilidad compartida, lo que incluye explicar cómo es posible que entendamos las proferencias a pesar de la variación de contextos. Desde este punto de partida, se ha argumentado que este nivel puede explicarse mediante la conexión con el sistema conceptual. En lo que sigue se verá que el conocimiento generado por nuestra competencia lingüística puede explicar una comprensión suficiente de las proferencias sin necesidad de apelar a procesos pragmáticos de 
enriquecimiento. Esto lleva en la última sección a defender un modelo binario de la comprensión lingüística en el que solo tiene cabida una diferenciación entre el significado de la oración y el significado del hablante.

\subsubsection{Una explicación desde la competencia}

En virtud de nuestra competencia semántica conocemos a través de la entrada léxica de las expresiones la información acerca de las convenciones lingüísticas de las mismas y este conocimiento conlleva la información suficiente para que los intérpretes comprendan el significado de las oraciones. En este sentido, el conocimiento prototípico posibilita generalizaciones de significado que explican muchos de los factores involucrados en la crítica pragmatista sin necesidad de apelación al contexto, al menos en buena parte de nuestros intercambios. Como se muestra a continuación, es posible una explicación desde la competencia de la comprensión de proferencias que incluyen fenómenos como la vaguedad, la indeterminación de referencias y la omisión de constituyentes, sin necesidad de postular un nivel de significado enriquecido como la explicatura.

Vaguedad y referencias

Cuando uno se encuentra ante proferencias como las siguientes, no se puede esperar que su comprensión dependa de que el oyente haya resuelto la paradoja de sorites ni otro tipo de vaguedad de forma precisa, así como tampoco parece razonable pensar que proferencias sencillas y habituales como éstas requieran para su comprensión que el oyente lleve a cabo procesamientos inferenciales extra:

(37) Pablo es calvo

(38) Hay silencio aquí 


\section{(39) La fiesta es en la casa azul $6^{5}$}

Más bien lo que parece es que los hablantes utilizamos este tipo de proferencias con bastante soltura y sin ningún tipo de problema semejante a los problemas de la discusión teórica. A pesar de su vaguedad, su aplicación por parte de los hablantes ordinarios resulta sencilla y a menudo no se es consciente de la vaguedad a menos que no sea resuelta por otras palabras del contexto lingüístico de las proferencias (Johnson-Laird, 1987). Esto puede explicarse si se entiende su aplicación como el resultado de algo que ya figura en nuestra propia conceptualización previamente a su comprensión. Así, aplicamos calvo, azul o silencio en función de lo que esperamos como normal, de su semejanza a un estándar o prototipo, según sus propiedades perceptivas y los marcos socialmente convencionales (Hampton, 2006; Jackendoff, 2002; Seuren, 2009).

En conexión con la vaguedad, una de las cuestiones especialmente problemáticas en la visión clásica y los modelos posteriores ha sido, como ya se ha visto, la determinación de las referencias de las expresiones. El trabajo llevado aquí ha estado encaminado a mostrar que, si bien el lenguaje como sistema representacional está conectado con el mundo, el significado no es idéntico a la referencia. Siguiendo lo defendido aquí, la determinación de la referencia es un asunto extralingüístico que depende de las intenciones referenciales del hablante y de información extralingüística, mientras el contenido semántico remite al conocimiento de la entrada léxica de las expresiones. Este conocimiento que forma parte de nuestra competencia lingüística es suficiente para acomodar las variables en el schema representacional de forma que permite la comprensión de las proferencias aún cuando no se conocen las referencias.

Al igual que en la percepción, en el proceso de comprensión lingüística basado en schemata las variables que no se proporcionan se acomodan por defecto. Una de las herramientas que nuestra cognición usa para tal fin son los valores referenciales por defecto. De esta forma si alguien declara:

\footnotetext{
${ }^{65}$ Ejemplo adaptado de Rayo (2013, p. 648).
} 
(40) La otra noche se me cruzó un mastín en la carretera

El oyente no necesita identificar la referencia de mastín (probablemente no pudiera ni siquiera apelando al contexto), le basta con recuperar de su memoria a largo plazo el ejemplar prototípico con que cuente (quizá un mastín que vio una vez en un viaje o quizá uno que vio en un documental) que emule la referencia. Esto implica que las referencias de mastín para hablante y oyente serán diferentes pero la comunicación estará garantizada en tanto que, no solo el oyente ha comprendido la proferencia, sino que sus conceptualizaciones serán similares gracias a los factores de tipicalidad que están en la base de la convencionalidad de las palabras (con mucha probabilidad el mastín que tienen en mente hablante y oyente será muy parecido).

Además, el conocimiento lingüístico provee restricciones referenciales que sirven para facilitar la búsqueda en el contexto de los referentes cuando sea necesario. En este caso un ejemplo dado anteriormente servirá para aclarar aún más esta función de restricción contextual. Un compañero te invita a una fiesta en su casa, de la que conoces la calle pero no exactamente cuál es la casa, entonces preguntas a tu compañero y él responde:

\section{(39) La fiesta es en la casa azul}

Su respuesta no ha hecho que conozcas la casa, no has identificado el referente de la casa azul; sin embargo, estás mucho más tranquilo sabiendo que no tendrás que buscar casa por casa, has descartado las casas marrones, naranjas y blancas. El significado convencional de las palabras de la proferencia unido al conocimiento sintáctico de la lengua ha hecho su función. Esta información genera una especie de objeto mental que reúne las características asociadas al significado convencional y que servirá como un modelo para buscar el referente adecuado en el contexto. De esta forma, el significado lingüístico puede verse como una especie de instrucción para construir objetos mentales que restringen las interpretaciones y guían el uso del lenguaje en el 
contexto, ayudando a seleccionar en éste los elementos relevantes (Borg, 2004; Perry, 2006; Pietroski, 2005 y 2008; Rayo, 2013; Sainsbury, 2001).

Quizá la comprensión del significado de la oración por parte del oyente no sea idéntica al significado pretendido por el hablante. No obstante, esta comprensión parcial del significado es suficiente en varios en sentidos: permite interpretar las proferencias de forma que la comunicación sea suficientemente satisfactoria, ayuda a restringir la búsqueda en contexto de los referentes y posibilita que el oyente alcance las implicaturas (p.e., en (40) que el hablante se asustó o que debe tener cuidado cuando conduzca de noche).

En la misma línea, el conocimiento de la competencia lingüística posibilita la interpretación de las proferencias que contienen indéxicos con independencia del conocimiento de los referentes en contexto. A este respecto, como explica el Minimalismo, las expresiones indéxicas tienen condiciones léxicamente codificadas que los hablantes conocen en virtud de su competencia semántica, por lo que puede decirse que los indéxicos tienen significados asignados independientemente del contexto y de cuál sea el referente de la expresión. Sabemos que yo codifica al hablante que emite la proferencia; en el caso de indéxicos intencionales como ese niño, sabemos que la expresión codifica un niño saliente en el contexto. Esta información que provee nuestra competencia lingüística es suficiente para la comprensión de las proferencias.

Siguiendo a Borg (2004), los indéxicos llevan a la formación de conceptos singulares que representan los objetos demostrados aún cuando no los conocemos. Esto significa que un indéxico codifica la representación de un objeto concreto junto a cierta información descriptiva, p.e., en Ese niño es feliz el demostrativo codifica la representación de un objeto particular (un niño) que tiene una propiedad determinada (ser feliz) ${ }^{66}$. A la vista de lo argumentado en apartados anteriores, en

\footnotetext{
${ }^{66}$ Bach (2001) ofrece otra explicación para el caso de los indéxicos intencionales. Poniendo el énfasis en la diferencia entre el uso demostrativo y el uso descriptivo de los indéxicos, Bach muestra que el contenido semántico no tiene por qué incluir los valores suplidos por el contexto. Así, si Sam dice That tree is deciduous (ibid., p. 32), lo que Sam dijo no tiene por qué ser una proposición singular en la que that se esté usando demostrativamente, sino una proposición descriptiva, no objetual, abierta e inespecífica. Siendo así, lo que Sam dijo entonces es que un árbol indeterminado es de hoja caduca. En este caso, la referencia del árbol concreto debe determinarse por la intención referencial del hablante, que, siguiendo a Bach, es parte de la noción de intención del hablante y está más allá de lo dicho.
} 
ausencia del conocimiento del objeto esta representación se construye prototípicamente. Este es un conocimiento que los hablantes tienen en virtud de su conocimiento de la entrada léxica de dichas expresiones y, por tanto, de su competencia semántica. Poseer este concepto singular no implica ser capaz de identificar perceptivamente el objeto. El conocimiento lingüístico difiere del conocimiento perceptivo del objeto que es extralingüístico. Conocer el significado de Ese niño es feliz no es lo mismo que conocer al niño en cuestión, para lo que se requiere información perceptiva que es extralingüística y, por tanto, post-semántica:

For instance, if you, looking out of the window, tell me 'That is the woman I saw yesterday', and I come over the window and see the woman you saw, what I acquire is (post-semantic) perceptually identifying knowledge of the referent, but what I don't get is further knowledge about what the sentence you produced literally meant. (Borg, ibid. p. 188)

Además, como especificidad léxica, un indéxico provee una regla semántica para conectar la representación con la información extralingüística necesaria para reconocer el referente en la ocasión particular, de forma que los indéxicos proveen instrucciones desde la competencia lingüística para la búsqueda en el contexto de los referentes. En Ese niño es feliz el indéxico codifica la instrucción de que el objeto representado corresponde con el objeto demostrado por el hablante (el niño que el hablante está demostrando) (Bach, 2001; Borg, 2004; Stojanovic, 2007).

De esta forma, los indéxicos llevan a la formación de conceptos singulares que contribuyen al significado de las proferencias con propiedades semánticas tipo fijadas de forma convencional en nuestro lexicón. En este sentido, el contenido de las expresiones indéxicas debe entenderse en términos del tipo de objeto mental que crean y no en términos de sus extensiones en contextos. La semántica es un asunto de codificación y descodificación de objetos presentados formalmente y, como dice Borg, para que la descodificación sea útil comunicativamente se necesitará conocer cómo se conecta el mensaje con el mundo, pero esto no implica que esta conexión con el mundo sea parte de la semántica. 
Debe tenerse en cuenta, que cuando hablamos no siempre lo hacemos con el mismo objetivo comunicativo. Unas veces el hablante pretende que el oyente alcance el significado a través del mínimo esfuerzo y entonces sus proferencias tienden a la brevedad, pueden incluir términos vagos o referencias indeterminadas, precisamente porque el hablante no está interesado en que el oyente comprenda estos detalles sino un significado más general. En estos casos el oyente interpreta las proferencias en función de su conocimiento prototípico, colocando valores por defecto donde sea necesario. Así, como Levinson (2000) dice, lo que se expresa de forma simple se ejemplifica estereotípicamente. En otros casos el hablante pretende comunicar el significado tan claramente como sea posible de forma que sus proferencias tienden a la redundancia y a la extensión, se identifican referencias y se resuelve la vaguedad de forma explícita. En general, hablamos económicamente de forma que si hay algo especial se menciona y si se necesita ser más específico se es. La comunicación atiende al principio cooperativo en tanto que proceso racional pero también en tanto que proceso cognitivo.

El conocimiento prototípico guía nuestras elecciones léxicas de forma que elegimos nuestras palabras en función de qué consideramos que nuestra audiencia podrá interpretar. Usaremos un término referencial cuando creamos que el oyente podrá identificar el referente (Green, 2011), en caso contrario se usará más lenguaje. De esta forma, diremos La fiesta es en la casa azul si estamos seguros de que el oyente podrá identificarla al ser la única casa con un tono al menos semejante a azul o, como dice Stojanovic (2007, p. 20), en lugar de She is dangerous usaremos The woman with a pink hat is dangerous cuando sepamos que el oyente puede dudar sobre la mujer en cuestión. En general, elegiremos utilizar el lenguaje basándonos en expectativas sobre el uso normal de las expresiones ${ }^{67}$ y estándares prototípicos. A pesar de que estas elecciones son decisiones pragmáticas (Bach, 2006b; Green, 2011), esto no implica que el contenido semántico de las oraciones lo sea.

\footnotetext{
${ }^{67}$ Pueden verse en Green (2011) algunas propuestas de definición de la noción de uso normal en términos de creencia normal. Un significado se toma como normal cuando existe una creencia entre los hablantes de que ese es el significado que todos tomarían como normal.
} 


\section{Omisión de constituyentes}

En los intercambios comunicativos muchas veces omitimos cierta información en nuestras proferencias como los constituyentes de tiempo y lugar, los eventos en la metonimia lógica o el dominio de los cuantificadores. La omisión y recuperación de los constituyentes debe explicarse de una forma más eficiente que como proceso inferencial en consonancia con la rapidez y dinamicidad de los intercambios comunicativos. En lo que sigue puede verse una explicación desde la competencia lingüística de la comprensión de proferencias que incluyen buena parte de los fenómenos que el Pragmatismo alega en la defensa de la explicatura.

Como se vio en el capítulo anterior en relación a la crítica del tratamiento pragmatista de los constituyentes inarticulados, es posible dar una explicación desde la competencia lingüística de los constituyentes de tiempo y lugar omitidos en las proferencias. A este respecto conviene recordar brevemente cómo Hinzen (2015) explica que la gramática codifica los constituyentes de tiempo y localización. Las lenguas cuentan con los mecanismos gramaticales del tiempo verbal y la persona gramatical para expresar la referencia a las coordenadas espacio-temporales de los eventos de habla, por lo que en muchas ocasiones no es necesario explicitar estos constituyentes. Cuando las coordenadas del evento de habla coinciden con las de la proferencia tienden a omitirse en beneficio de una comunicación eficiente y económica; mientras que, si hay un desajuste entre el plano metafísico y el plano lingüístico, se explicitan. De esta forma, contamos con una explicación desde la competencia de la omisión de dichos constituyentes, así como una explicación de las condiciones en que pueden dejarse implícitos.

En la misma línea, como se anticipó también en el capítulo anterior, Groefsema (1995) ofrece una explicación semántica de cuándo pueden dejarse implícitos los argumentos en la metonimia lógica basada en las restricciones que impone el léxico. Siguiendo a Groefsema, solo pueden dejarse implícitos aquellos argumentos cuya interpretación está suficientemente restringida como para que su recuperación sea automática. En este sentido, usamos metonimias y omitimos algunos 
constituyentes siguiendo criterios de tipicalidad. El sistema conceptual incluye, como se ha explicado, prototipos para eventos que se generan a partir del conocimiento temático sobre los participantes típicos y los tipos semánticos generales de los argumentos de los verbos. Nuestra cognición utiliza este conocimiento en la comprensión lingüística recuperándolo en la memoria de trabajo para crear el schema facilitando la comprensión y explicando la omisión de los constituyentes. El oyente utiliza esta información para suplir el material omitido. Esto permite que comprendamos proferencias como (30) y (41) en las que algunos constituyentes están omitidos sin necesidad de apelar al contexto ni de efectuar procesamiento pragmático extra:

(30) She was enjoying the first coffee of the day

(41) The customer finished the hamburger

Ha sido común explicar proferencias como las anteriores a partir del fenómeno de la coerción en base a un análisis de cambio de tipo (Jackendoff, 1997; Pustejovsky, 1993 y 1995). En términos generales, se asume que los verbos, como se vio en el apartado anterior, imponen una restricción en el tipo semántico de sus argumentos. Así, cuando un verbo que requiere un complemento que denote un evento se acompaña de un complemento que denota una entidad, como en los ejemplos anteriores, se produce un desajuste en la representación semántica que fuerza a que el sistema de comprensión lleve a cabo un cambio en el tipo semántico en consonancia con la restricción que impone el verbo. De esta forma proferencias como las anteriores reciben una interpretación de evento como resultado del cambio de tipo semántico: (30) se interpreta como disfrutando de beber el café y (41) como acabó de comer la hamburguesa ${ }^{68}$.

No obstante, el enfoque del cambio de tipo parece insuficiente por sí solo para explicar todos los casos. La hipótesis del cambio de tipo predice un coste de procesamiento al forzarse el cambio de tipo, sin embargo no todos los casos implican un coste de procesamiento. Lai (2017), siguiendo

\footnotetext{
${ }^{68}$ En el modelo de Pustejovsky (1993) el evento se recupera a través de la estructura qualia de los ítems léxicos que son el complemento en las proferencias, p.e., en (30) el rol télico devuelve la interpretación de beber el café, mientras el rol agentivo devuelve la interpretación de preparar el café. De esta forma, para Pustejovsky el evento está incluido en la estructura qualia del ítem léxico café.
} 
el trabajo de Piñago y Deo (2012), presenta evidencias que muestran que los verbos de estado psicológico como enjoy no conllevan un coste de procesamiento ${ }^{69}$. Esto lleva a la idea de que el coste de procesamiento está en relación, no solo con una operación de cambio de tipo para aquellos verbos que lo requieren, sino además con la alta o baja predictibilidad del complemento del verbo, lo que apela en definitiva a un conocimiento prototípico más fino de los ítems léxicos. En la misma línea, Zarcone et al. (2017), argumentan que el coste de procesamiento está más bien conectado con las expectativas probabilísticas generadas durante la comprensión. Así, por ejemplo, los verbos que seleccionan eventos se leen más rápido si el objeto del evento es coherente con el conocimiento activado por el sujeto (p. 2):

\section{(41) The customer finished hamburger}

(42) The chef finished hamburger

En (41) y (42), el intérprete apela al conocimiento semántico asociado prototípicamente con el sujeto para interpretar el evento en correspondencia con el objeto del evento, de forma que para interpretar ambas se usa el conocimiento asociado de que los clientes típicamente comen hamburguesas mientras los cocineros típicamente las cocinan.

Puede decirse entonces que las estructuras generalizadas de evento imponen restricciones sintacto-semánticas en las interpretaciones en un doble sentido, restricciones acerca del tipo semántico general de los argumentos de los verbos así como restricciones relativas a un conocimiento más detallado sobre los participantes (Lai 2017; Zarcone et al., 2017). En base a esto, una consideración integrada de los tipos semánticos generales junto a un conocimiento prototípico más fino de los ítems léxicos puede explicar cómo los oyentes interpretan proferencias con ítems omitidos. En (30), (41) y (42) la representación conceptual en forma de schema que nuestra cognición crea para su comprensión representa un evento omitido y éste se computa en función de

\footnotetext{
${ }^{69}$ Esto lleva a Lai a descartar que en los verbos aspectuales exista realmente coerción, al menos no en términos del fenómeno clásico de coerción que conlleva una operación de cambio de tipo.
} 
estándares de prototipicalidad. De esta forma, al interpretar los items léxicos se genera una estructura en el schema representacional que restringe, anticipa y activa los posibles argumentos.

De la misma forma, la representación conceptual siguiendo estándares de tipicalidad puede explicar la cuantificación. El problema en estos casos no parece ser la cuantificación en sí misma, sino el encaje de la interpretación semántica de los términos para formar el schema:

(13) Every bottle is in the fridge

(36) Every bedroom in the hotel has its own bathroom

La representación del schema en nuestro sistema de comprensión de (13) aporta en sí mismo el dominio de la cuantificación. El significado léxico de fridge y bottle restringen suficientemente por sí mismos el dominio. Dado el conocimiento de lo que típicamente es una botella, así como del tamaño típico de un frigorífico y de las situaciones típicas que organizan nuestra experiencia pasada, puede obtenerse suficiente restricción para la cuantificación. En el caso de la proferencia (36) puede decirse que hay varias interpretaciones posibles pero lo que suele ocurrir es que se interprete de una forma. Siguiendo a Sandford y Garrod (1998, p. 172), (36) se interpreta como que cada habitación tiene un baño no compartido puesto que esta interpretación es más plausible en función del conocimiento acumulado en la memoria sobre cómo son típicamente los hoteles; el resto de posibilidades lógicas simplemente son académicas. En este sentido, parece que el sistema computa el significado de la oración más plausible semánticamente sin necesidad de procesos pragmáticos y de forma bastante automática (Ferreira y Patson, 2007), de manera que, como se vio en capítulos anteriores, se maneja con esta interpretación hasta que haya algo que le obligue a sustituirla. Además, parece un conocimiento suficiente, no sólo para interpretar las proferencias sino también para alcanzar las implicaturas (que si quiero algo de beber tengo que ir al frigorífico para (13) y que no debo preocuparme porque si necesito un baño tendré uno a mi disposición para (36)).

Por último, se incluye aquí una explicación de cómo nuestra competencia puede explicar la interpretación de las conectivas. Como se vio en el capítulo anterior, el Pragmatismo incluye las 
conectivas como un caso de enriquecimiento que da lugar a la explicatura al entender que su comprensión depende de un contenido que es comunicado aunque no codificado. Así, por ejemplo, para el Pragmatismo la conectiva en (14) tiene un significado temporal que no está codificado:

(14) She gave him her key and [then] he opened the door

Sin embargo, más bien parece que ejemplos como éste pueden explicarse desde la competencia sintacto-semántica y ciertas regularidades pragmáticas. Por un lado, usamos la conectiva siguiendo ciertas reglas gramaticales de forma que sabemos por la gramática que la conectiva sirve para unir cosas y se usa en las enumeraciones, tanto de términos como de oraciones. Por otro lado, solemos usar un orden cuando contamos los sucesos de forma que contamos las cosas siguiendo cierta lógica temporal. De esta forma, cuando queremos hablar de un acontecimiento, usamos varias proferencias que enumeramos siguiendo esta lógica temporal y la regla gramatical para la conectiva. No parece el resultado de un proceso inferencial, sino el resultado de aplicar nuestro conocimiento prototípico, esta vez aplicado a los mismos hechos lingüísticos; el orden en el que hablamos lo ponemos regularmente. El sistema de categorización en términos de tipicalidad afecta así mismo a la conceptualización de los eventos y prácticas lingüísticas. También categorizamos como más o menos típicas las conductas lingüísticas estableciendo regularidades pragmáticas, patrones generales de comunicación eficiente (Bach, 2008).

En conclusión, el conocimiento tipo de las situaciones permite que en nuestros intercambios omitamos cierta información en nuestras proferencias. En general, omitimos la información que creemos que está en el schema del oyente, siguiendo el prototipo semántico correspondiente en el sistema conceptual (Bosch, 2007; Brewer y Treyens, 1981; Zarcone, 2014), y que, por tanto, como dice Groefsema (1995), está suficientemente restringida como para que pueda recuperarse automáticamente sin constituir un esfuerzo de comprensión. 


\subsubsection{El significado de la oración y la distinción semántica-pragmática}

Los argumentos expuestos han dado lugar a varias ideas sobre el significado de la oración: no puede descansar en las intenciones del hablante ni en los procesos de comprensión efectuados por el oyente, es un nivel que debe ser invariable, con cierta estabilidad a través de los contextos, y está ligado al léxico y a la gramática. Estas ideas deben ahora integrarse en un una modificación de la visión del significado siguiendo un esquema binario.

No obstante, conviene recordar el esquema del modelo tripartito pragmatista. Para éste en la comprensión de las proferencias se distinguen tres niveles: el input lingüístico (forma lógica), la explicatura (lo dicho) y la implicatura. El nivel del input lingüístico se entiende como un nivel no veritativo-condicional, no informativo y $\sin$ rol en los procesos de interpretación de las proferencias. Sobre el input lingüístico se mantiene que actúan procesos pragmáticos que dan lugar a la explicatura, nivel de significado veritativo-condicional. Finalmente, sobre la explicatura actúan nuevamente procesos pragmáticos para alcanzar las implicaturas.

Frente a este modelo, lo expuesto en el presente trabajo lleva a la defensa de un modelo binario. En la línea de lo que algunos autores han defendido (Borg, 2016; Jary, 2016; Katz, 1977), en este modelo sólo cabe la diferenciación en dos niveles: significado lingüístico o significado de la oración y significado implicado o significado del hablante. Desde la perspectiva presentada aquí, el significado de la oración o significado lingüístico es un nivel de significado estable e invariable a los contextos que está conectado con nuestro conocimiento del mundo en forma de prototipos estabilizados por las prácticas y experiencias habituales de la comunidad. Este nivel de significado no es veritativo-condicional, sin embargo es un nivel informativo que cumple un papel en los procesos de interpretación y comunicación.

Como se ha visto, la comprensión lingüística puede verse como la construcción de un schema guiado por el conocimiento prototípico. El conocimiento lingüístico, sintacto-semántico, influencia el procesamiento y la interpretación de las proferencias de forma que las palabras activan los 
procesos cognitivos necesarios para la formación de las estructuras conceptuales interpretativas. Así, los inputs lingüísticos implican un conjunto de procesos semánticos: resolución de vaguedad, emulación de referencias, instanciación de valores por defecto e integración de la semántica léxica en el contexto de la oración. La conjunción de estos procesos semánticos produce el significado de la oración que corresponde a una estructura conceptual de nivel tipo, resultado de la composición sintáctica y gramatical del contenido rico que hace disponible el léxico en conexión con el sistema conceptual y el conocimiento acumulado en la memoria; entendiendo la composición, no como composición lógico-matemática, sino como la construcción de un schema representacional en el que se integran la información que hace disponible el léxico y la información de conocimiento general según patrones de tipicalidad.

Esta estructura conceptual de nivel tipo puede ser suficiente en muchos casos para la interpretación y una comunicación satisfactoria. En casos donde no lo fuera, serviría de base para la integración de la información provista por el contexto y otros recursos de información dependientes del conocimiento general en el modelo mental creado en la memoria de trabajo. De esta forma, sobre este nivel pueden actuar los procesos pragmáticos necesarios para alcanzar los significados secundarios cuando se produce una contradicción o contraste entre el significado tipo y el contexto, se da un fracaso en los procesos semánticos debido a la violación de máximas cooperativas o cuando se producen inferencias racionales fundadas en el conocimiento $\mathrm{u}$ otros recursos de información.

Este sentido integrador de los factores cognitivos involucrados en la categorización conceptual ofrece ventajas explicativas puesto que encaja con el modelo de ecología cognitiva y puede explicar el nivel de convencionalidad necesario que actúa como garantía en la comunicación, dejando espacio para la relativización al contexto de las proferencias.

En resumen, el significado de la oración está ligado a los inputs lingüísticos de las proferencias, construido a través del léxico y la gramática de forma convencional, prototípica y 
libre de contexto. Este nivel de significado, como se ha visto a lo largo del capítulo, cumple algunos roles. En este sentido, cumple el rol de restringir entre las posibles interpretaciones de una proferencia, funciona como base para la realización de inferencias, garantiza la comunicación y establece distinciones acerca de los compromisos del hablante, constituyéndose como el soporte de la responsabilidad estricta o conversacional del mismo.

Ahora bien, debe admitirse que, a pesar de ello, el significado lingüístico infradetermina las interpretaciones en el sentido en que puede no determinar una única interpretación correcta e idéntica a la intención del hablante. En el ejemplo de Rayo (2013, p. 648) en relación a la proferencia La fiesta es en la casa azul, la fiesta realmente se da en una casa de color gris azulado. Sin embargo, este es un asunto que no tiene por qué pertenecer a nuestra competencia semántica. Más bien, éste es el asunto de la pragmática. Uno no tiene por qué elegir entre una explicación del proceso de comprensión de las proferencias semántica o pragmática, sino más bien integrar los factores que entran en juego en el proceso y producir una explicación integrada. La competencia semántica del oyente funcionó correctamente dando significado al término azul en el ejemplo anterior; es parte de su competencia pragmática inferir en el contexto particular la pretensión del hablante de asimilar azul con azul grisáceo, así como pertenece al ámbito pragmático que el hablante escogiera azul para su proferencia y no el matiz azul grisáceo en detrimento de una comunicación cooperativa; como lo es también que el hablante identifique la casa a través del color azul de su fachada y no de su interior. A este respecto el rol a cumplir por la semántica es mínimo en cuanto al completo fenómeno de la comunicación. La semántica es un tipo de conocimiento lingüístico que contribuye al entendimiento de las proferencias pero que no es suficiente por sí solo para la tarea de explicar la comunicación. Además de este conocimiento se necesita el conocimiento extralingüístico, competencia de la pragmática. 



\section{Conclusiones}

El debate contemporáneo en torno a la cuestión del significado y la distinción semánticapragmática se constituye como una forma de acometer los problemas surgidos en el seno de la semántica de la concepción heredada.

La combinación de la semántica clásica y la teoría griceana forjó la visión de un modelo binario de la comprensión linguística. El significado de la oración, localizado en el nivel de lo dicho, se constituye como un significado lingüístico, ligado a las convenciones léxicas y gramaticales, independiente del contexto y sujeto a los requisitos de la composicionalidad y el compromiso del hablante; mientras el significado del hablante se constituye como un significado secundario dependiente del contexto en el que se engloban los significados figurados, no literales e implicados.

El desarrollo de la concepción heredada ha mostrado en la discusión contemporánea que en cuanto al nivel de lo dicho existe una tensión entre la dependencia del contexto del lenguaje y el supuesto veritativo-condicional, i.e., el significado se define partir de la noción de condiciones de verdad. Se intenta mostrar desde múltiples perspectivas que las características lingüísticas de las oraciones con independencia del contexto infradeterminan el significado. De esta forma, la tensión se resuelve, especialmente desde el Pragmatismo, manteniendo el carácter veritativo-condicional 
mientras se descarta la independencia del contexto. Esto da lugar a un giro pragmático en el supuesto veritativo-condicional que redefine la noción de lo dicho como un nivel enriquecido pragmáticamente dentro de un modelo tripartito del significado en el que se distinguen la forma lógica, la explicatura y las implicaturas.

Sin embargo, es posible resolver la tensión de manera inversa, descartando el criterio veritativo-condicional mientras se mantiene la independencia del contexto. Para ello, es necesario poner en cuestión, no sólo los argumentos contemporáneos en la línea contraria, sino además los presupuestos mismos de la teoría semántica dominante.

La semántica veritativo-condicional se sustenta en la idea de que la capacidad representacional del lenguaje se expresa en la relación lenguaje-realidad, lo que implica ciertas consecuencias para el estudio del significado. Por un lado, lleva a identificar la forma lógica como la estructura lingüística capaz de representar esa relación, estableciendo el nivel mínimo de análisis en la oración mientras se descarta el estudio de la semántica léxica. Por otro, se explica el significado como la relación entre las expresiones y sus referencias a partir de nociones lógico-matemáticas como denotación, satisfacción y función. El resultado es una semántica extensional en la que se define el significado de las oraciones recursivamente a través de la noción semántica de verdad, generalizando en las teorías posteriores la forma de definir el significado como la determinación del contenido proposicional, i.e, la determinación de las condiciones de verdad de las oraciones. Es desde esta concepción de donde surgen los argumentos pragmatistas para la defensa de la visión del significado como un asunto radicalmente pragmático. La determinación de las condiciones de verdad requiere identificar las referencias de las expresiones, pero las expresiones del lenguaje natural son a menudo indeterminadas en este sentido. Por ello, se entiende que los problemas para la determinación de las condiciones de verdad, dada la sensibilidad al contexto del lenguaje, pueden solucionarse desde la apelación al contexto de las proferencias. Desde esta perspectiva, se ha llevado a cabo la revisión tanto del supuesto veritativo-condicional como de la solución pragmática ofrecida en el debate contemporáneo. 
La revisión del supuesto veritativo-condicional muestra que el supuesto es injustificado e inadecuado para la explicación de la semántica del lenguaje natural al descansar en el dogma extensionalista. El supuesto se sustenta en tres tesis fundamentales: i) el lenguaje natural es una extensión de los lenguajes formales, por lo que puede tratarse formalmente, ii) el significado consiste en la referencia y iii) puede explicarse mediante la noción semántica de verdad. Sin embargo, tales presupuestos son problemáticos. Hay un hueco irrebasable entre los lenguajes naturales y los lenguajes formales, así como entre el significado y la verdad, fundamentalmente debido a que no es posible dar una teoría de la referencia para el lenguaje natural. Esto supone dejar sin garantía la noción semántica de verdad como correspondencia, necesaria para una teoría semántica veritativo-condicional. De manera que las nociones de referencia y verdad se revelan como nociones técnicas en una teoría semántica del lenguaje natural desnaturalizada.

En contraste, los argumentos presentados indican que ambas nociones deben desligarse de la explicación extensional al tiempo que se conectan con la cognición. Lo que tomamos como objetos y su caracterización depende de factores cognitivos, de forma que establecemos las referencias en función del entramado de información sobre el mundo, las experiencias individuales y las perspectivas escogidas. Así mismo, en lo relativo al lenguaje natural parece mejor hablar de juicios de verdad entre hablantes como un ajuste mutuo entre sus conceptualizaciones del mundo, por lo que la verdad en el lenguaje natural depende de la cognición.

La solución pragmatista en el debate contemporáneo no resuelve los problemas derivados de la concepción heredada. Por un lado, el tratamiento de la indexicalidad implica problemas tanto para la visión minimalista como para la pragmatista en un doble sentido: 1) El tratamiento del significado en términos de funciones de contextos a valores de verdad es problemático puesto que no explica el tratamiento de los indéxicos intencionales ni el hecho de la inteligibilidad de las oraciones sin contexto y 2) hay innumerables parámetros contextuales, lo que implica que si consideramos todos, incluida la intención del hablante, la función se vuelve inoperativa, pero si restringimos el límite de parámetros la explicación se vuelve arbitraria. 
Por otro lado, se ha mostrado que el modelo de enriquecimiento y explicatura parece injustificado. El enriquecimiento es un proceso excesivamente arbitrario e irrestricto, así como no es posible demarcar la explicatura frente a la forma lógica y las implicaturas. Los argumentos expuestos muestran que el criterio para decidir el material enriquecido descansa en última instancia en la noción de intención del hablante incluida en la noción de contexto cognitivo. Si bien, un análisis de ambas nociones revela que son inadecuadas para la explicación semántica. En consecuencia, parece más adecuado tomar las explicaturas como implicaturas materiales (Jary, 2013 y 2016) y caracterizar el contexto en un sentido clásico como el campo común saliente, el estado de la conversación, los interlocutores y los aspectos ambientales. De esta forma, el contexto no es constitutivo del significado, más bien su rol es epistémico, en el sentido en que proporciona la información necesaria para efectuar inferencias acerca de la intención del hablante y alcanzar las implicaturas.

Además, el modelo de inferencia post-léxica no encaja con algunas evidencias procedentes de estudios neurofisiológicos según los cuales no hay evidencia de inferencias pragmáticas en la recuperación de eventos de la metonimia lógica, así como las evidencias apuntan a que el sistema de comprensión es incremental y que la integración del significado con el conocimiento del mundo es temprana.

Un modelo en el que el sistema de comprensión construya un significado enriquecido considerando todos los recursos de información tras la decodificación léxica es contrario a la realidad de los intercambios comunicativos y a la ecología cognitiva. La semántica no es una cuestión de enriquecimiento de un material no explícito que está en la mente del hablante, sino una cuestión de explicar un nivel de significado compartido que permita la convergencia necesaria en los estados mentales de los hablantes para garantizar la comunicación. Este nivel compartido debe tener cierta independencia del contexto, lo que implica considerar el factor de convencionalidad como un factor importante en los procesos de producción y comprensión de las proferencias. 
Desde esta perspectiva, la noción de convención establece el vínculo necesario entre la cognición y la comunicación en la medida en que se entiende la convención como conceptualización compartida en términos de tipicalidad donde el léxico cobra un lugar predominante. El proceso de codificación/descodificación no puede infravalorarse como se ha hecho desde la concepción heredada desterrando la semántica léxica del estudio del significado. Es necesario dar cuenta de factores cognitivos como la categorización conceptual y la tipicalidad que están inmersos en el significado léxico. En este sentido, el sistema léxico se concibe, frente a la visión estándar, como un sistema rico en conexión con el sistema conceptual. Este sistema posibilita una explicación de muchos fenómenos lingüísticos problemáticos basada en la competencia sintacto-semántica con independencia del contexto y en consonancia con el principio cooperativo, entendido éste como un principio de eficiencia comunicativa y cognitiva. Esto lleva a explicar el modelo de comprensión lingüística siguiendo un esquema binario en conexión con la cognición.

Las palabras activan los procesos cognitivos necesarios para la formación de las estructuras conceptuales interpretativas guiando y restringiendo las interpretaciones. Así, los inputs lingüísticos implican un conjunto de procesos semánticos: resolución de vaguedad, emulación de referencias, instanciación de valores por defecto e integración de la semántica léxica en el contexto de la oración. La integración de estos procesos semánticos produce el significado de la oración que corresponde a una estructura conceptual de nivel tipo frente al significado del hablante. En base a esto, el sistema computa el significado de la oración más plausible en términos de tipicalidad y de manera bastante automática, incluso sin resolver la vaguedad o las anomalías en muchos casos. A pesar de que esto puede implicar una comprensión parcial del significado, ésta parece suficiente para una comunicación satisfactoria, así como para alcanzar implicaturas.

Este tipo de significado cumple además algunos roles: i) es el soporte de la responsabilidad estricta del hablante, ii) funciona como base para la realización de inferencias, iii) establece garantía en la comunicación y iv) explica el lenguaje natural como una facultad compartida por los 
hablantes. No obstante, este nivel de significado puede no determinar la interpretación correspondiente a la intención del hablante, por lo que su rol en cuanto al completo fenómeno de la comunicación es mínimo.

En conclusión, la capacidad representacional del lenguaje debe entenderse desde la relación que se establece entre el lenguaje y el pensamiento:

But just as we say that the gardener mows the lawn when we know that it is the lawn-mower which actually does the cutting, so, though we know that the direct relation of symbols is with thought, we also say that symbols record events and communicate facts (Ogden y Richards, 1923, p. 9).

El significado es una estructura mental donde la referencia está mediada por el sistema de conceptualización de los hablantes y por la convención surgida de la generalización cognitiva de las experiencias y prácticas sociales. 


\section{Referencias}

Acero, J. J. (1998). Introducción: concepciones del lenguaje. En J. J. Acero (Ed.), Filosofía del lenguaje I. Semántica (pp. 11-25). Barcelona, España: Trotta.

Acero, J. J., Bustos, E., y Quesada, D. (1982). Introducción a la filosofía del lenguaje. Madrid, España: Cátedra.

Anderson, L., y Lepore, E. (2013). Slurring words. Nous, 47(1), 25-48.

Ariel, M. (2002). The demise of a unique concept of literal meaning. Journal of Pragmatics, 34, $361-402$.

Bach, E. W. (1986). The algebra of events. Linguistics \& Philosophy, 9, 5-16.

Bach, E. W. (1989). Informal Lectures On Formal Semantics. New York, N.Y.: State University of New York Press.

Bach, E. W., y Chao, W. (2012). The metaphysics of natural language(s). En R. M. Kempson, T. Fernando y N. Asher (Eds.), Philosophy of Linguistics (pp. 175-196). Oxford, Inglaterra: North Holland.

Bach, K. (1994). Conversational Impliciture. Mind and Language, 9(2), 124-162.

Bach, K. (1999). The Semantics-Pragmatics Distinction: What It Is and Why It Matters. En K. Turner (Ed.), The Semantics-Pragmatics Interface from Different Points of View (pp. 65-84). Oxford, Inglaterra: Elsevier.

Bach, K. (2001). You don't say? Synthese, 128, 15-44. 
Bach, K. (2005). Context ex machina. En Z. Szabó (Ed.), Semantics vs. Pragmatics (pp. 15-44). Oxford, Inglaterra: Oxford University Press.

Bach, K. (2006a). Regressions in pragmatics (and semantics). En N. Burton-Roberts (Ed.), Advances in Pragmatics (pp. 24-44). Houndmills, Inglaterra: Palgrave Macmillan.

Bach, K. (2006b). What Does it Take to Refer? En E. Lepore y B. Smith (Eds.), The Oxford Handbook of Philosophy of Language (pp. 516-554). Oxford, Inglaterra: Oxford University Press.

Bach, K. (2008). Statements and Beliefs without Truth-Aptitude. Recuperado de http://userwww.sfsu.edu/kbach/Minimalism.htm

Bar-Hillel, Y. (1954). Indexical Expressions. Mind, 63(251), 359-379.

Bar-Hillel, Y. (1971). Out of the Pragmatic Wastebasket. Linguistic Inquiry, 2(3), 401-407.

Barba, J. L. (2007). Formal semantics in the age of pragmatics. Linguistics and Philosophy, 30(6), 637-668.

Barba, J. L. (2010). Lógica, lógicas. Valladolid, España: Universidad de Valladolid, Secretariado de Publicaciones e Intercambio Editorial.

Baron-Cohen, S., Leslie, A. M., y Frith, U. (1985). Does the autistic child have a "theory of mind"? Cognition, 21, 37-46.

Barsalou, L. W. (1985). Ideals, Central Tendency, and Frequency of Instantiation as Determinants of Graded Structure in Categories. Journal of Experimental Psychology: Learning, Memory, and Cognition, 11(4), 629-654.

Barsalou, L. W. (1987). The instability of graded structure: implications for the nature of concepts. En U. Neisser (Ed.), Concepts and Conceptual Development: Ecological and Intellectual Factors in Categorization (pp. 101-140). Cambridge, MA: Cambridge University Press.

Barsalou, L. W. (1999). Perceptual symbol systems. Behavioral and Brain Sciences, 22, 577-660.

Barwise, J., y Perry, J. (1981). Situations and attitudes. Journal of Philosophy 78(11), 668-691.

Bezuidenhout, A. (2001). Metaphor and What is Said: A Defense of a Direct Expression View of Metaphor. Midwest Studies in Philosophy, 25, 156-186. 
Bianchi, C. (2004). Semantics and Pragmatics: The Distinction Reloaded. En C. Bianchi (Ed.), The Semantics/Pragmatics Distinction (pp. 1-11). Stanford, CA: CSLI Publications.

Bierwisch, M., y Schreuder, R. (1992). From Concepts to Lexical Items. Cognition, 42, 23-60.

Blakemore, D. (1987). Semantic Constraints on Relevance. Oxford, Inglaterra: Blackwell.

Borg, E. (2004). Minimal Semantics. Oxford, Inglaterra: Oxford University Press.

Borg, E. (2007). Minimalism vs. Contextualism in Semantics. En M. Ezcurdia y R. J. Stainton (Eds.), The Semantics-Pragmatics Boundary in Philosophy (pp. 429-448). Toronto, ON: Broadview Press, 2013.

Borg, E. (2016). Exploding explicatures. Mind and Language, 31(3), 335-355.

Borg, E. (2017). Explanatory Roles for Minimal Content. Noûs, 1-27. doi: https://doi.org/10.1111/nous.12217

Bosch, P. (2007). Productivity, Polisemy, and Predicate Indexicality. En B. ten Cate y H. Zeevat (Eds.), Proceedings of the Sixth International Tbilisi Symposium on Language, Logic and Computation (pp. 58-71). Berlin/Heidelberg: Springer.

Bower, G. H., Black, J. B., y Turner, T. J. (1979). Scripts in Memory for Text. Cognitive Psychology, 11, 177-220.

Branquinho, J. (2001). Enciclopédia de Termos Lógico-Filosóficos. Lisboa, Portugal: Gradiva.

Briscoe, T., Copestake, A., y Boguraev, B. (1990). Enjoy the paper: Lexical semantics via lexicology. En Proceedings of the 13th conference on Computational linguistics: Vol. 2. (pp. 42-47). Helsinki, Finlandia: Association for Computational Linguistics.

Brewer, W. F., y Treyens, J. C. (1981). Role of Schemata in Memory for Places. Cognitive Psychology, 13, 207-230.

Camós, F., y Frápolli, M. J. (2008). Contextualismo y Semanticismo: Debate abierto en la filosofía del lenguaje contemporánea. Episteme, 28(1), 1-20.

Camp, E. (2006). Contextualism, Metaphor, and What is Said. Mind and language, 21, 280-309.

Camp, E. (2013). Slurring Perspectives. Analytic Philosophy, 54(3), 330-349. 
Cappelen, H., y Lepore, E. (2005). Radical and Moderate Pragmatics: Does Meaning Determine Truth Conditions? En Z. G. Szabó (Ed.), Semantics versus pragmatics (pp. 45-71). Oxford, Inglaterra: Oxford University Press.

Carlson, G. N. (1977). Reference to Kinds in English. New York, NY: Garland Press.

Carlson, G., y Pelletier, F. J. (2002). The average American has 2.3 children. Journal of Semantics, 19, 73-104.

Carston, R. (1997). Enrichment and Loosening: Complementary Processes in Deriving the Proposition Expresed. Linguistische Berichte, 8, 103-177.

Carston, R. (2002a). Linguistic Meaning, Communicated Meaning and Cognitive Pragmatics. Mind and Language, 17(1-2), 127-148.

Carston, R. (2002b). Thoughts and Utterances: The Pragmatics of Explicit Communication. Oxford, Inglaterra: Blackwell Publishers.

Carston, R. (2007). How many pragmatic systems are there? En M. J. Frápoli (Ed.) Saying, Meaning and Referring. Essays on François Recanati's Philosophy of Language (pp. 18-48). Basingstoke, Inglaterra: Palgrave Macmillan.

Carston, R. (2008). Linguistic Communication and the Semantics/Pragmatics Distinction. Synthese, 165(3), 321-345.

Carston, R. (2009). The Explicit/Implicit Distinction in Pragmatics and the Limits of Explicit Communication. International Review of Pragmatics, 1, 35-62.

Carston, R. (2012). Word Meaning and Concept Expressed. The Linguistic Review, 29(4), 607-623.

Carston, R., y Hall. A. (2012). Implicature and explicatura. En H. J. Schmid (Ed.), Cognitive Pragmatics, Vol.4 (pp. 47-84). Berlín/New York: Mouton de Gruyter.

Chomsky, N. (1957). Syntactic Structures. París, Francia: Mouton.

Chomsky, N. (1965). Aspects of the Theory of Syntax. Cambridge, MA: MIT Press.

Chomsky, N. (2000). New Horizons in the Study of Language and Mind. New York, NY: Cambridge University Press. 
Crespo, N., Manghi, D., García, G., y Cáceres, P. (2007). Déficit de atención y comprensión de significados no literales: interpretación de actos de habla indirectos y frases hechas. Revista de Neurología, 44(2), 75-80.

Creswell, M. J. (1973). Logics and languages. London, Inglaterra: Methuen.

Creswell, M. J. (2006). Formal Semantics. En M. Devitt y R. Hanley (Eds.), The Blackwell Guide to the Philosophy of Language (pp. 131-146). Oxford, Inglaterra: Blackwell Publishing.

Corredor, C. (1999). Filosofía del lenguaje. Una aproximación a las teorías del significado del siglo XX. Madrid, España: Visor.

Covington, N.V., y Duff, M. (2016). Expanding the Language Network: Direct Contributions from the Hippocampus. Trends in Cognitive Sciences, 20(12), 869-870.

Dascal, M. (1985). Language use in jokes and dreams: sociopragmatics vs. psychopragmatics. Language and Communication, 5(2), 95-106.

Dascal, M. (1987). Defending Literal Meaning. Cognitive Science, 11, 259-281.

Davidson, D. (1967a). Verdad y significado (Trad. Filipi, G.). En De la verdad y de la interpretación (pp. 39-56). Barcelona, España: Gedisa, 1990.

Davidson, D. (1967b). The logical form of action sentences. En Essays on Actions and Events (pp. 105-122). Oxford, Inglaterra: Clarendon Press, 1980.

Davidson, D. (1970). Semántica para los lenguajes naturales (Trad. Filipi, G.). En De la verdad y de la interpretación (pp. 73-81). Barcelona, España: Gedisa, 1990.

Davidson, D. (1973). En defensa de la convención T (Trad. Filipi, G.). En De la verdad y la Interpretación (pp. 82-91). Barcelona, España: Gedisa, 1990.

Davidson, D. (1974). De la idea misma de un esquema conceptual (Trad. Filipi, G.). En De la verdad y de la interpretación (pp. 189-203). Barcelona, España: Gedisa, 1990.

Davidson, D. (1977a). El método de la verdad en metafísica (Trad. Filipi, G.). En De la verdad y de la interpretación (pp. 204-218). Barcelona, España: Gedisa, 1990.

Davidson, D. (1977b). Realidad sin referencia (Trad. Filipi, G.). En De la verdad y de la interpretación (pp. 219-28.) Barcelona, España: Gedisa, 1990. 
De Almeida, R. G., y Dwivedi, V. D. (2008). Coercion without lexical decomposition: Type-hifting effects revisited. Canadian Journal of Linguistics, 53(2/3), 301-326.

Del Pinal, G. (2018). Meaning, Modulation, and Context: A Multidimensional Semantics for Truthconditional Pragmatics. Linguistics and Philosophy, 41(2), 165-207.

Deaño, A. (1974). Introducción a la lógica formal. Madrid, España: Alianza.

Descartes, R. (1641). Meditaciones metafísicas (Trad. Morente, M. G.). Madrid, España: EspasaCalpe, 1982.

Dowty, D. R. (1979). Word Meaning and Montague Grammar. The Semantics of Verbs and Times in Generative Semantics and in Montague's PTQ. Dordrecht, Holanda: Reidel.

Dowty, D. R., Wall, R. E., y Peters, S. (1981). Introduction to Montague Semantics. Dordrecht, Holanda: Reidel.

Duranti, A. (1992). La etnografía del habla: hacia una lingüística de la praxis. En F. J. Newmeyer (Ed.), Panorama de la lingüística moderna de la Universidad de Cambridge, Vol. 4 (pp. 253 274). Madrid, España: Visor.

Elman, J. L. (2011). Lexical knowledge without a lexicon? The Mental Lexicon, 6(1), 1-33.

Escandell, M. V., y Leonetti, M. (2000). Categorías funcionales y semántica procedimental. En M. Martínez et al. (Eds.), Cien años de investigación semántica: de Michel Bréal a la actualidad. Vol.1 (pp. 363-378). Madrid, España: Ed. Clásicas.

Evans, G. (1976). Semantic Structure and Logical Form. En G. Evans (Ed.), Collected Papers (pp. 49-75). Oxford, Inglaterra: Clarendon Press, 1985.

Evans, V. (2006). Lexical Concepts, Cognitive Models and Meaning-Construction. Cognitive Linguistics, 17(4), 491-534.

Falkum, I. L., y Vicente, A. (2015). Polysemy: Current perspectives and approaches. Lingua, 157, $1-16$.

Ferreira, F., Ferraro, V., y Bailey, K. G. D. (2002). Good-enough representations in language comprehension. Current Directions in Psychological Science, 11(1), 11-15. 
Ferreira, F. y Patson, N. D. (2007). The 'Good Enough' Approach to language comprehension. Language and Linguistics Compass, 1(1-2), 71-83.

Ferretti, T. R., McRae, K. y Hatherell, A. (2001). Integrating verbs, situation schemas, and thematic role concepts. Journal of Memory and Language, 44, 516-547.

Field, H. (1972). Tarski's Theory of Truth. Journal of Philosophy, 69(13), 347-375.

Filip, H. (2011). Aspectual class and Aktionsart. En C. Maienborn, K. von Heusinger y P. Portner (Eds.), Semantics. An International Handbook of Natural Language Meaning. Vol. 2 (pp. 1186-1217). Berlín/Boston: de Gruyter.

Fleisner, A. (2011). Hacia una teoría de la referencia para los términos de magnitudes físicas. Revista Internacional de Filosofía, 37(1), 5-33.

Frápoli, M. J., y Villanueva, N. (2013). François Recanati: Contextualismo y pragmática de las condiciones de verdad. En D. Pérez Chico (Ed.), Perspectivas en la Filosofía del lenguaje (pp. 491-520). Zaragoza, España: Prensas de la Universidad de Zaragoza.

Frege, G. (1891). Función y concepto (Trad. Valdés, L. M.). En L. M. Valdés (Ed.), Gottlob Frege. Ensayos de semántica y filosofía de la lógica (pp. 53-79). Madrid, España: Tecnos, 2013.

Frege, G. (1892). Sobre sentido y referencia (Trad. Valdés, L. M.). En L. M. Valdés (Ed.), Gottlob Frege. Ensayos de semántica y filosofía de la lógica (pp. 84-111). Madrid, España: Tecnos, 2013.

Frege, G. (1904). ¿Qué es una función? (Trad. Valdés, L. M.). En L. M. Valdés (Ed.), Gottlob Frege. Ensayos de semántica y filosofía de la lógica (pp. 160-170). Madrid, España: Tecnos, 2013.

Frege, G. (1918). El pensamiento. Una investigación lógica (Trad. Valdés, L. M.). En L. M. Valdés (Ed.), Gottlob Frege. Ensayos de semántica y filosofía de la lógica (pp. 196-225). Madrid, España: Tecnos, 2013.

Frege, G. (1972). Conceptografía. Los fundamentos de la aritmética. Otros estudios filosóficos (Trad. Padilla, H.). México DF, México: Universidad Nacional Autónoma de México.

Fox Tree, J. E. (1995). The effects of false starts and repetitions on the processing of subsequent 
words in spontaneous speech. Journal of Memory and Language 34, 709-738.

Gauker, C. (2010). Context in Formal Semantics. Philosophy Compass, 5/7, 568-578.

Gerrig, R.J. y Littman, M.L. (1990). Disambiguation by community membership. Memory and Cognition, 18(4), 331-338.

Geurts, B. (2018). Convention and common ground. Mind and Language, 33, 115-129.

Gill, K. (1993). On the Metaphysical Distinction between Processes and Events. Canadian Journal of Philosophy, 23(3), 365-384.

Glanzberg, M. (2015). Logical Consequence and Natural Language. En C. Caret y O. Hjortland (Eds.), Foundations of Logical Consequence (pp. 71-120). Oxford, Inglaterra: Oxford University Press.

Green, G. M. (2011). Meaning in language use. En C. Maienborn, K. von Heusinger y P. Portner (Eds.), Semantics: An International Handbook of Natural Language Meaning.Vol.1 (pp. 7495). Berlín/Boston: De Gruyter Mouton.

Groefsema, M. (1995). Understood arguments: A semantic/pragmatic approach. Lingua, 96, 139161.

Gureckis, T., y Goldstone, R. L. (2010). Schema. En P.C. Hogan (Ed.), The Cambridge encyclopedia of the language sciences (pp. 725-727). Cambridge, MA: Cambridge University Press.

Haack, S. (1978) Filosofía de las lógicas (Trad. Antón, A.). Madrid, España: Cátedra, 1982.

Hagoort, P., Hald, L., Bastiaansen, M., y Petersson, K. M. (2004). Integration of Word Meaning and World Knowledge in Language Comprehension. Science, 304, 438-441.

Hall, A. (2008). Free Enrichment or Hidden Indexicals? Mind and Language, 23(4), 426-456.

Hansen, M. (2008). On the availability of 'literal' meaning: Evidence from courtroom interaction. Journal of Pragmatics, 40, 1392-1410.

Hampton, J. A. (2006). Concepts as Prototypes. The Psychology of Learning and Motivation, 46, $79-113$. 
Happé, F. G. E. (1993). Communicative competence and theory of mind in autism: A test of relevance theory. Cognition, 48(2), 101-119.

Heck, R. G. (2014). Semantics and Context-Dependence: Towards Strawsonian Account. En B. Shermany A. y Burgess (Eds.), Metasemantics: New Essays on the Foundations of Meaning (pp. 327-364). Oxford, Inglaterra: Oxford University Press.

Higginbotham, J. (1985). On Semantics. Linguistic Inquiry, 16(4), 547-593.

Higginbotham, J. (2001). On Referential Semantics and Cognitive Science. En J. Branquinho (Ed.), The Foundations of Cognitive Science (pp. 145-156). Oxford, Inglaterra: Clarendon Press.

Hinzen, W. (2015). Nothing is Hidden: Contextualismo and the Grammar-Meaning Interface. Mind and Language, 30(3), 259-291.

Hom, C. (2008). The Semantics of Racial Epithets. Journal of Philosophy, 105(8), 416-440.

Horgan, T. (1986). Psychologism, Semantics, and Ontology. Noûs, 20(1), 21-31.

Horn, L. R. (2001). A natural history of negation. Stanford, CA: CSLI Publications.

Iacona, A. (2013). Logical Form and Truth-Conditions. Theoria, 78, 439-457.

Israel, M. (2002). Literally speaking. Journal of Pragmatics, 34, 423-432.

Jackendoff, R. (1990). Semantic Structures. Cambridge, MA: MIT Press.

Jackendoff, R. (2002). Foundations of Language: Brain, Meaning, Grammar, Evolution. Oxford, Inglaterra: University Press.

Jackendoff, R. (2011). Conceptual semantics. En C. Maienborn, K. von Heusinger y P. Portner (Eds.), Semantics. An International Handbook of Natural Language Meaning. Vol. 1 (pp. 688709). Berlín/Boston: de Gruyter.

Jary, M. (2013). Two Types of Implicature: Material and Behavioural. Mind and Language, 28(5), $638-660$.

Jary, M. (2016). Rethinking explicit utterance content. Journal of Pragmatics, 102, 24-37.

Jastrzembski, J. E. (1981). Multiple Meanings, Number of Related Meanings, Frequency of Occurrence, and the Lexicon. Cognitive Psychology, 13, 278-305.

Johnson, K. (2007). Tacit and accessible understanding of language. Synthese, 156, 253-279. 
Johnson-Laird, P. N. (1987). The mental representation of the meaning of words. Cognition, 25, $189-211$

Johnson-Laird, P. N. (2004). The history of mental models. En Manktelow, K., Chung, M.C. (Eds.) Psychology of Reasoning: Theoretical and Historical Perspectives (179-212). New York, NY: Psychology Press.

Kaplan, D. (1975). Dthat. En A. P. Martinich (Ed.), The philosophy of Language (pp. 292-305). Oxford, Inglaterra: University Press, 1996.

Katz, J. (1977). Propositional Structure and Illocutionary Force. A Study of the Contribution of Sentence Meaning to Speech Acts. New York, NY: The Harvest Press.

Katz, J. (1981). Literal Meaning and Logical Theory. The Journal of Philosophy, 78(4), 203-233.

Kennedy, C., y Stanley, J. (2009). On 'Average'. Mind, 118(471), 583-646.

King, J. C., y Stanley, J. (2005). Semantics, Pragmatics, and the Role of Semantic Content. En Z Szabo (Ed.), Semantics vs. Pragmatics (pp.111-164).Oxford, Inglaterra: Oxford University Press.

Korta, K. (2001). Conflictos territoriales entre la semántica y la pragmática. Contextos, XIX-XX $(37-40), 185-208$

Korta, K., y Perry, J. (2006). Varieties of minimalist semantics. Philosophy and Phenomenological Research, 73(2), 451-459.

Kripke, S. A. (1975). Outline of a theory of truth. Journal of Philosophy, 72(19), 690-716.

Kuperberg, G. R., y Jaeger, T. F. (2016). What do we mean by prediction in language comprehension? Lang Cogn Neurosci., 31(1), 32-59.

Kutas, M., y Federmeier, K. D. (2011). Finding Meaning in the N400 Component of the EventRelated Brain Potential (ERP). Annual Review of Psichology, 62(14), 1-14.

Lai, Y. (2017). The complement coercion phenomenon: Implications for models of sentence processing $(\mathrm{PhD})$. Yale University, $\mathrm{CT}$. 
Lakoff, G. (1986). The meanings of literal. Metaphor and Symbolic Activity, I(4). Recuperado de https://georgelakoff.files.wordpress.com/2011/04/metamorphical-issues-the-meanings-ofliteral-lakoff-1986.pdf

Lakoff, G. (1987). Women, Fire, and dangerous Things. What Categories Reveal about the Mind. Chicago, IL: University of Chicago Press.

Langdon, R., Davies, M., y Coltheart, M. (2002). Understanding Minds and Understanding Communicated Meanings in Schizophrenia. Mind and Language, 17(1/2), 68-104.

Levinson, S. C. (2000). Presumptive Meanings: The Theory of Generalized Conversational Implicature. Cambridge, MA: MIT Press.

Link, G. (1983). The Logical Analysis of Plurals and Mass Terms. En R. Bäuerle, Ch. Schwarze y A. von Stechow (Eds.), Meaning, Use, and Interpretation of Language (pp. 302-323). Berlín, Alemania: de Gruyter.

Locke, J. (1956). Ensayo sobre el entendimiento humano (Trad. O'Gorman, E.). México DF, México: Fondo de Cultura Económica, 1999.

Ludwig, K. (2012). Logical Form. En G. Russell y D. Graff (Eds.), The Routledge Companion to the Philosophy of Language (pp. 29-41). NY/Londres: Routledge.

Maienborn, C. (2011). Event semantics. En C. Maienborn, K. von Heusinger y P. Portner (Eds.), Semantics. An International Handbook of Natural Language Meaning. Vol. 1 (pp. 802-829). Berlín/Boston: de Gruyter.

Machery, E. (2010). Précis of Doing without Concepts. Philosophy Studies, 149, 401-410.

McRae, K., Ferretti, T., y, Amyote, L. (1997). Thematic Roles as Verb-specific Concepts. Language and Cognitive Processes, 12, 137-176.

McRae, K. y Matsuki, K. (2009). People Use their Knowledge of Common Events to Understand Language, and Do So as Quickly as Possible. Lang Linguist Compass, 3(6), 1417-1429.

McRae, K. y Matsuki, K. (2013). Constraint-based Models of Sentence Processing. En R. Van Gompel (Ed.), Sentence processing (pp. 51-77). New York, NY: Psychology Press.

Malt, B. C. (1994). Water Is Not $\mathrm{H}_{2} \mathrm{O}$. Cognitive Psychology, 27, 41-70. 
Martí, G. (1998). Forma lógica. En J. J. Acero (Ed.), Filosofía del lenguaje I. Semántica (pp. 157168). Barcelona, España: Trotta.

Martín-Borreguero, P. (2005). Perfil lingüístico del individuo con síndrome de Asperger: implicaciones para la investigación y la práctica clínica. Revista de Neurología, 4l(1), 115-22.

Mazzone, M. (2014). The continuum problem: Modified Occam's Razor and conventionalisation of meaning. International Review of Pragmatics, 6, 29-58.

Mazzone, M. (2015). Constructing the context through goals and schemata: top-down processes in comprehension and beyond. Frontiers in Psychology, 6, 651.

Mazzone, M., y Campisi, E. (2010). Are there communicative intentions? En L. A. Perez Miranda y A. I. Madariaga (Eds.), Advances in cognitive science. Proceedings of the ILCLI International Workshop on Cognitive Science Workshop on Cognitive Science (pp. 307-322). Bilbao, España: Universidad del País Vasco.

McGee, V. (2006). Truth. En Devitt, M. y Hanley R. (Eds), The Blackwell Guide to the Philosophy of Language (pp. 392-410). Oxford, Inglaterra: Blackwell Publishing.

Millikan, R. G. (2005). Language: A Biological Model. Oxford, Inglaterra: Oxford University Press.

Minsky, M. (1974). A framework for representing knowledge. En P.H. Winston (Ed.), The psychology of computer vision (pp. 211-275). New York, NY: McGraw-Hill, 1975.

Mitchley, N. J., Barber, J., Gray, J. M., Brooks, D. N., y Livingston, M. G. (1998). Comprehension of irony in Schizophrenia. Cognitive Neuropsychiatry, 3(2), 127-138.

Montague, R. (1973). The Proper Treatment of Quantification in Ordinary English. En Hintikka, J., Moravcsik J. y Suppes P. (Eds.), Approaches to Natural Language (pp. 221-242). Dordrecht/Boston: Reidel.

Murphy, G. L. (2016). Is there an exemplar theory of concepts? Psychonomic Bulletin and Review, 23(4), 1035-1042.

Neale, S. (1999). Colouring and Composition. En K. Murasugi y R. Stainton (Eds.), Philosophy and Linguistics (pp. 35-82). Boulder, CO: Westview Press. 
Newmeyer, F. J. (1980). Linguistic theory in America: The First Quarter Century of Transformational Generative Grammar. New York, NY: Academic Press.

Ockham, W. (1324-1328). Suma de lógica (Trad. Flórez, A.). Barcelona, España: Grupo Editorial Norma (1994).

Ogden, C. K., y Richards, I. A. (1923). The Meaning of Meaning: A Study of the Influence of Language upon Thought and of the Science of Symbolism. New York, NY: Harcourt, Brace \& World, Inc.

Partee, B. (2011). Formal semantics: origins, issues, early impact. The Baltic International Yearbook of Cognition, Logic and Communication: Vol. 6 (1-52). https://doi.org/10.4148/biyclc.v6i0.1580

Partee, B. (2015). The Garden of Eden Period for Deep Structure and Semantics. En A. J. Gallego y D. Ott (Eds.), 50 Years later: Reflections on Chomsky's Aspects (pp. 187-198). Cambridge, MA: MIT Working Papers in Linguistics.

Peacocke, C. (2000). Theories of concepts: a wider task. European Journal of Philosophy, 8(3), 298-321.

Perry, J. (1998). Indexicals, Contexts and Unarticulated Constituents. En A. Aliseda-Llera, R. J. Van Glabbeek y D. Westerståhl (Eds.), Proceedings of the 1995 CSLI-Armsterdam Logic, Language and Computation Conference. Standford, CA: CSLI Publications, Stanford University.

Perry, J. (2006). Using Indexicals. En M. Devitt y R. Hanley (Eds.), The Blackwell Guide to the Philosophy of Language (pp. 314-334). Oxford, Inglaterra: Blackwell.

Petten, C. V., y Kutas, M. (1990). Interactions between sentence context and word frequency in event-related brain potentials. Memory and Cognition, 18(4), 380-393.

Pexman, P. M., Hargreaves, I. S., Edwards, J. D., Henry, L. C., y Goodyear, B. G. (2007). The Neural Consequences of Semantic Richness: When More Comes to Mind, less Activation Is observed. Psychology Science, 18(5), 401-406. 
Piai, V., Anderson, K. L., Lin, J. J., Dewar, C., Parvizi, J., Dronkers, N. F., y Knight, R.T. (2016). Direct brain recordings reveal hippocampal rhythm underpinnings of language processing Proceedings of the National Academy of Sciences of the United States of America, 113(40), $11366-11371$

Pickering, M. J., y Garrod, S. (2006). Do people use language production to make predictions during comprehension? Cognitive Sciences, 11(3), 105-110.

Pietroski, P.M. (2003). The Character of Natural Language Semantics. En A. Barber (Ed.), Epistemology of Language (pp. 217-256). Oxford, Inglaterra: Oxford University Press.

Pietroski, P. M. (2005). Meaning before truh. En G. Preyer y G. Peter (Eds.), Contextualism in Philosophy: Knowledge, Meaning, and Truth (pp. 253-300). Oxford, Inglaterra: University Press.

Pietroski, P. M. (2008). Semantic Minimalism, Internalist Interpretation. Biolinguistics, 2, 317-41.

Piñago, M. M., y Deo, A. (2012). Aspectual verbs and the "coercion" effect. En Proceedings of Semantics and Linguistic Theory, 22.

Portner, P. H. (2005). What is meaning? Fundamentals of Formal Semantics. Oxford, Inglaterra: Blackwell Publishing.

Predelli, S. (2004). The Lean Mean Semantic Machine. En C. Bianchi (Ed.), The Semantics/Pragmatics Distinction (pp. 13-26). Stanford, CA: CSLI Publications.

Premack, D., y Woodruff, G. (1978). Does the chimpanzee have a theory of mind? The Behavioral and Brain Sciences, 4, 515-526.

Pustejovsky, J. 1993. Type coercion and lexical selection. En Pustejovsky J. (Ed.) Semantics and the lexicon (pp. 73-94). Dordrecht, Holanda: Kluwer Academic.

Pustejovsky, J. (1995). The Generative Lexicon. Cambridge, MA: The MIT Press.

Putnam, H. (1975) El significado de significado. Teorema 14, 345-406.

Quine, W. V. O. (1948). Acerca de lo que hay (Trad. Sacristán, M.). En Desde un punto de vista lógico (pp. 25-48). Barcelona, España: Ariel, 1962. 
Quine, W. V. O. (1951). Dos dogmas del empirismo (Trad. Sacristán, M.). En Desde un punto de vista lógico (pp. 49-82). Barcelona, España: Ariel, 1962.

Quine, W. V. O. (1956). Quantifiers and Propositional Attitudes. The Journal of Philosophy, 53(5), $177-187$.

Quine, W. V. O. (1960). Palabra y objeto (Trad. Sacristán, M.). Barcelona, España: Labor, 1968.

Quine, W. V. O. (1977). Filosofía de la lógica (Trad. Sacristán, M.). Madrid, España: Alianza.

Quine, W. V. O. (1986). La relatividad ontológica y otros ensayos (Trad. Garrido, M. y Blasco, J. L.). Madrid, España: Tecnos.

Rayo, A. (2013). A Plea for Semantic Localism. Noûs, 47(4), 647-679.

Recanati, F. (2002). Unarticulated Constituents. Linguistics and Philosophy, 25(3), 299-345.

Recanati, F. (2004). Literal Meaning. Cambridge, MA: Cambridge University Press.

Recanati, F. (2010). Truth-Conditional Pragmatics. Oxford, Inglaterra: Clarendon Press.

Richard, M. (2008). When Truth Gives Out. Oxford, Inglaterra: Oxford University Press.

Robinson, H. (2009). Vagueness, Realism, Language and Thought. Proceedings of the Aristotelian Society, New Series, 109, 83-101.

Rosch, E. (1998). Principles of Categorization, En D. J. Levitin (Ed.), Foundations of Cognitive Psychology (pp.251-270). Cambridge, MA: MIT Press, 2002.

Rosch, E., y Mervis, C. B. (1975): Family resemblances: Studies in the internal structure of categories. Cognitive Psychology, 7, 573-605.

Rumelhart, D. E. (1980). Schemata: The Building Blocks of Cognition. En R. J. Spiro, B. C. Bruce y W. F. Brewer (Eds.), Theoretical Issues in Reading Comprehension: Perspectives from Cognitive Psychology, Linguistics, Artificial Intelligence and Education (pp. 33-58). Hillsdale, NJ: Lawrence Erlbaum.

Russell, B. (1905). On denoting. En A. P. Martinich (Ed.), The philosophy of language (pp. 212220). New York, NY: Oxford University Press, 2001.

Russell, B. (1918). Los problemas de la filosofía (Trad. Xirau, J.). Barcelona, España: Labor, 1953.

Sainsbury, R. M. (2001). Two ways to smoke a cigarette. Ratio, 14(4), 386-406. 
Saka, P. (2007). How to think about meaning. Dordrecht, Holanda: Springer.

Sandford, A. J., y Garrod, S. C. (1998). The role of scenario mapping in text comprehension. Discourse Processes, 26(2-3), 159-190.

Schank, R. C., y Abelson, R.P. (1975). Scripts, Plans, and Knowledge. Proceedings of the 4th international joint conference on Artificial intelligence. Vol. 1 (pp. 151-157). San Francisco, CA: Morgan Kaufmann Publishers Inc.

Schiffer, S. (2005). Russell's theory of descriptions. Mind 114(456), 1135-1183.

Schiffer, S. (2015). Meaning and Formal Semantics in Generative Grammar. Erkenntnis, 80(1), 6187.

Searle, J. R. (1978). Literal Meaning. Erkenntnis, 13, 207-224.

Sennet, A. (2011). Unarticulated Constituents and propositional Structure. Mind and Language, 26(4), 412-435.

Seuren, P. A. M. (2009). Language from Within Vol. I. Language in Cognition. Oxford, Inglaterra: Oxford University Press.

Smith, E. E., y Medin, D. L. (1999). The Exemplar View. En D. J. Levitin (Ed.), Foundations of Cognitive Psychology (pp.277-292). Cambridge, MA: MIT Press, 2002.

Solan, L. M., y Tiersma, P. M. (2012). The language of crime. En P. M. Tiersma y L. M. Solan (Eds.), The Oxford Handbook of Language and Law (pp. 340-353). Oxford, Inglaterra: University Press.

Sperber, D., y Wilson, D. (1986). Relevance: Communication and Cognition. Oxford, Inglaterra: Blackwell.

Sperber, D., y Wilson, D. (2002). Truthfulness and relevance. Mind, 111, 583-632.

Sperber, D., y Wilson, D. (2015). Beyond Speaker's Meaning. Croatian Journal of Philosophy, 15(2), 117-149.

Stanley, J. (2000). Context and logical form. Linguistics and philosophy, 23(4), 391-434.

Stanley, J. (2002). Making it articulated. Mind and Language, 17(1y2), 149-168.

Stern, J. (2000). Metaphor in context. Cambridge, MA: MIT Press. 
Stern, J. (2006). Metaphor, Literal, Literalism. Mind and Language, 21, 243-279.

Stojanovic, I. (2007). What Is Said. An Inquiry into Reference, Meaning, and Content (PhD). Stanford University, CA.

Strawson, P. F. (1950). Sobre el referir (Trad. Valdés, L. M.). En L. M. Valdés (Ed.), La búsqueda del significado. Lecturas de filosofía del lenguaje (pp. 61-84). Madrid, España: Tecnos, 1991.

Strawson, P. F. (1952). Introducción a la teoría lógica (Trad. Ameller, J.). Buenos Aires, Argentina: Editorial Nova, 1969.

Strawson, P. F. (1969). Significado y verdad (Trad. Valdés, L. M.). En L. M. Valdés (Ed.), La búsqueda del significado. Lecturas de filosofía del lenguaje (pp. 356-373). Madrid, España: Tecnos, 1991.

Strawson, P. F. (1981). Análisis y metafísica descriptiva (Trad. Zofío, J. L.). En J. Muguerza (Ed.), La concepción analítica de la filosofía (pp. 597-644). Madrid, España: Alianza, 1986.

Szabó, Z.G. (2012). Against logical form. En G. Preyer (Ed.), Donald Davidson on Truth, Meaning, and the Mental (pp. 105-126). Oxford, Inglaterra: Oxford University Press.

Tarski, A. (1944). La concepción semántica de la verdad y los fundamentos de la semántica. En L. M. Valdés (Ed.), La búsqueda del significado. Lecturas de filosofía del lenguaje (pp. 275313). Madrid, España: Tecnos, 1991.

Thomason, R. H. (Ed.) (1974). Formal Philosophy; Selected Papers of Richard Montague. New Haven, CT: Yale University Press.

Tiersma, P. M. (1993). Linguistic issues in the law. Language, 69(1), 113-137.

Valdés, L. M. (1998). El significado: los constructores. En J. J. Acero (Ed.), Filosofía del lenguaje I. Semántica (pp. 107-134). Barcelona: Trotta, 2007.

Vendler, Z. (1957). Verbs and Times. The Philosophical Review, 66(2), 143-160.

Verspoor, C. M. (1996). Lexical limits on the Influence of Context. En Proceedings of Cognitive Sciences, 96, 116-120.

Verspoor, C. M. (1997). Conventionality-governed logical metonymy. En H. Bunt, L. Kievit, R. Muskens, y N. Verlinden (Eds.), Proceedings of the Second International Workshop on 
Computational Semantics (pp. 300-312). Tilburg, HO.

Vicente, A. (2017). Truth-conditions for cities, countries and schools. En C. Penco y M. Vignolo (Eds.), Proceedings of the Workshop on Contexts in Philosophy, 144-58.

Vicente, B. y Groefsema, M. (2013). Something out of nothing? Rethinking unarticulated constituents. Journal of Pragmatics, 47, 108-127.

Vooorspoels, W., Vanpaemel, W., y Storms, G. (2008). Exemplars and prototypes in natural language concepts: A typicality-based evaluation. Psychonomic Bulletin and Review, 15(3), $630-637$

Williamson, T. (1992). Vagueness and Ignorance. Proceedings of the Aristotelian Society Supplementary Vol. 66,145-162.

Wittgenstein, L. (1954). Investigaciones filosóficas (Trad. Gracía Suárez, A. y Moulines, U.). Barcelona, España: Crítica, 1988.

Yalcin, S. (2014). Semantics and Metasemantics in the Context of Generative Grammar. En A. Burgess y B. Sherman (Eds.), Metasemantics: New Essays on the Foundations of Meaning (pp. 17-54). Oxford, Inglaterra: Oxford University Press.

Yee, E., Jones, M. N., y McRae, K. (2017). Semantic Memory. En J. T. Wixted y S. ThompsonSchill (Eds.), The Stevens' Handbook of Experimental Psychology and Cognitive Neuroscience. Vol. 3: Language and Thought. New York, NY: Wiley.

Zarcone, A. (2014). Event Knowledge and Models of Logical Metoymy Interpretation (PhD) Universität Stuttgart, Stutgart.

Zarcone A., McRae K., Lenci, A. y Padó, S. (2017). Complement Coercion: The Joint Effects of Type and Typicality. Front. Psychol., 8, 1987. doi: 10.3389/fpsyg.2017.01987 